\title{
Radiological Considerations for the Operation of the Advanced Photon Source Storage Ring - Revised
}

\author{
H. J. Moe
}

September 24, 1997

\section{General}

This report deals with the radiological considerations of operations using 7700-MeV positron and electron beams in the storage ring (SR) tunnel. The radiological considerations addressed include the following: prompt secondary radiation (bremsstrahlung, giant resonance neutrons, medium and high energy neutrons, and muons) produced by electrons/positrons interacting in a beam stop or by particle losses in the component structures; skyshine radiation, which produces a radiation field in nearby areas and at the nearest off-site location; radioactive gases produced by neutron irradiation of air in the vicinity of a particle loss site; noxious gases (ozone and others) produced in air by the escaping bremsstrahlung radiation that results from absorbing particles in the components or by synchrotron radiation escaping into the tunnel; activation of the storage ring components that results in a residual radiation field in the vicinity of these materials following shutdown; potential activation of water used for cooling the magnets and other purposes in the SR tunnel; evaluation of the radiation fields due to escaping synchrotron radiation and gas bremsstrahlung. Estimated dose rates outside of the tunnel, in the early assembly area (EAA), and in the Experiment Hall for several modes of operation (including potential safety envelope beam power, normal beam power, and MCI (maximum credible incident) conditions) have been computed. Shielding in the first optics enclosure (FOE) and for the photon beamlines is discussed in ANL/APS/TB-7 (IPE 93), but additional radiological considerations for the ASD diagnostic beamlines are contained in Appendix C. Although the calculations refer to positrons, electron operation would produce essentially the same effects for the identical assumptions.

\section{Beam Parameters and Storage Ring Tunnel Information}

Computations have been based upon these parameters for normal operations with positrons: $50 \mathrm{nC} /$ pulse, 48 pulses/s and an electron energy of $200 \mathrm{MeV}$. This results in a beam power of $480 \mathrm{~W}$ incident on the tungsten target in the linac. A net conversion factor of $0.005 \mathrm{e}^{+} / \mathrm{e}^{-}$is assumed $(0.0083$ conversion factor in the $\mathrm{W}$ target and 0.6 transmission to the positron linac), resulting in a current of $12 \mathrm{nA}$ of $\mathrm{e}^{+}$, and a beam power of $5.4 \mathrm{~W}$ for $450 \mathrm{MeV} \mathrm{e}^{+}$being sent from the positron accumulator ring (PAR) to the synchrotron. In the synchrotron, the accelerated beam reaches $7000 \mathrm{MeV}$, giving a Design Performance Goal operational power of $84 \mathrm{~W}$. For the case of operation at the linac safety envelope of $1000 \mathrm{~W}$, the $\mathrm{e}^{+}$beam power delivered to the synchrotron has been taken to be $20 \mathrm{~W}$ with an $\mathrm{e}^{+}$current of $40 \mathrm{nA}$ and energy of $500 \mathrm{MeV}$. The safety envelope for synchrotron operation has been set at $308 \mathrm{~W}$. This implies a maximum $\mathrm{e}^{+}$current of $40 \mathrm{nA}$ for $7700-\mathrm{MeV}$ operations (the maximum energy in the synchrotron). As concerns the storage ring, Design Performance Goal operation is considered to be $100 \mathrm{~mA}$ of circulating current at $7 \mathrm{GeV} \mathrm{e}^{+}(2578 \mathrm{~J})$, and the safety envelope is $360 \mathrm{~mA}$ of circulating current at $7.0 \mathrm{GeV}(9280 \mathrm{~J})$, or the relevant circulating current for an equivalent stored energy $(9280 \mathrm{~J})$ at some other particle energy. 
The storage ring, shown in Figure 1, has a circumference of $1104 \mathrm{~m}$. The beam height is $1.4 \mathrm{~m}$ above the floor, and the height of the tunnel is $2.743 \mathrm{~m}(9 \mathrm{ft})$ with width about $3 \mathrm{~m}(\sim 10 \mathrm{ft})$, except in the ratchet door regions and the tunnel region adjacent to the EAA, where the tunnel is wider. The volume of the enclosure is approximately $10670 \mathrm{~m}^{3}$. The eighty $4.5^{\circ}$ bending magnets have a radius of $38.96 \mathrm{~m}$. The shield over most of the tunnel consists of ordinary concrete $(\rho=2.35 \mathrm{~g} / \mathrm{cc})$ that is $1 \mathrm{~m}$ thick on the roof, $80 \mathrm{~cm}$ thick on the wall of the tunnel that is opposite the ratchet wall (nearest the infield side of the ring), $56 \mathrm{~cm}$ thick above a height of $2.13 \mathrm{~m}(7 \mathrm{ft})$ on the ratchet wall, and $1.1 \mathrm{~m}$ thick in the EAA. The remainder of the ratchet wall is made of high-density concrete $(\rho=3.7 \mathrm{~g} / \mathrm{cc})$. The radial part of the ratchet consists of $80 \mathrm{~cm}$ of high-density concrete and features a Pb-concrete (high density) plug ( $46 \mathrm{~cm}$ by $46 \mathrm{~cm}$ ) centered about the photon beamline to provide increased protection from upstream bremsstrahlung. The ratchet doors are $28 \mathrm{~cm}$ thick, composed of a steel casing filled with a castable shield material comprising $65 \% \mathrm{~Pb}, 34 \%$ neutron shielding, and $1 \%$ $\mathrm{B}_{4} \mathrm{C}$, of composite density $3.93 \mathrm{~g} / \mathrm{cc}$.

\section{Radiation Dose Rates}

\subsection{Bremsstrahlung Dose Rates}

The unshielded bremsstrahlung dose profile angular dependence was estimated from an expression adapted from Swanson et al. (SWA 85):

$$
\mathrm{H}_{\mathrm{B}}\left(\theta_{\mathrm{B}}\right)=16.7 \mathrm{E}_{\mathrm{o}}\left(2^{-\theta_{\mathrm{B}} / \theta_{1 / 2}}\right)+833\left(10^{-\theta_{\mathrm{B}} / 21}\right)+25\left(10^{-\theta_{\mathrm{B}} / 110}\right) \mathrm{mrem} / \mathrm{J} \text { at } 1 \mathrm{~m},
$$

in which $\mathrm{E}_{\mathrm{o}}=$ the positron energy in $\mathrm{MeV}, \theta_{1 / 2}=100 / \mathrm{E}_{\mathrm{o}}$ deg, and $\theta_{\mathrm{B}}$ is the angle between the forward direction of the electron beam at the point where it strikes the component and the line segment from that point to the dose point. The first term in the expression accounts for the intense, highly peaked forward component of the bremsstrahlung, the remaining two terms give the contribution at the other angles. The dose factor is applicable to cases where the stored beam is being lost. The factor can be expressed as a dose equivalent rate factor at 1 meter by multiplying each term by the energy loss rate in $\mathrm{J} / \mathrm{h}(3600 \mathrm{~W}$, where $\mathrm{W}$ is in watts). The dose rate factor is applicable to the case of injection where losses at a site continue at a rate of $2 \mathrm{~Hz}$. The factor becomes

$$
\begin{aligned}
\dot{\mathrm{H}}_{\mathrm{B}}\left(\theta_{\mathrm{B}}\right)= & 6.012 \times 10^{4} \mathrm{E}_{\mathrm{o}} \mathrm{W}\left(2^{-\theta_{\mathrm{B}} / \theta_{1 / 2}}\right)+3.0 \times 10^{6} \mathrm{~W}\left(10^{-\theta_{\mathrm{B}} / 21}\right) \\
& +9.0 \times 10^{4} \mathrm{~W}\left(10^{-\theta_{\mathrm{B}} / 110}\right) \mathrm{mrem} / \mathrm{h} \text { at } 1 \mathrm{~m} .
\end{aligned}
$$




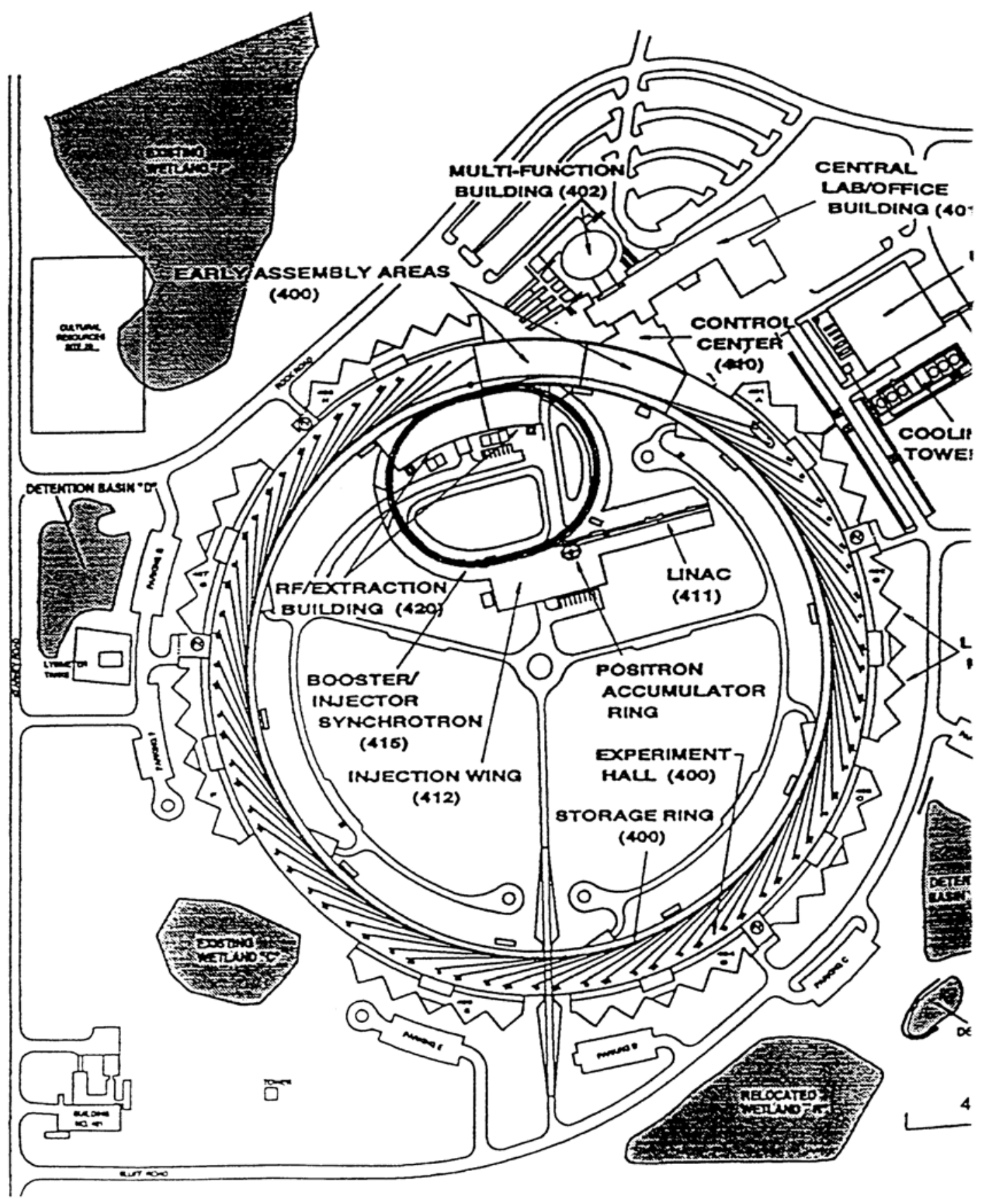

Figure 1 - Layout of the APS 
Three relevant dose rates during injection scenarios are those for $\theta_{\mathrm{B}}=0^{\circ}, 90^{\circ}$, and $180^{\circ}$, for a total beam loss of $308 \mathrm{~W}$ and $\mathrm{e}^{+}$energy of $7700 \mathrm{MeV}$, which are

$$
\begin{aligned}
& \dot{\mathrm{H}}_{\mathrm{B}}\left(0^{\circ}\right)=1.43 \times 10^{11} \mathrm{mrem} / \mathrm{h} \text { at } 1 \mathrm{~m}, \\
& \dot{\mathrm{H}}_{\mathrm{B}}\left(90^{\circ}\right)=4.26 \times 10^{6} \mathrm{mrem} / \mathrm{h} \text { at } 1 \mathrm{~m}, \\
& \dot{\mathrm{H}}_{\mathrm{B}}\left(180^{\circ}\right)=6.40 \times 10^{5} \mathrm{mrem} / \mathrm{h} \text { at } 1 \mathrm{~m} .
\end{aligned}
$$

\subsection{Giant Resonance Neutron (GRN) Dose Rate}

The distribution with angle for the giant resonance neutron (GRN) component was taken as isotropic. The GRN neutron yield in the injection septum and/or SR components was based on (SWA 79):

$$
\mathrm{Y}=1.21 \times 10^{8} \mathrm{Z}^{0.66}(\mathrm{n} / \mathrm{J})
$$

Using a conversion factor of about $7 \mathrm{n} / \mathrm{cm}^{2} \mathrm{~s}=1 \mathrm{mrem} / \mathrm{h}$, the dose equivalent factor at 1 meter for the GRN component can be approximated by $0.20 \mathrm{mrem} / \mathrm{J}$ at $1 \mathrm{~m}$ for aluminum components, which for a 308-W loss gives a dose rate of

$$
\dot{\mathrm{H}}_{\mathrm{GRN}}=2.22 \times 10^{5} \mathrm{mrem} / \mathrm{h} \text { at } 1 \mathrm{~m} \text { unshielded }
$$

Corresponding dose equivalent factors for iron and copper are 0.33 and $0.35 \mathrm{mrem} / \mathrm{J}$ at $1 \mathrm{~m}$, respectively.

\subsection{Medium- and High-Energy Neutron Dose Rates}

Dose equivalent factors for the medium-energy neutron (MEN) and high-energy neutron (HEN) components at $0^{\circ}, 90^{\circ}$, and $180^{\circ}$ from a $\mathrm{Cu}$ target were taken from CERN 84-02 (CER 84) and Jenkins (JEN 79). These dose constants are given for $90^{\circ}$ in the CERN report and the variation with angle is given by Jenkins. The angular relationships of Jenkins are

$$
\begin{aligned}
& \mathrm{F}(\theta)_{\mathrm{MEN}}=\mathrm{F}\left(90^{\circ}\right)_{\mathrm{MEN}} /(1-0.75 \cos \theta), \\
& \mathrm{F}(\theta)_{\mathrm{HEN}}=\mathrm{F}\left(90^{\circ}\right)_{\mathrm{HEN}} /(1-0.72 \cos \theta)^{2},
\end{aligned}
$$

in which $\mathrm{F}\left(90^{\circ}\right)_{\mathrm{MEN}}=3.3 \times 10^{-2} \mathrm{mrem} / \mathrm{J} @ 1 \mathrm{~m}$ and $\mathrm{F}\left(90^{\circ}\right)_{\mathrm{HEN}}=8.3 \times 10^{-3} \mathrm{mrem} / \mathrm{J} @ 1 \mathrm{~m}$. High-energy neutron production decreases with increasing $Z$, and Tesch (TES 88) gives the theoretical correction factor of 1.86 for $\mathrm{Al}$, and the factor 0.6 for neutron production in high $\mathrm{Z}$ materials ( $\mathrm{W}$ and $\mathrm{Pb}$ ), relative to copper. Since iron and copper are close in atomic number, the production values in $\mathrm{Cu}$ have been assumed for $\mathrm{Fe}$. Combining the factors above (dose constant and $\mathrm{Z}$ correction), the revised unshielded dose factors at $1 \mathrm{~m}$ for $\mathrm{Al}$ components, as a function of the emission angle $\theta$ become: 
Aluminum Component

$(\mathrm{mrem} / \mathrm{J}$ at $1 \mathrm{~m})$

\begin{tabular}{|l|c|c|}
\hline Angle & MEN & HEN \\
\hline $0^{\circ}$ & $2.46 \times 10^{-1}$ & $1.97 \times 10^{-1}$ \\
\hline $90^{\circ}$ & $6.14 \times 10^{-2}$ & $1.54 \times 10^{-2}$ \\
\hline $180^{\circ}$ & $3.51 \times 10^{-2}$ & $5.22 \times 10^{-3}$ \\
\hline
\end{tabular}

These factors would be 0.54 times lower in iron, which is close to $\mathrm{Cu}$ in $\mathrm{Z}$ number, and 0.32 times lower in lead or tungsten. Using all of the above factors for the radiation components, the unshielded dose rates at 1 meter from an aluminum component, for the three relevant angles used in this evaluation are shown in Table 1.

Table 1 - Unshielded Dose Rates at $1 \mathrm{~m}$ for Radiation Components for $7700-\mathrm{MeV}$ Operation at $308 \mathrm{~W}$

\begin{tabular}{|c|c|c|c|c|}
\hline \multirow{2}{*}{$\begin{array}{c}\text { BLUMINUM } \\
\text { Angle, deg. }\end{array}$} & \multirow{2}{*}{ BREMS. } & GRN & MEN & \multirow{2}{*}{ HEN } \\
\cline { 3 - 4 } & & \multicolumn{2}{|c|}{$(\mathbf{m r e m} / \mathbf{h}$ at $\mathbf{1 ~ m )}$} & \\
\hline $0^{\circ}$ & $1.43 \times 10^{11}$ & $2.22 \times 10^{5}$ & $2.73 \times 10^{5}$ & $2.18 \times 10^{5}$ \\
\hline $90^{\circ}$ & $4.26 \times 10^{6}$ & $2.22 \times 10^{5}$ & $6.81 \times 10^{4}$ & $1.71 \times 10^{4}$ \\
\hline $180^{\circ}$ & $6.40 \times 10^{5}$ & $2.22 \times 10^{5}$ & $3.89 \times 10^{4}$ & $5.79 \times 10^{3}$ \\
\hline
\end{tabular}

For computations around the ring, the bremsstrahlung, medium-energy and high-energy neutron component angular dependence was taken into account as the forward angle with respect to the positron beam direction varied. For these estimates the ring was assumed to be a circle. A separate calculation of the dose rates behind the radial portion of the ratchet walls was made in the Addendum to APS-LS-141 Revised (MOE 91). The result of this latter calculation indicated that $10.16 \mathrm{~cm} \mathrm{of} \mathrm{Pb}$ judiciously placed at key points along the beamline would intercept the upstream radiation and effectively attenuate the dose in a total beam loss to $<100 \mathrm{mrem}$ behind the wall, and would give a factor of 100 attenuation in the case of continuous normal loss at these sites, giving a greatly reduced dose rate relative to that calculated for the circular case. 


\section{Shielding Computations}

The shielding computations were based upon the following expression for the beam loss in an SR component:

$$
\dot{\mathrm{H}}_{\mathrm{Tot}}=\frac{\sum_{\mathrm{i}} \dot{\mathrm{H}}_{\mathrm{i}} \prod_{\mathrm{i}, \mathrm{j}} \exp -\frac{\mathrm{d}_{\mathrm{j}}}{\lambda_{\mathrm{i}, \mathrm{j}}}}{\mathrm{r}^{2}}
$$

in which $\dot{\mathrm{H}}_{\text {Tot }}$ has units of mrem/h, $\dot{\mathrm{H}}_{\mathrm{i}}$ is the appropriate dose rate conversion factor for the $\mathrm{i}^{\text {th }}$ radiation component, $r$ is the source-to-dose-point distance in $m, d_{j}$ is the shield thickness in $\mathrm{g} / \mathrm{cm}^{2}$ for the $\mathrm{j}^{\text {th }}$ shield, and $\lambda_{\mathrm{i}, \mathrm{j}}, \mathrm{g} / \mathrm{cm}^{2}$ is the attenuation length of the $\mathrm{i}^{\text {th }}$ radiation component for the $\mathrm{j}^{\text {th }}$ shielding material. A similar expression, in which $\mathrm{H}_{\text {Tot }}$ and $\mathrm{H}_{\mathrm{i}}$ replace the dose rate and dose rate factor, respectively, gives the dose equivalent for the case of stored beam losses.

The shield design calculations for non-accident conditions were based upon the operating parameters for the safety envelope. Estimates of the dose rates for this case were then scaled down by the ratio of the respective powers (or stored energy values in the case of stored beam losses) to obtain the estimated dose rates or doses for the case of the normal operational mode. In any case in which the estimates are slightly greater than the DOE design guideline of $0.25 \mathrm{mrem} / \mathrm{h}$ (DOE 92), additional local shielding will be added to achieve the guideline if actual survey measurements confirm that such calculated dose rates may be realized. Measured doses in the case of accident situations involving the stored beam will be mitigated if they indicate greater than $100 \mathrm{mrem}$.

\subsection{Attenuation Length of Shielding Materials}

Attenuation lengths for the various shielding materials were obtained from Swanson (SWA 79a) and Moe (MOE 91). The value of each of these parameters, for a monoenergetic source, is expected to be constant with depth of penetration, if no secondary radiation is produced. For a spectrum of radiation, the energy composition changes with penetration, and the initial tenth value layer (TVL) will often differ from the equilibrium value. Values chosen for the attenuation lengths are effective values (spectrum-averaged), measured for spectra encountered at similar electron machines. In the absence of values for the MEN component, the value for the HEN component was used in order to be conservative. The attenuation length for the HEN component in all shield materials-except concrete, which was obtained from the literature - was computed from

$$
\lambda=38.5 \mathrm{~A}^{0.3} \mathrm{~g} / \mathrm{cm}^{2},
$$

as given in ICRU Report 28 (ICR 78).

The attenuation lengths, in $\mathrm{g} / \mathrm{cm}^{2}$, used in the computations and the density of the various shielding materials are shown in Table 2. 


\subsection{Component and Beam Shielding Material Data}

Table 3 contains a listing of parameters for the assumed component and beam shielding materials. These parameters are used in the calculations to estimate the $\mathrm{e}^{-} / \mathrm{e}^{+}$stopping ability and the expected attenuation of the shower radiation by various components and shielding materials in the longitudinal and transverse directions.

Table 2 - Attenuation Lengths of Shielding Materials

\begin{tabular}{|c|c|c|c|c|}
\hline \multirow[t]{2}{*}{ MATERIAL (density-g/ $\mathrm{cm}^{3}$ ) } & \multirow[t]{2}{*}{ BREMS } & GRN & MEN & \multirow[t]{2}{*}{ HEN } \\
\hline & & \multicolumn{2}{|c|}{$\lambda\left(\mathrm{g} / \mathrm{cm}^{2}\right)$} & \\
\hline Concrete (2.35) & 49 & 40 & 65 & 115 \\
\hline Concrete (3.7) & 50 & 45 & 70 & 125 \\
\hline Concrete Block (2.08) & 49 & 40 & 65 & 115 \\
\hline $\mathrm{Pb}(11.35)$ & 24 & 161 & 191 & 191 \\
\hline Polyethylene (0.93) & 70 & 6.3 & 62 & 62 \\
\hline $\mathrm{Fe}(7.87)$ & 34 & 100 & 138 & 138 \\
\hline W (densalloy 18.0) & 26.3 & 161 & 184 & 184 \\
\hline
\end{tabular}

Table 3 - Component and Beam Shielding Material Data

\begin{tabular}{|l|c|c|c|c|c|c|}
\hline MATERIAL & $\mathbf{Z}$ & $\begin{array}{c}\text { Density } \\
\mathbf{g} / \mathbf{c m}^{\mathbf{3}}\end{array}$ & $\begin{array}{c}\mathbf{E}_{\mathbf{c}} \\
\mathbf{C r i t i c a l} \\
\text { Energy } \\
\mathbf{M e V}\end{array}$ & $\begin{array}{c}\boldsymbol{\lambda}_{\mathbf{m}} \\
\text { Attenuation } \\
\text { Length } \\
\mathbf{g} / \mathbf{c m}^{\mathbf{2}}\end{array}$ & $\begin{array}{c}\mathbf{X}_{\mathbf{o}} \\
\text { Radiation } \\
\text { Length } \\
\mathbf{g} / \mathbf{c m}^{2}\end{array}$ & $\begin{array}{c}\mathbf{X}_{\mathbf{m}} \\
\text { Moliere } \\
\text { Radius } \\
\mathbf{g} / \mathbf{c m}^{\mathbf{2}}\end{array}$ \\
\hline $\mathrm{Al}$ & 13 & 2.7 & 51 & 46.5 & 24.0 & 10.0 \\
\hline $\mathrm{Fe}$ & 26 & 7.87 & 27.4 & 34.0 & 13.84 & 10.7 \\
\hline $\mathrm{Cu}$ & 29 & 8.96 & 24.8 & 33.0 & 12.86 & 11.0 \\
\hline $\mathrm{W}$ & 74 & 19.3 & 10.2 & 24.0 & 6.76 & 14.0 \\
\hline $\mathrm{Pb}$ & 82 & 11.35 & 9.51 & 24.0 & 6.37 & 14.2 \\
\hline $\mathrm{Conc}$. & 11.6 & 2.35 & 51 & 49.0 & 25.71 & 10.7 \\
\hline
\end{tabular}

Note - Densalloy is about $95 \% \mathrm{~W}$ and has a density of $18 \mathrm{~g} / \mathrm{cc}$. For values of range, critical energy, radiation length, and Moliere radius for densalloy, the values for $\mathrm{W}$ were used. 
The critical energy, $E_{c}$, the minimum attenuation length for bremsstrahlung, $\lambda_{m}$, and radiation length, $\mathrm{X}_{\mathrm{o}}$, values were obtained from Swanson (SWA 79a). The Moliere radius, $X_{\mathrm{m}}$, is related to the transverse development of the shower in a given material. The fraction of energy that escapes cylindrical volumes of a given radius can be estimated from the Moliere radius, according to Nelson (NEL 66). When the radius of the cylinder equals 1 Moliere unit, the fraction of energy that escapes is $\sim 0.1$. One may estimate the fraction of energy escaping through the side of the cylinder of radius, $\mathrm{R}$, using an expression from Swanson (SWA 87):

$$
\text { Fraction }=0.8 \mathrm{e}^{-3.45 \mathrm{R} / \mathrm{X}_{\mathrm{m}}}+0.2 \mathrm{e}^{-0.889 \mathrm{R} / \mathrm{X}_{\mathrm{m}}},
$$

in which $\mathrm{R}$ and $\mathrm{X}_{\mathrm{m}}$ are expressed in the same units. The Moliere radius is related to the radiation length and the critical energy by the expression from ICRU Report 28 (ICR 78):

$$
\mathrm{X}_{\mathrm{m}}=\mathrm{X}_{\mathrm{o}} \frac{21.2}{\mathrm{E}_{\mathrm{c}}}
$$

in which $E_{c}$ is in $\mathrm{MeV}$ and $\mathrm{X}_{\mathrm{m}}$ is in the same units as $\mathrm{X}_{\mathrm{o}}$.

\subsection{Shielding Approach}

The critical energy represents that energy at which the loss of energy per unit path $\left(\mathrm{cm} \mathrm{or} \mathrm{g} / \mathrm{cm}^{2}\right)$ of a given material is equal for both radiation production through the bremsstrahlung process and collision loss. Above the critical energy, more energy is lost to radiation formation (bremsstrahlung) than in the collision processes. The electromagnetic shower is not expected to develop significantly unless the electron energy is well above the critical energy in the given material. When the electron energy is high enough for the shower to develop significantly, the number of particles, photons, and/or electrons and positrons, will initially increase with absorber thickness, reaching a maximum value at a thickness, $\mathrm{t}$, given roughly by Bathow, et al. (BAT 67):

$$
\mathrm{t} \sim \mathrm{X}_{\mathrm{o}} \ln \mathrm{E} / \mathrm{E}_{\mathrm{c}}
$$

in which $\mathrm{E}$ is the initial electron energy, and then be attenuated by the medium with an attenuation length that eventually is expressed by $\lambda_{\mathrm{m}}$. As the initial energy of the electron goes to higher and higher values, the attenuation of the electron becomes quite complex. In the electromagnetic shower process electrons produce photons of high enough energy so that, when pair production occurs, the secondary electrons and positrons also have high enough energy to have long ranges in the material. In this situation the radiation length becomes the important parameter since it gives the thickness in which the electron loses 1/e of its energy to photon production. For high enough initial electron energy, several radiation lengths will be required before the particles in the shower reach a maximum value and begin to be attenuated. So, the amount of shielding needed will be more than just the range of the initial electrons of a given energy. For lower $\mathrm{Z}$ materials and not too high initial electron energy, the critical energy is high enough $(51 \mathrm{MeV}$ for $\mathrm{Al})$ so that shower development is not too extensive. In high $\mathrm{Z}$ materials, such as $\mathrm{W}$ and $\mathrm{Pb}$, the critical energies are low enough (see Table 3 ) for extensive shower development even at fairly low electron energy. To stop the beam for a lowenergy electron source, high-Z materials are more efficient and require less thickness, but the photon radiation will be higher than that in low-Z materials, and, as indicated in Eq. (3), the giant resonance 
neutron production will be higher. The strategy then is to use low-Z material to attenuate low-energy electron beams in order to avoid significant shower development with the increased giant resonance neutron production, if possible, and to use local supplemental shielding ( $\mathrm{Pb}$ and/or polyethylene) in order to attenuate the secondary radiations adequately. As the energy of the electron or positron increases, low- $Z$ materials require too large a thickness to adequately stop the beam so high- $Z$ materials are used. For the higher energy electron beams, the production of higher energy neutrons (MEN and HEN) is less in high-Z materials than that in low-Z materials, so beam stops made of high-Z material are more desirable, especially where space is a concern since the density of these materials is higher.

\subsection{Shielding Locations \& Composition and Distance Parameters}

There are two main regions at which beam will be lost during injection: at the injection septum and in the transition region from the standard Al vacuum chamber to an insertion device (ID). In the latter case, the reduction in physical aperture (from $46 \mathrm{~mm}$ down to $12 \mathrm{~mm}$ ) increases the probability of losing particles in the first few ID sections. Tracking programs indicate that significant loss does not occur after about three sections. Positrons that are extracted from the synchrotron are directed via the high energy transport (HET) line into the storage ring and injected into the SR orbit by the injection septum magnet (Figure 2). Local Pb shielding (40.64 cm thick), consisting of lead bricks, has been supplied in the forward direction and on the side of the septum closest to the EAA, and an additional $50 \mathrm{~cm}$ of concrete block may need to be installed along the EAA wall. The distance from the septum magnet to the nearest dose point outside of the 1.6-m-thick concrete shield in the EAA is $3.2 \mathrm{~m}$. Additional shielding of $35.56 \mathrm{~cm}$ of $\mathrm{Pb}$ over the septum may be needed to reduce the dose rate on the SR roof over the septum, where the roof is $1 \mathrm{~m}$ of concrete and the distance to the nearest dose point is $3.34 \mathrm{~m}$. The area immediately above the septum is normally not an occupied area.

During transfer from the HET, $20 \%$ of the beam is assumed to be lost at the injection septum. The dose rate outside of the SR tunnel wall on the infield side is not relevant since this will be an exclusion area, so the EAA is the occupied region of interest for dose rate determinations. The shortest distance from the septum to the EAA is $3.2 \mathrm{~m}$ at about $90^{\circ}$ and a total of $1.6 \mathrm{~m}$ of concrete shielding intercepts the radiation. Because occasional occupancy may be required on the roof above the SR tunnel, significant local shielding of the injection septum will still be required on the top and in the forward direction $\left(0^{\circ}\right)$. Based upon the assumed loss rate at the septum, $30.48 \mathrm{~cm} \mathrm{of} \mathrm{Pb}$ is required in the forward direction, $35.56 \mathrm{~cm}$ in the overhead direction, and $40.64 \mathrm{~cm}$ on both the side facing the EAA and on the other side. The dose point distance in the overhead direction is only $3.34 \mathrm{~m}$ and the concrete shielding is $1 \mathrm{~m}$, necessitating a thick $\mathrm{Pb}$ shield in the overhead direction. In the $0^{\circ}$ direction, the EAA distance is about $17 \mathrm{~m}$, the minimum $\mathrm{Pb}$ thickness is $30.48 \mathrm{~cm}$, and the slant thickness of the concrete EAA wall is about $6.34 \mathrm{~m}$, making the dose contribution in the EAA negligible.

Positrons that are injected into the SR orbit continue on to the transition region at the first ID. The probability of loss at this ID is the highest, but there also exists a smaller probability of loss at each of the next two ID sections. Since these IDs are close to the FOE, an additional $15.24 \mathrm{~cm}$ of Pb may need to be added to the inside of the ratchet wall for the second and third ID, and additional concrete has been planned for the EAA wall adjacent to the first ID. Positrons that survive these obstacles during injection are expected to be part of the circulating current. The circulating current exhibits distributed losses around the ring but these occur over a mean lifetime, which should be in excess of 
10 hours. Consequently, the operational dose rates outside the SR tunnel should be well below the design goal of $<0.25 \mathrm{mrem} / \mathrm{h}$, assuming that the losses are fairly evenly distributed over the circumference of the ring.

\section{Estimated Radiation Dose Rates at Safety Envelope Operation}

\subsection{Injection Septum Magnet}

The assumption is made that $20 \%$ of the incoming beam is lost at the injection septum. For operation at the safety envelope of the synchrotron $(308 \mathrm{~W})$, relevant dose rates were determined for a number of points, some of which are shown on Figure 2. The dose rates are given in Table 4.

Table 4 - Dose Rates at Relevant Points from 20\% Loss on the Injection Septum for 308-W Operation

\begin{tabular}{|c|c|}
\hline $\begin{array}{c}\text { Location } \\
\text { Degrees }\end{array}$ & $\begin{array}{c}\text { Total Dose Equivalent Rate } \\
\mathbf{m r e m} / \mathbf{h}\end{array}$ \\
\hline 0 & 0.08 \\
\hline 20 & 0.32 \\
\hline 25 & 1.35 \\
\hline 32.4 & 0.90 \\
\hline 70 & 0.82 \\
\hline 90 & 0.87 \\
\hline 120 & 0.20 \\
\hline 139.4 & 0.33 \\
\hline 152.3 & 0.27 \\
\hline
\end{tabular}

The dose rate in the backward direction toward the rf/Extraction Building is the value shown for $155^{\circ}$. The dose rate on the roof of the storage ring, for a point directly above the septum, assuming $35.56 \mathrm{~cm}$ of $\mathrm{Pb}$ is used over the loss region, is $2.13 \mathrm{mrem} / \mathrm{h}$. This region of the roof is a low occupancy area and access can be controlled administratively. However, this action may not be needed since only a few minutes of injecting time is anticipated for storing the full beam for normal operations. Since no more than a total of $10 \%$ operational time is envisioned, the average dose rate is expected to meet the DOE criterion. 


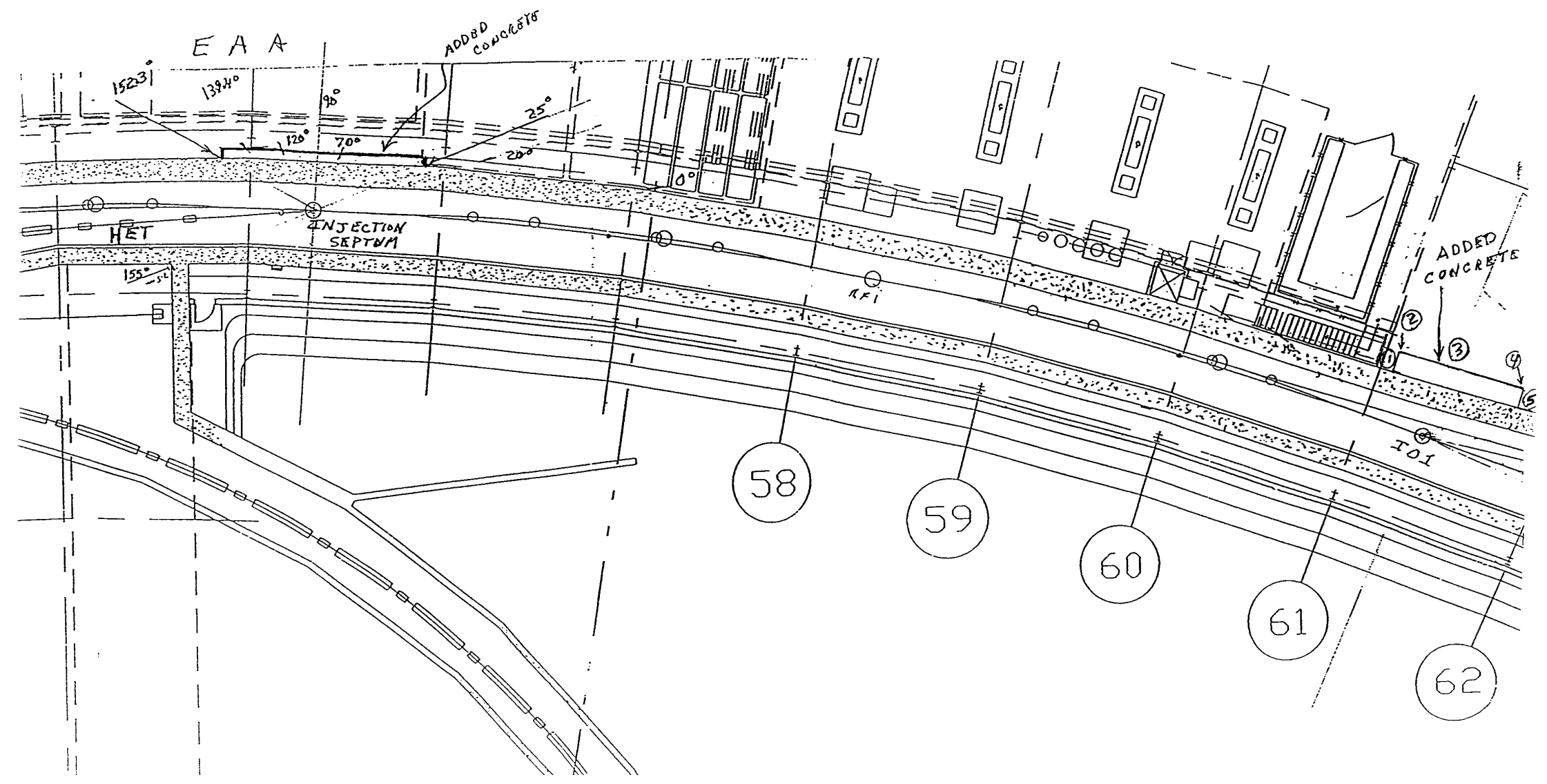

Figure 2 - Dose Rates Around the Injection Septum Region and 1-ID Region During Injection 


\subsection{Transition Piece of an Insertion Device}

At the insertion devices, the vacuum chamber gap dimension changes from about $4 \mathrm{~cm}$ down to $1 \mathrm{~cm}$. This is accomplished through a transition piece made out of a block of copper, containing a machined elliptical cone with the desired tapered shape. The copper block is housed in a steel box and each ID has a transition piece at each end. Figure 3 indicates the site of the front transition piece for 1-ID, the first ID in the SR, which is located near the end of the EAA. Figure 4 shows the arrangement for the rest of the ID devices in the ring, which are located near the radial ratchet wall of the SR tunnel. Experience at ESRF during injection indicates that the first two or three IDs will sustain most of the losses, and machine calculations at ANL predict a similar outcome. For this reason, additional shielding is planned for the first three IDs of the SR to guard against significant doses being received by individuals during the injection phase.

The copper block is about $18 \mathrm{~cm}$ in length and from 1.5 to $3.2 \mathrm{~cm}$ in thickness $(2.4 \mathrm{~cm}$ average thickness is used in the calculations). From Table 3, the radiation length (RL) of copper is $12.86 \mathrm{~g} / \mathrm{cm}^{2}$, which gives $1.4 \mathrm{~cm}$ for a density of $8.96 \mathrm{~g} / \mathrm{cc}$. Since the total length of the block is about $13 \mathrm{RL}$, the entire shower could develop in the copper block if the positron beam strikes the block at a sufficiently shallow angle. To be conservative, it is assumed that $20 \%$ of the beam is lost on the transition piece, and the full shower develops in the copper block. For operation at the synchrotron safety envelope, and the assumption of $20 \%$ loss on the injection septum, the power loss on the transition piece is $49.3 \mathrm{~W}$.

For the case in Figure 3, the transition piece is shown at the beginning of the ID, so the relevant dose points are around dose point A. It is possible that the device could be located at the centerline of the ID and dose points around B would then be the relevant locations. For locations at the centerline of the ID, the dose point $C$ of Figure 3 will also be of interest. On the basis of a circulating current of $360 \mathrm{~mA}$ in the SR, and an injection rate of $2.5 \times 10^{11} \mathrm{e}^{+} / \mathrm{s}$, the fill time will be 52 seconds for $20 \%$ loss on the septum and the loss on the transition piece. The dose rate for these loss conditions at dose point A in Figure 3, a distance of $2.61 \mathrm{~m}$ away and shielded by $2.4 \mathrm{~cm}$ of copper and $1.1 \mathrm{~m}$ of concrete, is $287 \mathrm{mrem} / \mathrm{h}$ without additional shielding. The dose delivered during injection would be $4.1 \mathrm{mrem}$. At A1, the dose rate is $115 \mathrm{mrem} / \mathrm{h}$ and dose during injection $1.7 \mathrm{mrem}$. At A2, the dose rate is $107 \mathrm{mrem} / \mathrm{h}$ and dose during injection is $1.5 \mathrm{mrem}$. If the transition piece is at the center, the dose rate at dose point $\mathrm{B}$ would be $248 \mathrm{mrem} / \mathrm{h}$ and $159 \mathrm{mrem} / \mathrm{h}$ at dose point $\mathrm{C}$ without additional shielding. This results in doses of 3.6 and $2.3 \mathrm{mrem}$, respectively, for the injection period. APS shielding policy requires that the maximum dose per injection be $\leq 2 \mathrm{mrem}$, so additional shielding is planned.

With the addition of $1 \mathrm{~m}$ of concrete at the EAA wall, extending $2.5 \mathrm{~m}$ to the left of dose point A and $4 \mathrm{~m}$ to the right (see Figure 2), the relevant dose rates for the points indicated in Figure 2 are shown in Table 5. For the ID located at the centerline, a similar shielding arrangement for dose point B would effect a similar reduction in the dose rates. Using $60.96 \mathrm{~cm}$ of concrete in the corner by dose point $C$ would result in a residual dose rate of about $8 \mathrm{mrem} / \mathrm{h}$. This region is expected to be a low occupancy area. On the basis of an assumed $10 \%$ operational time for injection, the average dose rates will be $1 / 10$ of those in Table 5 . 
Table 5 - Dose Rates at Relevant Points from 20\% Loss on the Transition Piece of 1-ID for 308-W Operation

\begin{tabular}{|c|c|}
\hline Location Number & $\begin{array}{c}\text { Total Dose Equivalent Rate } \\
\mathbf{m r e m} / \mathbf{h}\end{array}$ \\
\hline 1 & 6.1 \\
\hline 2 & 0.13 \\
\hline 3 & 0.77 \\
\hline 4 & 0.01 \\
\hline 5 & 7.1 \\
\hline
\end{tabular}

For the roof of the SR, the dose point is only $3.34 \mathrm{~m}$ away so that regardless of where the transition piece is located, the dose rate on the SR roof directly above the radiation source will be $302 \mathrm{mrem} / \mathrm{h}$, giving a dose of 3.6 mrem during the time of injection.

When the transition piece is located as in Figure 4, which is for the rest of the SR, the highest dose rates occur for the situation in which the transition piece is located at the beginning of the ID. For this case, the FOE for the upstream ID is adjacent to the ID of interest. Though most of the loss is expected to occur on 1-ID, for this computation we assume that the $20 \%$ is all lost at this ID. For no additional shielding, the dose rates in the FOE vary from $338-1635 \mathrm{mrem} / \mathrm{h}$. For the assumed injection conditions, the dose would vary from 5-23.6 mrem per injection, depending upon the location of the individual in the FOE. This range of dose per injection is unacceptable and indicates that additional shielding is required. With the addition of $15.24 \mathrm{~cm}$ of $\mathrm{Pb}$ on the SR tunnel wall (see Figure 4), the dose rates are reduced to $31-88 \mathrm{mrem} / \mathrm{h}$ in the covered region and $338 \mathrm{mrem} / \mathrm{h}$ in the region just outside of the $\mathrm{Pb}$ shield coverage. The resultant doses in the covered region would be 0.4$1.3 \mathrm{mrem}$ and $5 \mathrm{mrem}$ in the uncovered region, taking no credit for intervening shielding provided by the components of the bending magnet (BM) front end. Additional shielding may be needed to assure that dose rates outside of the FOE are below $5 \mathrm{mrem} / \mathrm{h}$, but this will be determined by radiation surveys during commissioning. Central to the issue of the shielding needed is the actual loss fraction on this ID. If most of the loss occurs on 1-ID, the planned shielding may be adequate. For the case of the transition piece located at the centerline, the dose rates will be lower than those quoted above, but the additional $\mathrm{Pb}$ shielding will still be required. 


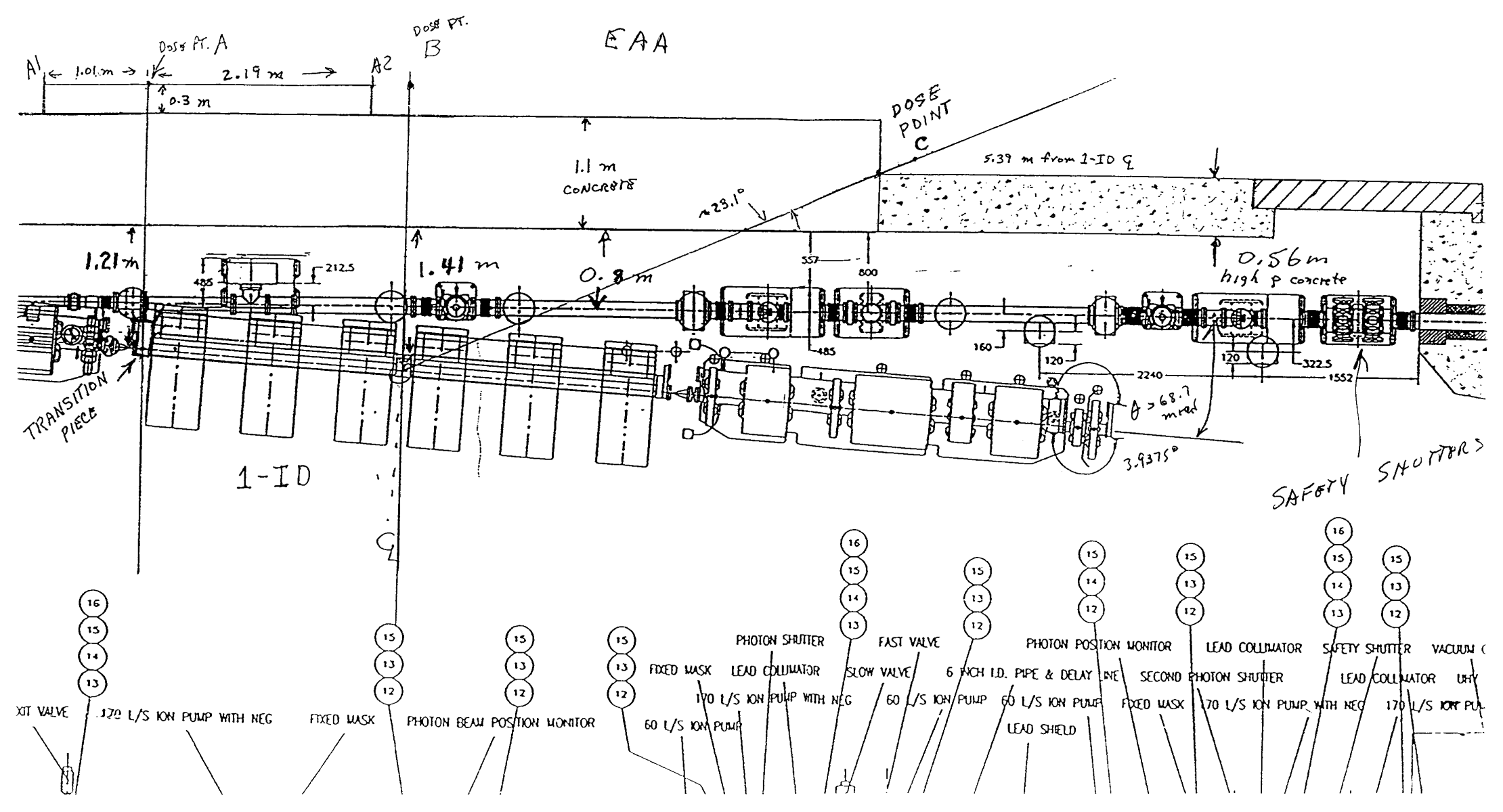

Figure 3 - Location of the Forward Transition Piece in 1-ID and Relevant Dose Points 


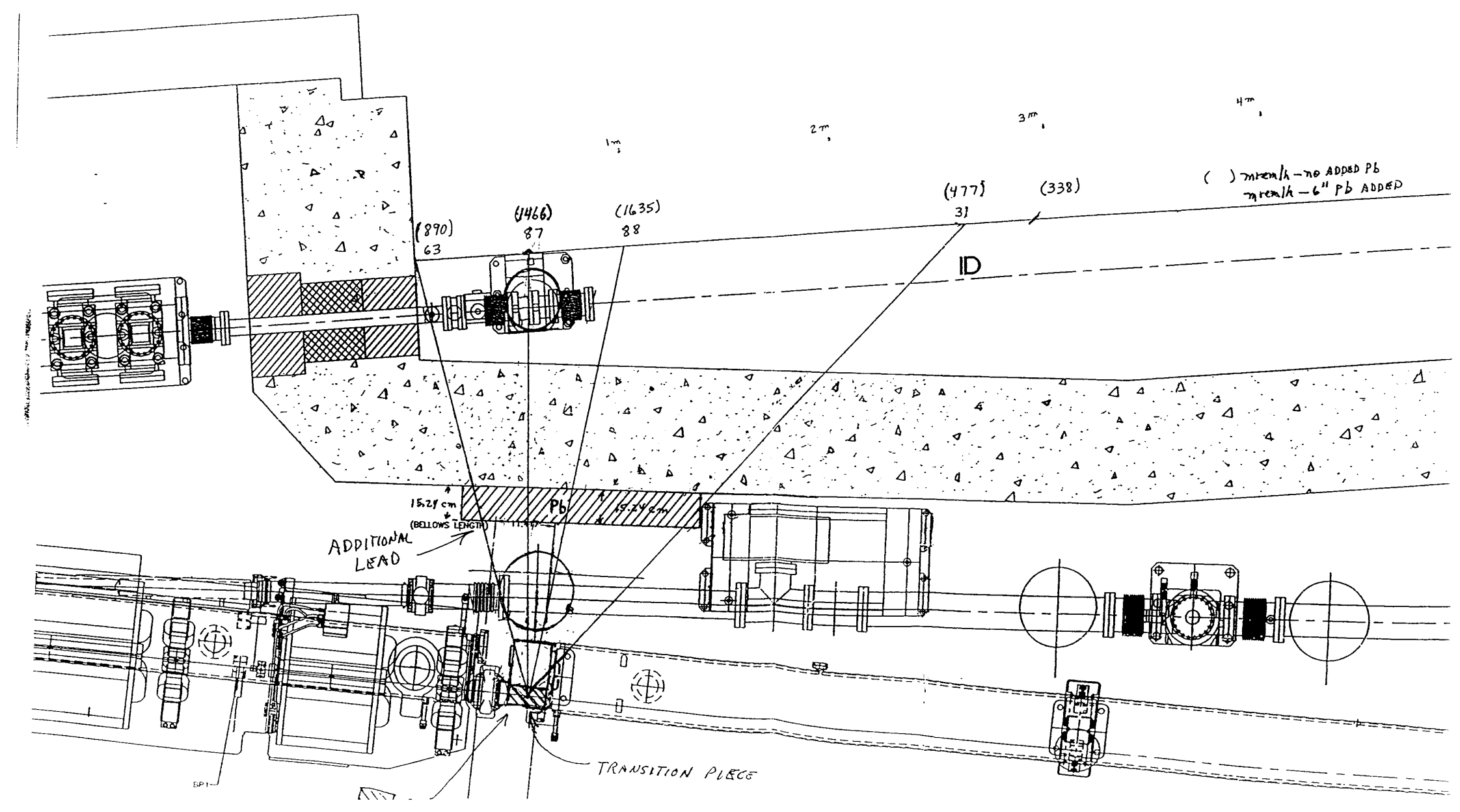

Figure 4 - Location of the Forward Transition Piece in 2-ID and Relevant Dose Points in the FOE 


\subsection{Loss Estimate for a Beam Spill}

Although the storage ring is roughly circular, it actually consists of an alternating series of bends and straight sections. For estimating the dose contributions from a beam spill in the SR, the spill is assumed to occur over a length of the ring that can be considered to be a straight line. This simplification makes the dose estimation easier and does not introduce a large error in the estimated dose or dose rates.

In the straight portions of the ring, a spill results in the radiation being emitted along a line source toward the dose point, as the particles strike an accelerator component and initiate an electromagnetic shower. As shown in the following sketch, radiation from each differential element, $\mathrm{dl}$, contributes to the total dose rate at the dose point, $\mathrm{P}$, after passing through two different shield materials of thickness $t_{1}$ and $t_{2}$, respectively:

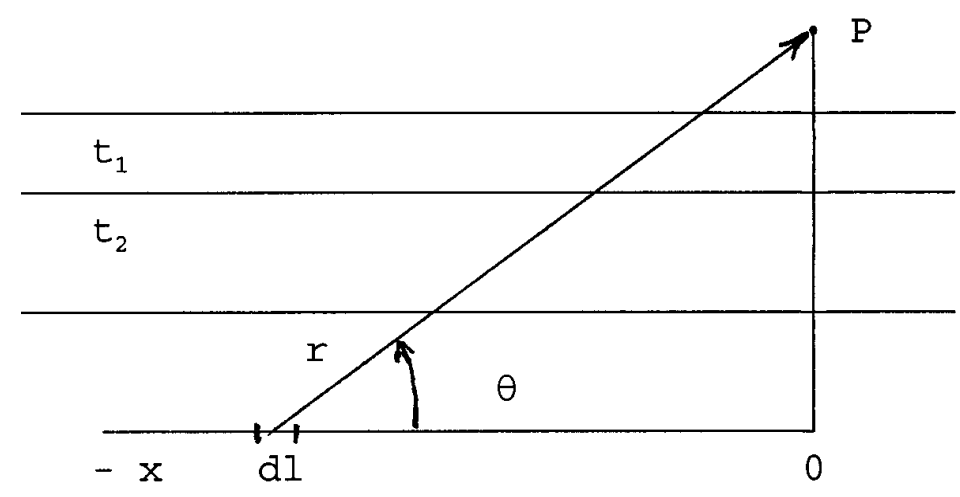

The dose rate contribution $(\mathrm{mrem} / \mathrm{h})$ at the point $\mathrm{P}$ from the differential line segment $\mathrm{dl}$ for the ith radiation component can be expressed as

$$
\mathrm{dH}_{\mathrm{i}}=\left[3600 \mathrm{PF}_{\mathrm{i}} \prod_{\mathrm{i}, \mathrm{j}} \exp ^{-\mathrm{t}_{\mathrm{j}} /(\sin \theta) \lambda_{i, j}}\right] \frac{\mathrm{dl}}{\mathrm{r}(\theta)^{2}}
$$

where $P$ is the power lost per $\mathrm{m}$ of length $(\mathrm{W} / \mathrm{m}), 3600 \mathrm{~s} / \mathrm{h}$ converts $\mathrm{W}$ to $\mathrm{J} / \mathrm{h}, \mathrm{F}_{\mathrm{i}}$ is the dose constant $(\mathrm{mrem} / \mathrm{J}$ at $1 \mathrm{~m})$ for the ith radiation component, $\mathrm{t}_{\mathrm{j}}$ is the straight through thickness of the jth shield material in $\mathrm{g} / \mathrm{cm}^{2}, \lambda_{i, j}$ is the attenuation length of the ith radiation component for the jth shield material in $\mathrm{g} / \mathrm{cm}^{2}, \mathrm{r}(\theta)$ is the distance $(\mathrm{m})$ from the differential line segment to the dose point $\mathrm{P}$, and $\theta$ is the angle between the line segment and the dose point. This geometry was used for estimating both the side and overhead doses. For small segments of the ring, the source is considered a line source without curvature; for longer sections of the ring, the estimate should be based upon the analysis described by Moe (MOE 93c), or the actual layout of the ring used as in the Addendum of APS-LS-141 Revised (MOE 91). The total dose rate contribution ( $\mathrm{mrem} / \mathrm{h}$ ) at the point $\mathrm{P}$ is found by integrating over the length of the line segment: 


$$
\dot{\mathrm{H}}_{\mathrm{i}}=3600 \mathrm{P} \sum_{\mathrm{i}} \int_{-\mathrm{x}}^{0} \frac{\mathrm{F}_{\mathrm{i}} \prod_{\mathrm{i}, \mathrm{j}} \exp ^{-\mathrm{t}_{\mathrm{j}} /(\sin \theta) \lambda_{\mathrm{i}, \mathrm{j}}}}{\mathrm{r}(\theta)^{2}} \mathrm{dl} .
$$

Equations (9) and (10) were used for the evaluation of dose rates on the top of the SR and in the EAA for injection losses on the septum, in the high dispersion region of a section, and for other loss locations. In the case of the top of the SR, the perpendicular distance from the orbit to the dose point is $3.34 \mathrm{~m}$, consisting of $1.34 \mathrm{~m}$ above the ring, $1 \mathrm{~m}$ of concrete in the roof, and $1 \mathrm{~m}$ to the dose point. A minimum of $10.16 \mathrm{~cm}$ of overhead Fe shielding was assumed for the calculations because of the overhead steel in the magnets. For the side dose rate in the EAA, the perpendicular distance from the orbit to the dose point is $2.75 \mathrm{~m}$, consisting of $1.35 \mathrm{~m}$ from the ring to the tunnel wall, $1.1 \mathrm{~m}$ of concrete in the EAA wall, and $30 \mathrm{~cm}$ to the dose point. The average integrated SR roof dose, for a spill over a 4-m length (the length of a high dispersion region), is $5.81 \times 10^{-2} \mathrm{mrem} / \mathrm{p}$, and the average side dose in the EAA is $5.59 \times 10^{-2} \mathrm{mrem} / \mathrm{p}$.

\subsection{Muon Dose Rates}

When the electron energy is above $1 \mathrm{GeV}$, the production rate of muons may become a problem, but generally only in the forward direction. Muons can be produced as pairs in electromagnetic interactions and by decay of pions (ICR 78). Muons are initially emitted in a narrow cone within a few units of the characteristic angle given by $105.66 / \mathrm{E}_{\mu}$ radians (TSA 74), in which $105.66 \mathrm{MeV}$ is the rest energy of the muon and $\mathrm{E}_{\mu}$ is the muon energy in $\mathrm{MeV}$. Some scattering occurs, but the major attenuation is by energy loss through ionization. So, muons have great penetrating power and require large thicknesses of material to attenuate them. The fluence rate of muons has been measured by Nelson (NEL 68) and this data can be adapted to dose rates as given in Swanson (SWA 79a). Using the graph in Swanson for the fluence rate of muons $\left(3.1 \times 10^{5} \mu / \mathrm{cm}^{2} \mathrm{~s}\right)$ for $7.7 \mathrm{GeV} \mathrm{e}$, and the dose rate constant of $7.23 \mu / \mathrm{cm}^{2} \mathrm{~s}=1 \mathrm{mrem} / \mathrm{h}$ obtained from ICRP Publication 51 (ICP 87), the unshielded dose rate constant for $7.7 \mathrm{GeV}$ muons becomes $42.9 \mathrm{rem} / \mathrm{kWh}$ at $1 \mathrm{~m}$. To estimate attenuation and scattering of the muon component, Swanson gives an expression that can be used to take these factors into account, correcting the unshielded component for both of these effects. This expression for the scattered muon dose rate relative to the unshielded dose rate, evaluated at the dose point distance, is:

$$
\dot{\mathrm{H}}(\mathrm{scat})=\left[\frac{25}{25+\mathrm{X} / \mathrm{X}_{0}}\right]\left[\frac{\mathrm{X}\left(\mathrm{E}_{0}\right)-\mathrm{X}}{\mathrm{X}\left(\mathrm{E}_{0}\right)}\right] \dot{\mathrm{H}}(\text { unshiel }),
$$

where $\mathrm{X}$ is the thickness of the shield material and $\mathrm{X}_{0}$ is the radiation length, both quantities in the same units, and $\mathrm{X}\left(\mathrm{E}_{0}\right)$ is the maximum muon range in the shield material at the initial positron energy $\left(E_{0}\right)$.

There are two situations in which one would be interested in evaluating the potential muon radiation dose rate: from the injection septum and from the transition region of the first ID in the $0^{\circ}$ direction. The muon dose rate from the stored beam losses will be $<1 \mu \mathrm{rem} / \mathrm{h}$. Using the data in Swanson for the radiation length and range of muons in different materials, in Eq. (11), and applying the 
relationship for each shielding material, $\mathrm{Pb}$ and concrete, one may estimate the dose rate due to muons in the EAA and Experiment Hall for both the injection septum and the ID transition piece for operation at the safety envelope. In the case of the septum magnet, the dose point is in the EAA, a distance of $17 \mathrm{~m}$ from the magnet, and the shielding consists of $6.34 \mathrm{~m}$ of concrete and $2.92 \mathrm{~m} \mathrm{of} \mathrm{Pb}$. The resultant dose rate in the EAA is $0.03 \mathrm{mrem} / \mathrm{h}$. In the case of the transition piece, the dose point is in the Experiment Hall, outside of the $\mathrm{Pb}$-concrete plug for 1-ID in the radial part of the ratchet wall, but at a distance of $27 \mathrm{~m}$ from the ID. The shielding consists of $18 \mathrm{~cm}$ of $\mathrm{Cu}, 25.4 \mathrm{~cm}$ of $\mathrm{Pb}$, and $55 \mathrm{~cm}$ of high density concrete. The resultant dose rate is $0.46 \mathrm{mrem} / \mathrm{h}$, assuming that the shower takes place in the $\mathrm{Cu}$ transition piece between the $\mathrm{Al}$ vacuum chamber of the SR and the ID. Although the latter dose rate is above the DOE guideline, the average dose rate, based upon 10\% operation, is within the guideline for the Experiment Hall region. In addition, the beam size in each case is rather small and does not constitute a potential area-wide radiation field, so the beam can be easily avoided. Therefore, the muon contribution is considered to be relatively unimportant. Health Physics personnel will be making real-time surveys with portable instruments and will be positioning passive detectors in areas to check out the actual readings.

\section{Dose Rates for Design Performance Goal Operating Mode}

For design performance goal operation of the SR at $84 \mathrm{~W}\left(7000 \mathrm{MeV}\right.$ and $12 \mathrm{nA}$ of $\mathrm{e}^{+}$current) delivered from the synchrotron, the dose rates for the previous locations can be scaled down by the ratio of the power lost. This ratio is $84 / 308=0.273$ for the injection region and the transition piece. Although the forward-directed bremsstrahlung radiation varies with the positron energy, the usual shielding in the forward direction is sufficient to insure that showers induced by $\mathrm{e}^{+}$at either 7 or 7.7 $\mathrm{GeV}$ will be adequately attenuated. Dose rates for the loss rate at the injection septum for $84-\mathrm{W}$ operation are shown in Table 6 for the locations on Figure 2. With the exception of the location at $25^{\circ}$, all relevant sites meet the DOE requirement without invoking averaging. For $10 \%$ operational time, all locations are within the dose rate guideline. The dose rate on the storage ring roof, for a point directly above the septum, is $0.58 \mathrm{mrem} / \mathrm{h}$. Although this is above $0.25 \mathrm{mrem} / \mathrm{h}$, with averaging it will be well below this value.

For the case of a beam spill, the average integrated SR roof dose is $5.81 \times 10^{-2} \mathrm{mrem} / \mathrm{p}$ and the side dose in the EAA is $5.59 \times 10^{-2} \mathrm{mrem} / \mathrm{p}$.

Dose rates for occupied areas in the Experiment Hall for operation at the design performance goal and for a $20 \%$ loss on the transition zone of 1-ID are shown in Table 7 . The dose rates in the table indicate that the dose requirements should be met at most relevant occupied EAA locations without averaging the dose rate. All locations will be well within the requirement when the average dose rate is taken into account. At $84-\mathrm{W}$ operation, the expected dose rate on the SR roof is $72 \mathrm{mrem} / \mathrm{h}$, and the dose rate outside of the building in the exclusion zone on the infield side of the ring is $61 \mathrm{mrem} / \mathrm{h}$. 
Table 6 - Dose Rates at Relevant Occupied Points from 20\% Loss on the Injection Septum for 84-W Operation

\begin{tabular}{|c|c|}
\hline Location Degrees & $\begin{array}{c}\text { Total Dose Equivalent Rate } \\
\mathbf{m r e m} / \mathbf{h}\end{array}$ \\
\hline 0 & 0.021 \\
\hline 20 & 0.087 \\
\hline 25 & 0.367 \\
\hline 32.4 & 0.245 \\
\hline 70 & 0.223 \\
\hline 90 & 0.238 \\
\hline 120 & 0.056 \\
\hline 139.4 & 0.091 \\
\hline 152.3 & 0.074 \\
\hline 155 & 0.022 \\
\hline
\end{tabular}

Table 7 - Dose Rates for Occupied Areas in the EAA for 84-W Operation and $20 \%$ Loss on the 1-ID Transition Piece

\begin{tabular}{|c|c|}
\hline $\begin{array}{c}\text { Location } \\
\text { Number }\end{array}$ & $\begin{array}{c}\text { Total Dose Equivalent Rate } \\
\mathbf{m r e m} / \mathbf{h}\end{array}$ \\
\hline 1 & 1.7 \\
\hline 2 & 0.04 \\
\hline 3 & 0.21 \\
\hline 4 & 0.003 \\
\hline 5 & 1.9 \\
\hline
\end{tabular}

Although not an important radiation field, the muon dose rates at the design performance goal operation are expected to be $0.008 \mathrm{mrem} / \mathrm{h}$ and $0.13 \mathrm{mrem} / \mathrm{h}$ from the injection septum and the transition piece, respectively, for the dose points in the EAA and at the end of the Pb-concrete plug in the ratchet wall.

With the exception of the roof of the storage ring and the area outside the exclusion zone in the corridor, the estimated dose rates at all other relevant points are generally within the DOE guideline. During the initial operations for the storage ring, the proposed shielding should be satisfactory. The actual radiation fields need to be measured during operation to establish the validity of the estimates or to help determine whatever additional local shielding may be needed. 


\section{Synchrotron Radiation}

In general, synchrotron radiation losses are insignificant for linear accelerators (GOD 68). However, when electrons or positrons are bent in circular orbits, they radiate intense electromagnetic radiation in a highly peaked forward cone of radiation. The alternating magnetic fields in an insertion device produce synchrotron radiation at greater intensity than the bending magnets do. In the storage ring, synchrotron radiation is emitted as the particles go through bending magnets and IDs. If the energy of the accelerated $\mathrm{e}+$ is high enough, some of the bending-magnet synchrotron radiation will escape the aluminum vacuum chamber and irradiate the air in the SR tunnel, potentially causing radioactive and/or noxious gas production. The synchrotron radiation from the IDs proceeds directly forward down the beamline, but can be scattered by any component that it strikes. Little scattering is expected during transport of the synchrotron radiation until the beam gets to the first optics enclosure. Shielding for the FOE and the photon beamlines has been treated by Ipe et al. (IPE 93). The emitted radiation covers a spectrum of energies. Half of the emitted power in the spectrum is above a certain energy and half below. This energy value is also called the critical energy $\mathrm{E}_{\mathrm{c}}{ }_{\mathrm{c}}$ and is given by (WIN 78):

$$
\mathrm{E}_{\mathrm{c}}^{\prime}=2.218 \mathrm{E}^{3} / \mathrm{r}(\mathrm{keV})
$$

for the positron energy $\mathrm{E}$ in $\mathrm{GeV}$ and the radius $\mathrm{r}$ of the magnet in $\mathrm{m}$. For a 7.7-GeV beam and a radius of $38.96 \mathrm{~m}, \mathrm{E}_{\mathrm{c}}^{\prime}=26 \mathrm{keV}$. The number of photons produced can be found with the use of an expression from Green (GRE 76, p. 1-9):

$$
\frac{\partial \mathrm{N}(\mathrm{E}, \mathrm{t}, \mathrm{I}, \theta)}{\partial \mathrm{E} \partial \mathrm{t} \partial \mathrm{I} \partial \theta}=4.2419 \times 10^{16} \times \frac{\mathrm{R}}{\gamma^{2}} \int_{\mathrm{y}}^{\infty} \mathrm{K}_{5 / 3} \eta(\mathrm{d} \eta)
$$

in which $\partial \mathrm{N}(\mathrm{E}, \mathrm{t}, \mathrm{I}, \theta) / \partial \mathrm{E} \partial \mathrm{t} \partial \mathrm{I} \partial \theta$ is the number of photons per eV per s per $\mathrm{mA}$ per mrad in the horizontal, for the entire opening angle $\psi ; \mathrm{R}$ is the radius of the bending magnet in $\mathrm{m} ; \gamma=$ $7700 / 0.511 ; \mathrm{y}=\mathrm{E} / \mathrm{E}_{\mathrm{c}}{ }_{\mathrm{c}}=\mathrm{E} / 26000$, in which $\mathrm{E}$ is the photon energy in $\mathrm{eV}$; and $\mathrm{K}_{5 / 3}(\eta)$ is a modified Bessel function (WAT 48). By integrating the above equation over dE, the number of photons per $\mathrm{s}$ per $\mathrm{mA}$ per mradh is obtained for one magnet. Assuming $327 \mathrm{~mA}$ of average circulating current (at $7700 \mathrm{MeV}$ ) and multiplying by the number of bending magnets ( 80 in the storage ring), one arrives at an estimate of the total number of photons per s per mradh. The synchrotron radiation will intercept the wall thickness of the chamber at an angle that varies depending upon where the photon is emitted along the bending magnet arc. These angles are all oblique enough to greatly increase the total path through the chamber wall, so that significant attenuation of the radiation occurs. However, the vacuum chamber actual thickness is only $1.5 \mathrm{~cm}$ of aluminum so that some synchrotron radiation will get out into the tunnel. Although this radiation will not penetrate the tunnel shielding, it can produce ozone and other noxious gases in the air. An estimate of the noxious gas production in the storage ring tunnel was made in APS-LS-141 Revised (MOE 91). Figure 5, taken from this publication, shows the estimated energy absorption rate in air due to synchrotron radiation in the synchrotron and storage ring. The data from this figure can be used to conservatively estimate the production rate of noxious gases (see Section 12.2). 


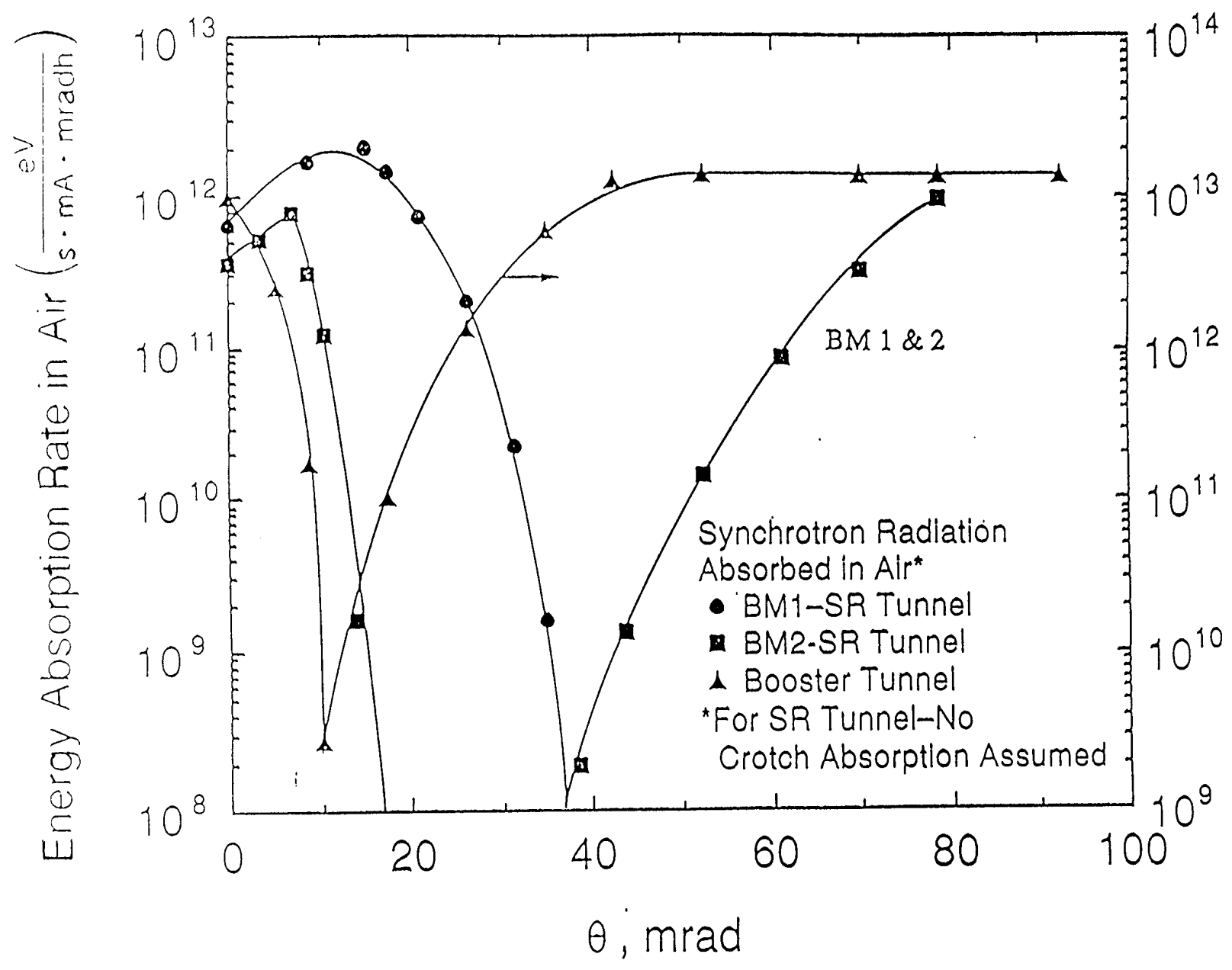

Figure 5 - Estimated Energy Absorption Rate in Air Due to Synchrotron Radiation in the Synchrotron and Storage Ring Tunnels 


\section{Gas Bremsstrahlung}

The interaction of particles with the residual molecules of air in the vacuum chamber produces bremsstrahlung, which can be a problem in the long straight sections of a circular accelerator. Since this bremsstrahlung radiation is produced in a straight section, it will travel along with the synchrotron radiation in the photon beamline. This forward peaked component of the bremsstrahlung radiation travels down an experimental beamline giving an objectionable radiation level at the end of the line. Based upon an EGS4 Monte Carlo study and measurements at Frascati and KEK, Tromba and Rindi (TRO 90) have developed a semi-empirical expression for estimating dose rates from these bremsstrahlung photons. The total estimated dose rate at $10 \mathrm{~m}$ from the end of a straight section can be computed from:

$$
\dot{\mathrm{H}}[\mathrm{rem} / \mathrm{h}]_{10 \mathrm{~m}}=1.7 \times 10^{-14} \mathrm{E}^{2.43} \frac{\mathrm{P}}{760} \mathrm{IL},
$$

in which $\mathrm{E}$, the positron energy, is in $\mathrm{MeV}$, the pressure $\mathrm{P}$ is in $\mathrm{mm}$, the circulating current $\mathrm{I}$ is in $\mathrm{e}^{+} / \mathrm{s}$, and the length of the straight $\mathrm{L}$ is in $\mathrm{m}$. The above can be extended to other distances for $\mathrm{r}>\mathrm{L}$ and for points inside the radiation cone by using:

$$
\dot{\mathrm{H}}[\mathrm{rem} / \mathrm{h}]_{\mathrm{r}}=\dot{\mathrm{H}}_{10 \mathrm{~m}} \frac{(10+\mathrm{L} / 2)^{2}}{\mathrm{r}^{2}} \text {, }
$$

in which $\mathrm{r}(\mathrm{m})$ is the distance from the center of the straight section to the dose point.

Evaluation of the gas bremsstrahlung for the SR was accomplished to estimate the dose rate from this component. The longest straight section in the ring is $15.38 \mathrm{~m}$. The pressure was assumed to be $10^{-9} \mathrm{~mm}$, the positrons circulate at a current of $2.04 \times 10^{18} \mathrm{e}^{+} / \mathrm{s}$, the estimated dose rate at $10 \mathrm{~m}$ from the end of the long straight in the SR is $1953 \mathrm{rem} / \mathrm{h}$, and the estimated radiation field in the FOE, about $30 \mathrm{~m}$ away, is computed to be $679 \mathrm{rem} / \mathrm{h}$. This radiation level is of importance for the shielding of the FOE and requires significant $\mathrm{Pb}$ shielding on the back and side walls, but the neutron contribution is expected to be negligible (IPE 93).

In order to roughly estimate the contribution of gas bremsstrahlung from a bending magnet, the result from the above computation can be scaled. For a 6-mradian acceptance and a bending radius of 38.96 $\mathrm{m}$, the arc length of the bending magnet seen by a photon beamline is $23.4 \mathrm{~cm}$. This path length is only 0.015 of the path length in an ID, and scaling the dose rate above gives an estimated dose rate of $10.3 \mathrm{rem} / \mathrm{h}$. 


\section{X Rays from rf Cavities}

The rf cavities used to replenish energy lost by the circulating $\mathrm{e}^{+}$beam in the storage ring emit a spectrum of $x$ rays. Measurements of radiation levels produced by several of the single-cell cavities in the rf test stand indicated $<200 \mathrm{mR} / \mathrm{h}$ at $1 \mathrm{~m}$ from the cells. The exclusion zone in the SR includes the four rf stations of four single-cell cavities each. The distance from the closest station to the exclusion fence is far enough so that no radiation hazard is expected at the fence. However, radiation measurements will be made, and if shielding is indicated, it will be added.

\section{Storage Ring Normal and Accidental Losses}

A number of potential incidents in the APS and the dose consequences have been previously addressed (MOE 91). For these incidents, the safety shutdown system mechanisms are assumed to function properly and produce a shutdown within a few pulses. The resulting doses are on the order of $\mu$ rems to a few mrems in many of these cases. In the maximum credible incident (MCI), the sequence of events is such that the incident continues for an unspecified amount of time. In this case, the total dose will be more than that determined for the incidents analyzed in APS-LS-141 Revised. The discussion of the MCI and its dose consequences are in Appendix A.

During storage ring operation, particle losses occur during injection and during the period when the beam is stored. Injection losses may occur at the thin septum, limiting horizontal apertures, limiting vertical apertures and on the transition piece of the ID sections. In the latter case, the losses are expected to occur primarily at the first three ID sections. Horizontal missteering of the beam may also produce losses in the quadrupoles AQ2 and BQ2 on Girders 1 and 5, respectively, as well as in the high-dispersion regions near sextupole AS4 on Girder 3 in any of the 40 sectors of the SR (see Figure 6). As the stored beam circulates, a small fraction of the beam will be lost due to collisions with gas molecules, interactions among beam particles, and orbital excursions that lead to positrons being lost from the beam and striking the vacuum chamber. This will be a small continuous loss over many hours and the losses will be somewhat distributed around the ring. Failure of the rf or a shorted dipole magnet will cause the beam to be lost from the orbit and hit the vacuum chamber. This section deals with the dose consequences that result from these losses.

\subsection{Losses During Injection}

The safety envelope for the injection case is $308 \mathrm{~W}$. As suggested before, this is represented by 7700 $\mathrm{MeV}$ and a current of $40 \mathrm{nA}$ from the synchrotron. The following analysis of injected beam losses will be based upon the power delivered at the safety envelope.

\subsubsection{Loss in a High-Dispersion Region}

For an accidental loss of the entire beam in a high-dispersion region of the SR during injection, the system will normally shut down within a few pulses. The probability of the loss occurring in this region is higher than that for other regions because the beam dispersion tends to be greater here than in the rest of the ring. For this incident, a dump of $2.5 \times 10^{11} \mathrm{e}^{+} / \mathrm{s}$ of $7700 \mathrm{MeV}$ occurs at one of the high-dispersion regions (around AS4 in Figure 6) such that the forward-directed radiation $\left(0^{\circ}\right)$ is 


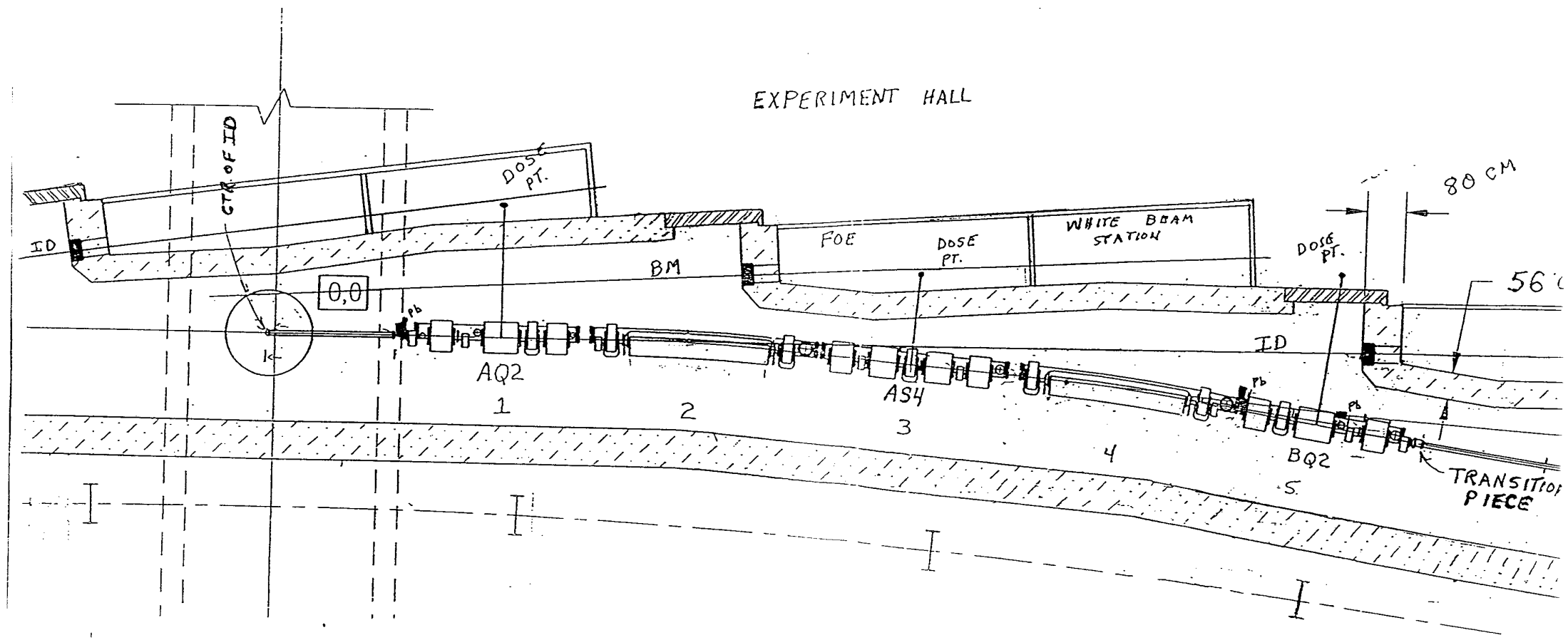

Figure 6 - Loss Sites around the Storage Ring 
intercepted by the ratchet plug ( $25 \mathrm{~cm}$ of $\mathrm{Pb}$ backed by $55 \mathrm{~cm}$ of high density concrete) for the $\mathrm{BM}$ beamline originating in the dipole on Girder 4 (as discussed in the Addendum to LS-141 Revised (MOE 91)). The energy loss rate is $308 \mathrm{~W}$. The beam would be expected to spray along a length of the accelerator structure, taken as $4 \mathrm{~m}$ in length, and the dose points of interest would be in the FOE and on the SR roof. The reading in the FOE behind the Pb-concrete plug would be about $6 \mathrm{mrem} / \mathrm{h}$ for the forward-directed component. In the $90^{\circ}$ direction to the Experiment Hall side, the dose point is in an FOE at a perpendicular distance of $1.9 \mathrm{~m}$, and the shielding consists of $3 \mathrm{~cm}$ of $\mathrm{Al}$ and $56 \mathrm{~cm}$ of high-density concrete. The dose rate in the FOE is $10.7 \mathrm{rem} / \mathrm{h}$. For the roof of the SR, the dose point is $3.34 \mathrm{~m}$ above the loss region, the shielding consists of $10.16 \mathrm{~cm}$ of Fe and $1 \mathrm{~m}$ of concrete, and the average dose rate is $418 \mathrm{mrem} / \mathrm{h}$. For these conditions the beam would be expected to be shut down in 1-2 s, resulting in doses in the ranges of 2.9-6.1 mrem and 0.12-0.24 mrem, respectively.

\subsubsection{Uniform Beam Spray Over 10 Meters of the Storage Ring}

The case of a uniform 4-m-long spill has already been analyzed in Section 5.3 for the EAA region and in Section 10.1.1 above for the rest of the high-dispersion regions of the ring. This type of spill assumes that the beam does not hit at too shallow an angle. If the incident angle is very shallow, the spill might extend for $10 \mathrm{~m}$ or more, and consequently the dose rate would be lower, since only a few meters to either side of the dose point makes an effective contribution to the dose. Assuming operation at the safety envelope and a 10-m-long spill, the roof dose rate in the EAA or Experiment Hall would be about $132 \mathrm{mrem} / \mathrm{h}$, and the highest side dose rate in these areas is $4952 \mathrm{mrem} / \mathrm{h}$ (about a factor of 2 lower than that computed in Section 10.1.1 for a 4-m spill). For a continuing spill over an indefinite duration, both the resultant dose rates would be high enough to trigger a radiation monitor alarm to initiate shutdown.

Calculations of the dose rate for the MCI condition in the synchrotron using the EGS4 shower code (EME 94) indicated that the dose rate was about a factor of 8 lower than that computed on the basis of a 2-m spill using the empirical expressions developed by Swanson. This can be attributed to two factors, the lengthening of the shower development and the treatment of photon attenuation (EME 94). In assuming a longer shower length, the energy loss is spread over a greater length and the dose contribution from the line source to the dose point will be decreased. The empirical formulas use a fixed effective attenuation length based upon deep shield penetrations. When the shield is not so thick, the effective attenuation length will be significantly shorter than that used in the empirical formula, hence the overly conservative result. Reworking the MCI condition for a 4-m spill instead of $2 \mathrm{~m}$ gave results a factor of about 5 greater than the EGS4 value. A calculation for a 10-m-long spill gave results about 3.5 times greater than the EGS4 result. In order to maintain an adequate margin of conservatism yet achieve a more reasonable estimate of the dose rate, losses involving spills will be considered to be over a minimum length of $4 \mathrm{~m}$.

\subsubsection{Uniform Beam Spray Around the Storage Ring}

For the case in which there is a uniform spray around the storage ring, the loss of particles will be spread over $1104 \mathrm{~m}$. Scaling the results from Section 10.1.2, the dose rate at the closest point of potential occupancy is about $45 \mathrm{mrem} / \mathrm{h}$. For this condition, the beam would be expected to be shut down in 1-2 s, resulting in doses in the range $12-24 \mu \mathrm{rem}$. 


\subsubsection{Loss at Other Points Around the Ring}

As indicated in Figure 6, two other sites of potential beam loss are at AQ2 and BQ2. These are less likely than the AS4 site, but could result from horizontal missteering of the beam. For a spill at AQ2, the dose point is in a white beam station, a distance of $2.86 \mathrm{~m}$ from the loss region, and the shielding is $56 \mathrm{~cm}$ of high-density concrete. For BQ2, the dose point is $3.2 \mathrm{~m}$ away and the shielding is the 28 $\mathrm{cm}$ of the ratchet door, which contains a castable shield of $65 \% \mathrm{~Pb}, 34 \%$ of a neutron shield, and $1 \%$ of $\mathrm{B}_{4} \mathrm{C}$. The density of this shield material is $3.93 \mathrm{~g} / \mathrm{cc}$. The side dose rates for $100 \%$ loss at these two sites are $5987 \mathrm{mrem} / \mathrm{h}$ and $7237 \mathrm{mrem} / \mathrm{h}$, respectively. The beam would be expected to be shut down in 1-2 s, resulting in doses in the range 1.4-2.8 mrem and 2-4 mrem, respectively. In each of these cases, the average dose rate on the SR roof will be $418 \mathrm{mrem} / \mathrm{h}$, resulting in a dose of $0.12-0.24$ mrem.

\subsubsection{Nonuniform Spray Around Ring}

Another potential accident condition involves beam instabilities such that the beam is lost nonuniformly around the ring. The more likely regions are the high-dispersion regions of the sectors. The losses may occur equally at each of these regions, and we assume $100 \%$ loss of the beam spread equally at 40 sites during operation at the safety envelope in each 4-m-long high-dispersion section of the ring. For this incident, a relevant dose point is located on the SR roof, $3.34 \mathrm{~m}$ perpendicular distance above the loss region and is shielded by $10.16 \mathrm{~cm}$ of Fe and $1 \mathrm{~m}$ of concrete. Several dose points in the EAA are $2.75 \mathrm{~m}$ away and are shielded by $1.1 \mathrm{~m}$ of concrete and $3 \mathrm{~cm}$ of Al. But the highest dose rates will be obtained for the regions in the ratchet part of the SR, for the locations by AS4 on Figure 6, since the dose point in the FOE is only $1.9 \mathrm{~m}$ away and the Al shield is only $3 \mathrm{~cm}$ thick and the high-density concrete is only $56 \mathrm{~cm}$ thick. As in Section 5.3, Eqs. (9) and (10) were used to arrive at the total dose rate from the line sources. The highest side dose rates are $267 \mathrm{mrem} / \mathrm{h}$ and the roof dose rate is about $8.5 \mathrm{mrem} / \mathrm{h}$ at the various sites. Again, for shutdown occurring in $1-2$ $\mathrm{s}$, the dose ranges would be $73-146 \mu \mathrm{rem}$ and 2-5 $\mu \mathrm{rem}$, respectively.

\subsubsection{Total Beam Loss at Injection Septum}

The results for the case of $20 \%$ loss on the injection septum for operation at the safety envelope are contained in Table 4 . For $100 \%$ loss, these dose rates would be five times their values and the highest dose rate $(10.7 \mathrm{mrem} / \mathrm{h})$ would be on the roof of the SR.

\subsubsection{Total Beam Loss at the Transition Piece}

The results for the case of $20 \%$ loss on the transition piece for operation at the safety envelope are shown in Table 5. For 100\% loss, the highest dose rates would be five times greater and the highest dose rate $(440 \mathrm{mrem} / \mathrm{h}$ ) would be in the FOE (Figure 4). For shutdown occurring in 1-2 s, the highest dose range would be 0.12-0.24 mrem. A loss at any unshielded transition piece gives a dose rate of $8.2 \mathrm{rem} / \mathrm{h}$ and a shutdown dose range of 2.3-4.6 mrem. 


\subsubsection{Loss Down Photon Beamline Due to Shorted Dipole Magnet}

If a dipole shorts out during injection, it may be possible for a portion of the positron beam to proceed down a photon beamline. As the magnetic field of the dipole decays, the amount of bending force will decrease so that it becomes decreasingly probable that the beam will go down the photon vacuum tube, and instead will hit the $\mathrm{Al}$ vacuum chamber of the SR. For this computation, we assume $10 \%$ of the beam may go down the photon beamline and the duration will be limited since when the dipole field is completely decayed, the incoming beam will no longer be able to go down the beamline. During injection, the safety shutters of the front end (two tungsten stops, each $30 \mathrm{~cm}$ thick) are required to be closed if an individual is in the FOE. Although the beam should spray along the components of the front end, we assume that it proceeds down to the safety shutters. Assuming only one stop is in, the beam will shower in this stop. The closest an individual in the FOE could be to the shower is $1.75 \mathrm{~m}$, at an angle of $10^{\circ}$ with the axis of the beamline. The intervening shielding consists of $30 \mathrm{~cm}$ of tungsten, $25 \mathrm{~cm}$ of $\mathrm{Pb}$, and $55 \mathrm{~cm}$ of high-density concrete. The dose rate in the FOE is $6.3 \mathrm{mrem} / \mathrm{h}$ for this case.

\subsubsection{Beam Loss Due to rf Shutdown}

During the injection process, the beam is captured in orbit and becomes part of the circulating beam. In order to maintain the orbit, the rf must replace energy lost by the particles as they travel through the bending magnets and ID devices in the ring. If the rf is shut down or suffers a phase shift, the beam will be decelerated and begin to wipe out on the vacuum chamber as it sprays inward. This situation is similar to that in section 10.1.5, and if the high dispersion regions intercept the total beam, the highest dose rates will be obtained for the regions in the ratchet part of the SR, for the locations by AS4 on Figure 6, since the dose point in the FOE is only 1.9 m away, the Al shield is only $3 \mathrm{~cm}$ thick, and the high density concrete is only $56 \mathrm{~cm}$ thick. As in Section 5.3, Eqs. (9) and (10) were used to arrive at the total dose rate from the line sources. The highest side dose rates are $267 \mathrm{mrem} / \mathrm{h}$ and the roof dose rate is about $10.5 \mathrm{mrem} / \mathrm{h}$ at the various sites. Again, for shutdown occurring in 1-2 s, the dose ranges would be 73-146 $\mu \mathrm{rem}$ and 1.4-3 $\mu \mathrm{rem}$, respectively.

\subsubsection{Continuous Accidental Beam Loss}

In the case of a dump dose, the system should shut down within a short duration (1-2 s). In the unlikely event that the shutdown system does not work, the beam is assumed to dump in the same region at the rate of $2 \mathrm{pulses} / \mathrm{s}$ ( $7200 \mathrm{pulses} / \mathrm{h})$. Using the highest dose rate from the discussion of the nonuniform beam loss from Section 10.1.1 $(10.7 \mathrm{rem} / \mathrm{h})$, the condition would need to persist, along with failure of radiation alarms, with an individual in the dose region, for only about $34 \mathrm{~s}$ to deliver a dose of 100 mrem.

\subsection{Stored Beam Losses}

The safety envelope for the stored beam case is $9280 \mathrm{~J}$. As suggested before, this is represented by $7000 \mathrm{MeV}$ and a circulating current of $360 \mathrm{~mA}$, or some combination of particle energy and circulating current equivalent in stored energy to $9280 \mathrm{~J}$; i.e., $7700 \mathrm{MeV}$ and $327.5 \mathrm{~mA}$. The following analysis of stored beam losses will be based upon the stored energy at the safety envelope. 


\subsubsection{Stored Beam Losses in AQ2, AS4, and BQ2}

Of the three sites at which the stored beam could dump, the dose at AS4 will be the highest. Scaling the results for a 4-m-long spray, the dose would be 89.6 mrem for a total loss of the circulating beam at this site. The dose on the SR roof would be $2.9 \mathrm{mrem}$. Doses at AQ2 and BQ2 would be 50.1 and 60.6 mrem, respectively.

\subsubsection{Uniform Beam Spray Around the Storage Ring}

For a uniform spray of the beam around the SR, the location at AS4 will be the highest dose point. Scaling the result for a 10-m spray as computed in Section 10.1.2, the dose would be $0.375 \mathrm{mrem}$ for operation at the safety envelope. The SR roof dose would be $10 \mu \mathrm{rem}$.

\subsubsection{Nonuniform Spray Around the Ring}

In the case of a nonuniform spray over the 40 high-dispersion regions, the total dose at any one of these sites would be $2.2 \mathrm{mrem}$. The SR roof dose would be $88 \mu \mathrm{rem}$.

\subsubsection{Continuous Loss Around the Ring Due to Beam Decay}

As the stored beam circulates, a small fraction of the beam will be lost due to collisions with gas molecules, interactions among beam particles, and orbital excursions that lead to positrons being lost from the beam and striking the vacuum chamber. This will be a small continuous loss over many hours and the losses will be somewhat distributed around the ring. The mean lifetime of the beam is taken as $10 \mathrm{~h}$ for this estimate. For a uniform spray around the ring, the dose rate at the nearest dose point (1.9 $\mathrm{m}$ from AS4 in Figure 6) would be $0.04 \mathrm{mrem} / \mathrm{h}$, based upon scaling the result for a $10-\mathrm{m}$ $\operatorname{dump}(4952 \mathrm{mrem} / \mathrm{h})$ by the ratio of power lost $(9280 \mathrm{~J} /(1104 \mathrm{~m})(10 \mathrm{~h})$ to $308 \mathrm{~W}(3600 \mathrm{~s} / \mathrm{h}) / 10 \mathrm{~m})$. For a nonuniform spray, again the nearest dose point would be the same location as above, and assuming the loss is evenly distributed at the high-dispersion regions, the dose rate would be 0.22 $\mathrm{mrem} / \mathrm{h}$. Actually, it would be expected that the actual distribution would be somewhere between all uniform and all nonuniform, so the latter dose rate should be an upper bound. This dose rate is within the DOE guideline of $0.25 \mathrm{mrem} / \mathrm{h}$.

\subsubsection{Loss Down Photon Beamline Due to Shorted Dipole Magnet}

As in Section 10.1.8, we assume that $10 \%$ of the stored beam could go down a photon beamline. In this case the shutters are open and no one is in the FOE, so the beam proceeds into the FOE and strikes the $30-\mathrm{cm}$ tungsten stop. The width of the stop is taken as $24 \mathrm{~cm}$, and it is located about $1 \mathrm{~m}$ away from the dose point through the back wall of the FOE. The shielding on this wall is taken as $10.16 \mathrm{~cm}$ of $\mathrm{Pb}$. The total dose through the back of the FOE wall is about 14 mrem for this incident. The side wall has $2.54 \mathrm{~cm}$ of $\mathrm{Pb}$ shielding, and the dose point is about $1.5 \mathrm{~m}$ from the shutter at an angle of about $90^{\circ}$. The total dose through the side wall of the FOE for this incident is $60 \mathrm{mrem}$. 


\subsubsection{Beam Loss Due to rf Shutdown}

If the rf fails when the stored beam is circulating, the beam will spray around the ring. Assuming the distribution is among the high dispersion regions, the results of Section 10.1.9 can be scaled. The highest side dose at each of the sites is $2.2 \mathrm{mrem}$ and the roof dose is $88 \mu \mathrm{rem}$.

\subsubsection{Loss of Stored Beam on an ID Chamber}

This analysis was treated in APS-LS-141 Revised (MOE 91) for somewhat different conditions than for the present case. This scenario assumes that the positron beam "blows up" in such a way that the beam hits the ID wall and initiates bremsstrahlung. The entire beam is assumed to be lost on the ID and converted to bremsstrahlung, half of which travels down the photon beamline, through the ratchet wall section of the shield without attenuation, and into the shielded FOE. Only half of the radiation is assumed since roughly this fraction of radiation will escape for a glancing incidence on a flat surface (EME 94).

The FOE is a shielded, interlocked enclosure that cannot be occupied if the synchrotron radiation beamline is open. In direct line with the path of the radiation is a $30-\mathrm{cm}$-thick tungsten plug $(24 \mathrm{~cm}$ wide), surrounded on the sides and back by $10 \mathrm{~cm}$ of polyethylene. The bremsstrahlung that strikes the plug will produce an electromagnetic shower in which GRN, MEN, and HEN components are generated. The plug itself will produce a completely developed shower and is thick enough to absorb most of the photon radiation, but is not that effective for the giant resonance neutron component. Polyethylene provides effective attenuation of the GRN component. The shielding on the side walls of the FOE is taken as $2.54 \mathrm{~cm}$ of $\mathrm{Pb}$ and on the back wall, $10.16 \mathrm{~cm}$ of $\mathrm{Pb}$. The dose point in the forward direction is $1 \mathrm{~m}$ away and in the transverse direction is $1.53 \mathrm{~m}$ away. For operation at the safety envelope of $9280 \mathrm{~J}$ of stored energy, the total number of $7000 \mathrm{MeV}$ positrons in the beam is $8.28 \times 10^{12}$. Under these conditions, the total dose in the forward direction is computed to be 32 mrem and the total dose in the transverse direction is $78 \mathrm{mrem}$.

\subsubsection{Loss of Vacuum in a Section of a Long Straight}

This situation was treated earlier in Section 12.4 of APS-LS-141 Revised (MOE 91). An estimate of the bremsstrahlung dose that results from an instantaneous loss of vacuum was given. Such a loss is not considered a credible incident, since the elapsed time before the pressure will reach atmosphere will be much larger than the total time for the beam to interact (assumed to be $\sim 40 \mu \mathrm{s}$ ).

Assuming that any loss of the vacuum initiates a shutdown mechanism, the system will shut down in less than 50 turns. During each revolution, some positrons will interact and lose more energy than the bucket height (taken as $154 \mathrm{MeV}$ for $7700 \mathrm{MeV}$ ) and will be lost from the orbit, eventually colliding with the vacuum chamber. Using the methodology in APS-LS-141 Revised, the surviving fraction that continues to orbit is 0.7442 . For each succeeding revolution, this same fraction will survive, and the sum contribution is 3.91. Although it only takes about 10 turns to remove $95 \%$ of the beam, in effect, each positron makes a mean number of passes equal to 3.91. 
For an ID straight section, assume the loss occurs in a 20 -cm section of the straight. In going from $10^{-9}$ Torr to atmospheric pressure at $20^{\circ} \mathrm{C}$, the average path length is about $\left[(20 \mathrm{~cm}) 1.205 \times 10^{-3}\right.$ $\left.(\mathrm{g} / \mathrm{cc}) / 2\left(37.1 \mathrm{~g} / \mathrm{cm}^{2}\right)\right]=3.25 \times 10^{-4}$ radiation lengths, in which $37.1 \mathrm{~g} / \mathrm{cm}^{2}$ is the radiation length (RL) in air at atmospheric pressure (ICR 78). The total path length traveled through an ID for each positron is then $3.91\left(3.25 \times 10^{-4}\right)=1.27 \times 10^{-3} \mathrm{RL}$. The number of positrons in a circulating current of $327 \mathrm{~mA}$ is $7.53 \times 10^{12}$, so the total radiation length traveled by all particles is $9.57 \times 10^{9}$. During normal operation of the beam, the total path length per $\mathrm{h}$ for each $\mathrm{e}^{+}$in the beam in a long straight is

$$
\frac{\text { path length }}{\mathrm{h}}=\frac{1538\left(1.205 \times 10^{-3}\right)\left(1 \times 10^{-9}\right)\left(3 \times 10^{8}\right)(3600)}{(37.1)(760)(1104)}=\frac{6.43 \times 10^{-5} \mathrm{RL}}{\mathrm{h}} .
$$

For $327 \mathrm{~mA}$, the unshielded bremsstrahlung dose rate was determined in Section 8 to be $679 \mathrm{rem} / \mathrm{h}$. Dividing this dose rate by the total radiation length/h for all particles gives the rem/RL, and multiplying by $9.57 \times 10^{9} \mathrm{RL}$ gives $1.34 \times 10^{4} \mathrm{rem}$. This result implies that an equivalent circulating current of $4.02 \times 10^{19} \mathrm{e}^{+} / \mathrm{s}$, in the case of normal operation at $1 \mathrm{nT}$, would deliver the same dose to the FOE in one hour, and using Eqs. (14) and (15) gives an estimated total dose of 1.5 rem in the forward direction and a dose of 3.05 rem in the transverse direction.

\subsubsection{Muon Dose from a Loss of the Stored Beam}

For a dump of the stored beam, the muons are only important in the forward direction. Assuming the minimum distance to the dose point is $25 \mathrm{~m}$ and the muon beam is intercepted by the ratchet wall plug, the dose for operation at the safety envelope is $43 \mathrm{mrem}$. If the dump occurs in an upstream region such that the muon beam misses the ratchet wall plug, the distance increases to about $28 \mathrm{~m}$ and the total dose is $37 \mathrm{mrem}$.

\section{Skyshine Dose Estimates}

The sidewall shield of the SR tunnel contains the equivalent of $0.8 \mathrm{~m}$ of concrete, and the roof is $1 \mathrm{~m}$ of concrete. There will be some skyshine radiation produced during SR operations through both the side and roof of the shield. Because the upward radiation goes through increased thickness as it slants through the side and roof of the shield, the simplifying assumption has been made that the effective thickness, based upon the analyses discussed in Appendix B, can be used in place of the actual thickness. Other assumptions are that half of the radiation goes up and half goes down (solid angle $=$ $2 \pi)$ and that the closest dose point on site is about $60 \mathrm{~m}$ away. The dose at the nearest site boundary ( $\sim 450 \mathrm{~m}$ away from the injection septum and the 1-ID transition piece) is also estimated. For the SR losses of the stored beam, the shortest distance to the site boundary $(140 \mathrm{~m})$ was used. The power losses at the injection septum and transition piece during injection dominate the neutron production, so these loss sites were used to compute the estimated contributions as well as assuming that the entire circulating beam is lost during a 10-h lifetime. At the safety envelope the synchrotron delivers $308 \mathrm{~W}$ to the injection septum of the SR. Assuming 20\% is lost at the septum gives $61.6 \mathrm{~W}$ lost. If another $20 \%$ is lost at the transition piece, then $49.3 \mathrm{~W}$ is lost at this site. The total injection time is conservatively assumed to be $10 \%$ of the total operating time. Following injection, the entire beam stored energy $(9280 \mathrm{~W})$ is assumed to be lost over a 10-h period, giving a distributed power loss rate of $0.258 \mathrm{~W}$ for $90 \%$ of the operating time. 


\subsection{GRN Component}

The source term for the upward-directed GRN component (utilizing Eq. (3)) is given by

$$
\mathrm{Q}^{\prime}{ }_{\mathrm{GRN}}=1 / 2\left(1.21 \times 10^{8}(\mathrm{Z})^{0.66}\right)(\mathrm{n} / \mathrm{J}) \mathrm{W}(\mathrm{J} / \mathrm{s})=6.05 \times 10^{7} \mathrm{WZ}^{0.66} \mathrm{n} / \mathrm{s}
$$

into the upper hemisphere, in which $\mathrm{W}$ is the power lost and the assumption is made that the component/stop is the major source of neutron production. For the septum, $\mathrm{Q}^{\prime}{ }_{\mathrm{GRN}}$ is $3.31 \times 10^{10} \mathrm{n} / \mathrm{s}$ (the average for $\mathrm{Fe}$ and $\mathrm{Cu}$ since the septum wall is $\mathrm{Cu}$ on one side and $\mathrm{Fe}$ on the other); for the transition region, $\mathrm{Q}^{\prime}{ }_{\mathrm{GRN}}$ is $2.75 \times 10^{10} \mathrm{n} / \mathrm{s}$; and for the circulating beam, $\mathrm{Q}^{\prime}{ }_{\mathrm{GRN}}$ is $8.48 \times 10^{7} \mathrm{n} / \mathrm{s}$ for operation at the safety envelope. The unattenuated neutrons that emerge through the roof and sides of the SR are given by

$$
\begin{aligned}
\mathrm{Q}_{\mathrm{GRN}} & =\mathrm{Q}^{\prime}{ }_{\mathrm{GRN}} \mathrm{e}^{-1.7(7.87) / 100} \mathrm{e}^{-37(11.35) / 161} \mathrm{e}^{-102(2.35) / 40} \\
& =5.33 \times 10^{6} \times 0.1=5.33 \times 10^{5} \mathrm{n} / \mathrm{s}, \text { for the septum, and } \\
\mathrm{Q}_{\mathrm{GRN}} & =\mathrm{Q}^{\prime}{ }_{\mathrm{GRN}} \mathrm{e}^{-2.4(8.96) / 100} \mathrm{e}^{-1(7.87) / 100} \mathrm{e}^{-239.7 / 40} \\
& =5.13 \times 10^{7} \times 0.1=5.13 \times 10^{6} \mathrm{n} / \mathrm{s}, \text { for the transition region, } \\
\mathrm{Q}_{\text {GRN }} & =\mathrm{Q}^{\prime}{ }_{\text {GRN }} \mathrm{e}^{-8.7(7.87) / 100} \mathrm{e}^{-239.7 / 40} \\
& =1.07 \times 10^{5} \times 0.9=9.63 \times 10^{4} \mathrm{n} / \mathrm{s},
\end{aligned}
$$

giving a total emission of $5.76 \times 10^{6} \mathrm{n} / \mathrm{s}$, prorated for time of operation. The computation above assumes that the septum is shielded by effective thicknesses of $1.7 \mathrm{~cm}$ of Fe, $37 \mathrm{~cm}$ of $\mathrm{Pb}$, and $1.02 \mathrm{~m}$ of concrete in the upward direction. The transition piece is shielded by $2.4 \mathrm{~cm}$ of Cu, $1 \mathrm{~cm}$ of $\mathrm{Fe}$, and $1.02 \mathrm{~m}$ of concrete in the upward direction, and the rest of the ring is shielded (effectively) by $8.7 \mathrm{~cm}$ of $\mathrm{Fe}$ and $1.02 \mathrm{~m}$ of concrete in the upward direction.

The skyshine dose equivalent rate at $60 \mathrm{~m}$ away can be estimated from the modified expression (equation 8.6.3 of MOE 91):

$$
\begin{aligned}
\dot{\mathrm{H}}_{\mathrm{GRN}} & =\frac{\mathrm{a} \mathrm{Q}_{\mathrm{GRN}} \exp -\frac{\mathrm{r}}{\lambda}}{7(4) \pi \mathrm{r}^{2}} \\
& =1.06 \times 10^{-2} \mathrm{mrem} / \mathrm{h},
\end{aligned}
$$

in which a and $\lambda$ are constants, $Q$ is the source strength $(\mathrm{n} / \mathrm{s})$, and $\mathrm{r}$ is the distance to the dose point in $\mathrm{cm}$. Values of the constants a and $\lambda$ quoted from measurements at DESY by Rindi and Thomas (RIN $75)$ were used in the estimate. The values chosen $\left(\mathrm{a}=7\right.$ and $\left.\lambda=3.3 \times 10^{4} \mathrm{~cm}\right)$ give the largest fluence rate (most conservative) values for the DESY measurements. On the basis of $2000 \mathrm{~h}$ of occupational exposure, the total GRN dose would be $21.2 \mathrm{mrem}$. At the nearest site boundary, approximately 140- 
$450 \mathrm{~m}$ away from the storage ring, the annual GRN dose for $8000 \mathrm{~h}$ exposure would be about 0.66 mrem.

\subsection{MEN Component}

The dose factors for the MEN component at $90^{\circ}$, adapted from (CER 84), are $3.3 \times 10^{-2} \mathrm{mrem} / \mathrm{J} @$ $1 \mathrm{~m}$ for steel or copper and $6.14 \times 10^{-2} \mathrm{mrem} / \mathrm{J} @ 1 \mathrm{~m}$ for Al. Using an average value of $4.4 \times 10^{-8}$ $\mathrm{rem} / \mathrm{n} / \mathrm{cm}^{2}$ for neutrons between $25-100 \mathrm{MeV}$, obtained from ICRP 51 (ICP 87), results in an estimated MEN neutron yield of $9.42 \times 10^{7} \mathrm{n} / \mathrm{J}$ in $\mathrm{Fe}$ and $\mathrm{Cu}$ and $1.75 \times 10^{8} \mathrm{n} / \mathrm{J}$ in Al. The source terms ( $\mathrm{Q}^{\prime}{ }_{\mathrm{MEN}}$ ) for the upward-directed MEN component are given by the neutron yield multiplied by $1 / 2$ the power lost $-2.9 \times 10^{9} \mathrm{n} / \mathrm{s}$ for the septum, $2.32 \times 10^{9} \mathrm{n} / \mathrm{s}$ for the transition piece, and $2.26 \times$ $10^{7} \mathrm{n} / \mathrm{s}$ for the stored beam--into the upper atmosphere for operation at the safety envelope. The unattenuated neutrons that emerge through the roof are $\mathrm{Q}_{\mathrm{MEN}}=4.98 \times 10^{6} \mathrm{n} / \mathrm{s}$. The skyshine dose equivalent rate at $60 \mathrm{~m}$ away can be estimated from Eq. (17) with $\mathrm{Q}_{\mathrm{MEN}}$ replacing $\mathrm{Q}_{\mathrm{GRN}}$ :

$$
\dot{\mathrm{H}}_{\mathrm{MEN}}=9.17 \times 10^{-3} \mathrm{mrem} / \mathrm{h} \text {. }
$$

On the basis of $2000 \mathrm{~h}$ of occupational exposure, the total MEN dose would be $18.3 \mathrm{mrem}$. At the nearest site boundary, the annual MEN dose for $8000 \mathrm{~h}$ exposure would be $0.95 \mathrm{mrem}$.

\subsection{HEN Component}

The dose factors for the HEN component at $90^{\circ}$, adapted from (CER 84) are $8.3 \times 10^{-3} \mathrm{mrem} / \mathrm{J} @ 1$ $\mathrm{m}$ for $\mathrm{Fe}$ and $\mathrm{Cu}$ and $1.54 \times 10^{-2} \mathrm{mrem} / \mathrm{J} @ 1 \mathrm{~m}$ for Al. Using an average value of $1.0 \times 10^{-7}$ $\mathrm{rem} / \mathrm{n} / \mathrm{cm}^{2}$ for neutrons between $100-7700 \mathrm{MeV}$, adapted from ICRP 51 (ICP 87), results in an estimated HEN neutron yield of $1.04 \times 10^{7} \mathrm{n} / \mathrm{J}$ in Fe and $\mathrm{Cu}$ and $1.93 \times 10^{7} \mathrm{n} / \mathrm{J}$ in Al. The source terms ( $\mathrm{Q}^{\prime}{ }_{\mathrm{HEN}}$ ) for the upward-directed HEN component are given by the neutron yield multiplied by $1 / 2$ the power lost $=3.2 \times 10^{8} \mathrm{n} / \mathrm{s}$ for the septum component, $2.56 \times 10^{8}$ for the transition piece, and $2.07 \times 10^{6} \mathrm{n} / \mathrm{s}$ the stored beam for neutrons directed into the upper atmosphere at safety envelope operation. The unattenuated neutrons that emerge through the roof are $\mathrm{Q}_{\mathrm{HEN}}=2.74 \times 10^{6} \mathrm{n} / \mathrm{s}$. The skyshine dose equivalent rate at $60 \mathrm{~m}$ away can be estimated from Eq. (17) with $\mathrm{Q}_{\mathrm{HEN}}$ replacing Q $\mathrm{GRN}$ :

$$
\dot{\mathrm{H}}_{\mathrm{HEN}}=5.04 \times 10^{-3} \mathrm{mrem} / \mathrm{h} \text {. }
$$

On the basis of $2000 \mathrm{~h}$ of occupational exposure, the total HEN dose would be $10.1 \mathrm{mrem}$. At the site boundary, the HEN dose for $8000 \mathrm{~h}$ exposure would be about $0.52 \mathrm{mrem}$.

The total estimated annual dose equivalent from neutron skyshine is computed to be $49.6 \mathrm{mrem}$ at a distance of $60 \mathrm{~m}$ and $2.1 \mathrm{mrem}$ at the nearest site boundary. Previous estimates of the contribution to the skyshine dose of skyward-directed, scattered bremsstrahlung radiation from the linac test stand (LTS) indicated this component to be negligible. Since the roof on the LTS was only about $1 \mathrm{~m}$ thick, the attenuation of radiation by the storage ring should be comparable to the LTS and the scattered bremsstrahlung from the storage ring should also be negligible. 


\section{Radioactive and Noxious Gas Emissions}

Sources of radioactive and noxious gases found in the air around the storage ring result from loss of particles in the components of the system and escape of bremsstrahlung radiation from the components or from beam stops. As previously discussed, electron absorption results in bremsstrahlung formation and the interaction of this component with air results in the production of a number of radioactive products, primarily through the photonuclear reaction $(\gamma, n)($ CER 84$)$. Of the many possible radionuclides formed, only three (C-11, N-13, and O-15) are of importance in the operation of the APS. Of these three radionuclides, N-13 makes up about $90 \%$ of the concentration found in air (SWA 79a). One other potential radionuclide Ar-41 is formed by thermal neutron capture in argon. Since this is a second-order reaction (requiring slowing down of the fast neutrons created by the bremsstrahlung and capture by argon, which is $<1 \%$ abundant in air), the production of this component will be negligible. Irradiation of air by photon radiation below the threshold for neutron production (6-20 MeV in most materials) results in the production of ozone and oxides of nitrogen (SWA 79a). The products ozone $\left(\mathrm{O}_{3}\right)$, nitrogen dioxide $\left(\mathrm{NO}_{2}\right)$, and nitric acid $\left(\mathrm{HNO}_{3}\right)$ are the most prominent components formed.

\subsection{Radioactive Gas Formation}

The mechanism for formation of radionuclides in air is the photoneutron interaction of bremsstrahlung with air nuclei (SWA 79a). The $(\gamma, \mathrm{n})$ threshold for air is $10.55 \mathrm{MeV}$ for the formation of $\mathrm{N}-13$, and $15.67 \mathrm{MeV}$ for $\mathrm{O}-15$. In addition, some $\mathrm{C}-11$ is formed by photon spallation of both nitrogen and oxygen. Using the neutron yield expression given by Eq. (3) and the effective $Z$ of 7.26, according to Schaeffer ( $\mathrm{SCH} 73$ ), the neutron yield $\mathrm{Y}$ in air is

$$
\mathrm{Y}=1.21 \times 10^{8} \mathrm{Z}^{0.66}(\mathrm{n} / \mathrm{J})=4.5 \times 10^{8}(\mathrm{n} / \mathrm{J}) .
$$

Implicit in the release of the neutron is the formation of an unstable nucleus, which may be radioactive. We assume the yield of neutrons is also the yield of radionuclides. The yield of MEN and HEN neutrons increases the total neutron yield by about $10 \%$, but ignoring their contribution should not make a significant difference in the yield of radionuclides.

The change in the number of radioactive atoms present per unit time $\mathrm{dN} / \mathrm{dt}$ is

$$
\mathrm{dN} / \mathrm{dt}=\mathrm{WfY}\left(1-\mathrm{e}^{-\mathrm{x} / \lambda}\right)-\left(\lambda_{\mathrm{R}}+\mathrm{k} \mathrm{FR} / \mathrm{V}\right) \mathrm{N} \text { atoms } / \mathrm{s},
$$

in which W (watts) is the particle beam power loss; $f$ is the fraction of particle energy that converts to bremsstrahlung and escapes into air (see Appendix B); $\mathrm{x}$ is the average air path in $\mathrm{m}$, estimated to be $4 \mathrm{~m} ; \lambda$ is the attenuation length in air for bremsstrahlung in $\mathrm{m}$ (385 $\mathrm{m}$ as suggested in CER 84$) ; \lambda_{\mathrm{R}}$ is the radioactive decay constant of the radionuclide that is formed, $\mathrm{s}^{-1} ; \mathrm{k}$ is a factor to account for imperfect mixing of the radionuclide in air (assumed to be $1 / 10$ ); $\mathrm{V}$ is the volume of the region being ventilated $\left(\mathrm{m}^{3}\right)$; and $\mathrm{FR}$ is the ventilation flow rate $\left(\mathrm{m}^{3} / \mathrm{s}\right)$. For initial conditions $\mathrm{N}=0$ for $\mathrm{t}=0$, the solution is 


$$
\mathrm{N}=\frac{\mathrm{WfY}\left(1-\mathrm{e}^{-\mathrm{x} / \lambda}\right)\left(1-\mathrm{e}^{-\left(\lambda_{\mathrm{R}}+\mathrm{kFR} / \mathrm{v}\right) \mathrm{t}}\right)}{\lambda_{\mathrm{R}}+\mathrm{kFR} / \mathrm{V}}
$$

and the activity is $A=\lambda_{R} N$, so that

$$
\mathrm{A}=\frac{\lambda_{\mathrm{R}} \operatorname{WfY}\left(1-\mathrm{e}^{-\mathrm{x} / \lambda}\right)\left(1-\mathrm{e}^{-\left(\lambda_{\mathrm{R}}+\mathrm{kFR} / \mathrm{V}\right) \mathrm{t}}\right)}{\lambda_{\mathrm{R}}+\mathrm{kFR} / \mathrm{V}}(\mathrm{dis} / \mathrm{s}) .
$$

Since the radionuclides that are formed all have short half lives $(<20.5 \mathrm{~min}$.), saturation is achieved quickly so that the activity at saturation becomes

$$
\mathrm{A}=\frac{\lambda_{\mathrm{R}} \operatorname{WfY}\left(1-\mathrm{e}^{-\mathrm{x} / \lambda}\right)}{\lambda_{\mathrm{R}}+\mathrm{kFR} / \mathrm{V}}(\mathrm{dis} / \mathrm{s})
$$

in which the decay constant $\lambda_{\mathrm{R}}\left(\mathrm{s}^{-1}\right)$ is for N-13 (half life $\sim 10 \mathrm{~min}$ ), which is the most abundant radionuclide formed. The equilibrium concentration is then obtained from

$$
\mathrm{C}=\frac{\mathrm{A}}{3.7 \times 10^{4}(\mathrm{dis} / \mathrm{s} \mu \mathrm{Ci}) \mathrm{V}(\mathrm{cc})}(\mu \mathrm{Ci} / \mathrm{cc}),
$$

in which $\mathrm{V}$ is the volume of the section being evacuated, taken as the volume of the storage ring tunnel. Each two-sector section is supplied $13,600 \mathrm{cfm}$, so the total for the twenty fans is 272,000 cfm. Combining Eqs. (21) and (22), the concentration is given by

$$
\mathrm{C}=\frac{\lambda_{\mathrm{R}} \operatorname{WfY}\left(1-\mathrm{e}^{-\mathrm{x} / \lambda}\right)}{3.7 \times 10^{4} \mathrm{~V}\left(\lambda_{\mathrm{R}}+\mathrm{kFR} / \mathrm{V}\right)}
$$

where $\mathrm{kFR} / \mathrm{V}$ is $1.2 \times 10^{-3} \mathrm{~s}^{-1}$, FR is $2.72 \times 10^{5} \mathrm{cfm}$, and $\mathrm{V}$ is $1.067 \times 10^{10} \mathrm{~cm}^{3}$. Details of the estimate of $\mathrm{f}$ are given in Appendix B. Of the components that may contribute to radiogas formation - injection septum, the transition piece, and the stored beam loss around the ring - the fraction of energy escaping (f), modified for the fraction of operating time, is 0.0054 for the septum, 0.0029 for the transition piece, and 0.062 for the stored beam losses. Using appropriate values for $\mathrm{W}$ and $\mathrm{f}$ for each of the component radiations, the total equilibrium concentration is

$$
\mathrm{C}=2.8 \times 10^{-9} \mu \mathrm{Ci} / \mathrm{cc} \text {. }
$$

The computed concentration is a factor of over 1400 lower than the derived air concentration (DAC) for occupational exposure: $4 \times 10^{-6} \mu \mathrm{Ci} / \mathrm{cc}$ found in DOE Orders (DOE 88, DOE 94). Once the operation is shut down, this concentration will rapidly decrease due to both radioactive decay and the ventilation rate. 


\subsection{Noxious Gas Formation}

The basis of the formation of ozone $\left(\mathrm{O}_{3}\right)$ and other noxious gases (nitrogen oxides) in air is photon irradiation of the air molecules (CER 84), causing dissociation of oxygen molecules, leading to an active free atom of oxygen attaching to an oxygen molecule. Ozone also reacts with other materials formed in air, such as nitrogen oxide, to form nitrogen dioxide $\left(\mathrm{NO}_{2}\right)$, which reacts with water vapor in air to form nitric acid $\left(\mathrm{HNO}_{3}\right)$. The radiolytic yield of these products is expressed by the quantity $\mathrm{G}$, which is the number of molecules formed per unit energy absorbed. These values are usually given as molecules per $100 \mathrm{eV}$ absorbed. Because of its low threshold limit value (TLV) of 0.05 parts per million (ppm) for occupational exposure conditions ( $8 \mathrm{~h}$ per day, $40 \mathrm{~h}$ per week) (ACG 93) and its high production rate relative to the other products, ozone is the most important noxious product. Ozone is also chemically active and decomposes spontaneously with a chemical half life of about $50 \mathrm{~min}$.

The TLV values for $\mathrm{NO}_{2}$ and $\mathrm{HNO}_{3}$ are much higher at 3 and $2 \mathrm{ppm}$, respectively, than that for ozone. Estimates of the production of $\mathrm{O}_{3}, \mathrm{NO}_{2}$, and $\mathrm{HNO}_{3}$ are based upon $\mathrm{G}$ values of 10, 4.8, and 1.5 , respectively (SWA 79a, CER 84). Adapting the expression from Goebel (CER 81), the change in the number of ozone atoms present per $\mathrm{s}, \mathrm{dN} / \mathrm{dt}$, is

$$
\mathrm{dN} / \mathrm{dt}=\mathrm{PG}-\alpha \mathrm{N}-(\mathrm{KP} / \mathrm{V}) \mathrm{N}-(\mathrm{FR} / \mathrm{kV}) \mathrm{N},
$$

in which

$\mathrm{P}=$ power absorbed in air, $\mathrm{eV} / \mathrm{s}$

$\mathrm{FR}=$ ventilation rate, $\mathrm{cc} / \mathrm{s}$

$\mathrm{V}=$ volume irradiated, $\mathrm{cc}$

$\mathrm{k}=$ constant which accounts for imperfect mixing $=1 / 10$

$\alpha=$ chemical decay constant $=2.31 \times 10^{-4} / \mathrm{s}$

$\mathrm{K}=$ constant expressing the destructive effect of radiation on ozone molecules $=$ negligible for low bremsstrahlung intensity

$\mathrm{G}=$ chemical yield, the number of ozone molecules formed per $\mathrm{eV}=0.1 \mathrm{~mol} / \mathrm{eV}$.

The solution for initial conditions $\mathrm{N}=0$ when $\mathrm{t}=0$ is

$$
\mathrm{N}=\frac{\mathrm{PG}}{(\alpha+\mathrm{KP} / \mathrm{V}+\mathrm{FR} / 10 \mathrm{~V}}\left(1-\mathrm{e}^{-(\alpha+\mathrm{KP} / \mathrm{V}+\mathrm{FR} / 10 \mathrm{~V}) \mathrm{t}}\right) .
$$

Since the TLV is given in ppm, it is desirable to express the number of ozone molecules in terms of that unit, and

$$
\mathrm{C}_{\mathrm{O}_{3}}=\frac{\mathrm{N}(\text { mol ozone })}{\mathrm{V}(\mathrm{cc} \text { of air }) 2.463 \times 10^{13}(\text { mol ozone/(cc of air) } \mathrm{ppm})} .
$$

The power absorbed $\mathrm{P}$ for the case of bremsstrahlung resulting from loss of particles may be expressed as 


$$
\mathrm{P}=(\mathrm{Wfx} / \lambda)\left(6.25 \times 10^{18} \mathrm{eV} / \mathrm{J}\right),(\mathrm{eV} / \mathrm{s}),
$$

in which $\mathrm{W}$ (watts) is the particle beam power loss, $\mathrm{f}$ is the fraction of particle energy that converts to bremsstrahlung and escapes into air (details of the estimation of $\mathrm{f}$ are given in Appendix B), $\mathrm{x}$ is the average air path in $\mathrm{m}(4 \mathrm{~m})$, and $\lambda$ is the attenuation length in air for bremsstrahlung in $\mathrm{m}(385 \mathrm{~m})$. Combining Eqs. (25), (26), and (27), and noting that the term involving $\mathrm{K}$ is negligible for the low intensity of bremsstrahlung from the components, one arrives at the equilibrium concentration of ozone:

$$
\mathrm{C}_{\mathrm{O}_{3}}=\frac{2.54 \times 10^{5} \mathrm{Wf} \times \mathrm{G}}{\lambda \mathrm{V}(0.000231+0.0012)} \mathrm{ppm} .
$$

Substituting values for the parameters in Eq. (28), gives

$$
\mathrm{C}_{\mathrm{O}_{3}}=1.73 \times 10^{-5} \sum_{\mathrm{i}=1}^{3} \mathrm{~W}_{\mathrm{i}} \mathrm{f}_{\mathrm{i}} \mathrm{ppm}
$$

contributed by bremsstrahlung. The composite concentration is $6.2 \times 10^{-6} \mathrm{ppm}$, which is well below the TLV of $0.05 \mathrm{ppm}$. The total estimated annual release of noxious products due to bremsstrahlung would be $49 \mathrm{~g}$ of $\mathrm{O}_{3}, 23.5 \mathrm{~g}$ of $\mathrm{NO}_{2}$, and $7.4 \mathrm{~g}$ of $\mathrm{HNO}_{3}$ for the storage ring based upon scaling the ozone production by the ratio of $\mathrm{G}$ values for the other components.

With respect to noxious gas formed by escaping synchrotron radiation, an estimate of the contribution was made by Moe (MOE 91) for the storage ring. Adapting equation 10.3.4.6 from that report to the case of the equilibrium concentration gives

$$
\mathrm{C}_{\mathrm{O}_{3}}=\frac{4.06 \times 10^{-15} \mathrm{P}}{\mathrm{V}(\alpha+\mathrm{FR} / 3 \mathrm{~V})},
$$

in which $\mathrm{P}$ was based upon a circulating current of $100 \mathrm{~mA}$ and a different value of $\mathrm{FR} / \mathrm{kV}$ was used at that time. For storage ring operation at $7700 \mathrm{MeV}$, the circulating current is taken as $327 \mathrm{~mA}$. Scaling the value of $\mathrm{P}$ by the ratio of the currents, the estimated power loss for operation at the safety envelope is $327 / 100\left(2.12 \times 10^{17} \mathrm{eV} / \mathrm{s}\right)=6.93 \times 10^{17} \mathrm{eV} / \mathrm{s}$. Using current values for the other parameters in the equation gives

$$
\mathrm{C}_{\mathrm{O}_{3}}=1.83 \times 10^{-4} \mathrm{ppm},
$$

as the concentration of ozone contributed by synchrotron radiation. Again, this concentration is well below the TLV of $0.05 \mathrm{ppm}$, so no delay in entering the SR tunnel following shutdown is anticipated from the standpoint of ozone. The estimated annual release of ozone from this source is 


$$
\begin{aligned}
\mathrm{m}_{\mathrm{O}_{3}} / \mathrm{y}= & 1.83 \times 10^{-4}(\mathrm{ppm}) 1 \times 10^{-6}\left(\frac{\mathrm{cc} \text { ozone }}{\mathrm{cc} \text { air }}\right) 4.05 \times 10^{15}(\mathrm{cc} \mathrm{air}) \\
= & 7.41 \times 10^{5}(\mathrm{cc}) 1.964 \times 10^{-3}(\mathrm{~g} / \mathrm{cc})=1457 \mathrm{~g}
\end{aligned}
$$

Based upon the ratio of $\mathrm{G}$ values, the estimated annual release of $\mathrm{NO}_{2}$ is $699 \mathrm{~g}$ and that of $\mathrm{HNO}_{3}$ is $219 \mathrm{~g}$. However, the calculation above does not take into account the use of absorber crotches and end absorbers in the ring to intercept and absorb synchrotron radiation so that it will not penetrate the chamber walls. The crotches and end absorbers are estimated to intercept and absorb 90-95\% of the synchrotron radiation (ANL 87). If one assumes that $80 \%$ of the synchrotron radiation is intercepted and absorbed before it can get out of the chamber, the estimated annual releases become $291 \mathrm{~g} \mathrm{of}_{3}$, $140 \mathrm{~g}$ of $\mathrm{NO}_{2}$, and $44 \mathrm{~g}$ of $\mathrm{HNO}_{3}$ from this source. Adding the contribution due to bremsstrahlung gives a total annual release estimate of $340 \mathrm{~g}$ of $\mathrm{O}_{3}, 164 \mathrm{~g}$ of $\mathrm{NO}_{2}$, and $51 \mathrm{~g}$ of $\mathrm{HNO}_{3}$. The estimated total concentration $\left(\sim 4.3 \times 10^{-5} \mathrm{ppm}\right)$ in the SR tunnel then is a factor of about 1160 times lower than the TLV of $0.05 \mathrm{ppm}$.

\section{Activation of Beam Stop Materials and Storage Ring Components}

As discussed earlier, the photoneutron interaction of bremsstrahlung with the nuclei of materials leads to the formation of radioactive products in the air. This same interaction produces the major portion of activated components in the SR materials. The particular radionuclides that are produced will depend upon the $(\gamma, n),(\gamma, 2 n)$, and photospallation cross sections for the various materials that are present in these components. The radioactive materials that are formed have a range of half lives

from seconds to more than $10^{5}$ years (SWA 79a). The intensity of these radioactive products at some time following a shutdown is a function of the composition and amount of a given material present, the reaction cross section and the radioactive product half life. The materials of interest for the storage ring operation are aluminum, iron (in steel), copper, and lead. $\mathrm{Pb}$ is used as shielding for the injection septum magnet and at other locations around the ring. The $\mathrm{e}^{+}$beam vacuum chamber is aluminum, copper is in the ID transition pieces, and iron is in the septum and other magnets. Radioactivity builds up during system operation, and at shutdown there is initial rapid decay of the shorter-lived materials, then a slower decay of intermediate half life materials, leaving only the residual longer-lived components. At decommissioning, only the longer-lived components remain. For daily operation of the facility, the short-lived material is important because this activity in the storage ring components may be the source of an elevated radiation field, which may limit access time to the area.

\subsection{Residual Radioactivity Estimates}

An estimate of the activity of a radionuclide formed by $(\gamma, n)$ reactions in a particular material can be obtained from Eq. (3), modified to account for the abundance of the particular target isotope of a given element that becomes activated. We again assume that the yield of neutrons is also the yield of radionuclide atoms. This may be expressed as

$$
\mathrm{Y}^{\prime}=\mathrm{FY}=1.21 \times 10^{8} \mathrm{FZ}^{0.66}(\text { atoms } / \mathrm{sW})
$$


in which $\mathrm{F}$ is the fractional abundance of the isotope and $\mathrm{Z}$ is the atomic number of the element. For example, copper activation $(\mathrm{Z}=29)$ is the result of activation of $\mathrm{Cu}-63(\mathrm{~F}=0.691)$ and $\mathrm{Cu}-65(\mathrm{~F}=$ 0.309), leading to a number of radionuclides: Co-58, Co-58m, Co- 60, Ni-63, Cu-61, Cu-62, and Cu-64 (SWA 79a). Most of these radionuclides have half lives of minutes to hours, so they decay away quickly and do not contribute to residual radioactivity. But these radionuclides are important for short-term irradiations.

The change in the number of radioactive atoms present per unit time, $\mathrm{dN} / \mathrm{dt}$, is given by

$$
\mathrm{dN} / \mathrm{dt}=\mathrm{WfY}^{\prime}-\lambda_{\mathrm{R}} \mathrm{N} \quad(\text { atoms } / \mathrm{s}),
$$

in which $\mathrm{W}$ (watts) is the particle beam loss, $\mathrm{f}$ is the fraction of particle energy converted to bremsstrahlung and absorbed in the activated material (taken from Appendix B or $=0.5$ if no calculated value is available), and $\lambda_{R}$ is the radioactive decay constant of the radionuclide produced, $\mathrm{s}^{-1}$. For the initial conditions, $\mathrm{N}=0$ for $\mathrm{t}=0$, the solution is

$$
\mathrm{N}=\frac{\mathrm{W}^{\prime} \mathrm{fY}}{\lambda_{\mathrm{R}}}\left(1-\mathrm{e}^{-\lambda_{R} \mathrm{t}}\right) \text { (atoms), }
$$

and since the activity $\mathrm{A}=\lambda_{\mathrm{R}} \mathrm{N}$, the activity in units of millicuries $(\mathrm{mCi})$ becomes:

$$
A=W f Y^{\prime}\left(1-e^{-\lambda_{R} t}\right)(\operatorname{dis} / s)=\frac{W^{\prime} Y^{\prime}}{3.7 \times 10^{7}}\left(1-e^{-\lambda_{R} t}\right)(m C i)
$$

The product WfY' is the production rate of radionuclides of a given half life for $(\gamma, \mathrm{n})$ reactions. Similar expressions may be developed for the production rates of radionuclides of a certain half life for $(\gamma, 2 \mathrm{n})$ and photospallation reactions, given the yield values.

The realization of saturation activity for all radioactive products is more complicated than in the case of air activation, which contains only short half-life positron emitters (half lives $\leq 21 \mathrm{~min}$ ). One may assume that saturation is approximately reached when the operation time is about $3 \times$ the half life of the radionuclide being formed. The saturation activity $A_{S}$ is then

$$
\mathrm{As}_{\mathrm{s}}=\frac{\mathrm{WfY}^{\prime}}{3.7 \times 10^{7}}(\mathrm{mCi})
$$

For each of the potential activated materials, Swanson (SWA 79a) has prepared tables listing the saturation activities of the $(\gamma, n),(\gamma, 2 n)$, and photospallation products. These are in Tables XXIb-XXVIIb, and they contain information about the saturation activity $(\mathrm{Ci} / \mathrm{kW})$ of a given radionuclide and the exposure rate at 1 meter from the material of saturation activity, uncorrected for self-absorption.

The data in these tables has been used to estimate the expected radiation fields following certain operation times, the residual field at later times, and the importance of the residual radiation field for 
continued daily operation. The results are discussed in this section. Results for some other materials are discussed by Moe (MOE 93a-93d).

\subsubsection{Aluminum}

The SR vacuum chamber is made of aluminum. Irradiation of the aluminum can produce these activities: C-11, N-13, O-15, Ne-24, Al-25, AL-26m with half lives between $6.37 \mathrm{~s}$ and $20.5 \mathrm{~min}$, and F-18 with a half life of $110 \mathrm{~min}$. For the purpose of estimating aluminum activation during storage ring operations, it is assumed that $0.258 \mathrm{~W}$ is the power lost locally in the vacuum chamber sections of the SR. Although the loss will be distributed along the chamber in the ring, the assumption is made that a point loss occurs in order to get a conservative estimate of the maximum possible radiation dose rate. Operation for $1 \mathrm{~h}$ results in approximate saturation for all radionuclides except F-18. The estimated combined exposure rate at $1 \mathrm{~m}$ is $2.7 \mathrm{R} / \mathrm{hkW}$, which gives $0.70 \mathrm{mR} / \mathrm{h}$ at 1 $\mathrm{m}(7.5 \mathrm{mR} / \mathrm{h}$ at $1 \mathrm{ft})$, immediately after shutdown for operation at the safety envelope. The major contribution is from Al-26m (half life $=6.37 \mathrm{~s}$ ) so that, after a minute or so, the residual reading should be $<0.04 \mathrm{mR} / \mathrm{h}$ at $1 \mathrm{~m}$. Operation at the safety envelope for $8 \mathrm{~h}$ will cause this residual radiation field to build up only slightly because of F-18 buildup. So, the residual radiation field in this material is not important (only small activities of F-18 with a half life of $110 \mathrm{~min}$ are produced during prolonged operation).

\subsubsection{Copper}

As mentioned in Section 13.1, activated copper consists of several radionuclides, which include half lives from about $10 \mathrm{~min}$ to nearly 100 years. Relevant activities that may contribute to the residual radioactivity in the system are Co-60 (half life $=5.27 \mathrm{y}$ ) and Ni-63 (half life $=92 \mathrm{y}$ ). Estimates of the activities of these radionuclides at time of shutdown of the APS are contained in APS-LS-141 Revised. These estimates assume operation of the storage ring over many years at $7 \mathrm{GeV}$ and 300 $\mathrm{mA}$ of circulating current in order that a build-up of activity will occur. For short operation time and lower power, only a negligible amount of activity will be formed.

For the purpose of estimating copper activation during storage ring operations, it is assumed that $20 \%$ of the power $(49.3 \mathrm{~W})$ when operating at the safety envelope is lost locally on a transition piece during injection operations. The assumption is made that a point loss occurs in order to get a conservative estimate of the radiation field. Operation for $1 \mathrm{~h}$ with a copper stop results in about $97 \%$ of the radiation field being produced by $\mathrm{Cu}-62$ (half life $9.76 \mathrm{~min}$ ). Other products include $\mathrm{Co}-58 \mathrm{~m}$, $\mathrm{Cu}-61$, and $\mathrm{Cu}-64$. The estimated exposure rate immediately after shutdown for a $1-\mathrm{h}$ run is 332 $\mathrm{mR} / \mathrm{h}$ at $1 \mathrm{~m}$ (note that injection is expected to take on the order of a few minutes so that this assumption is very conservative). After $1.5 \mathrm{~h}$, the field is about $10 \mathrm{mR} / \mathrm{h}$ at $1 \mathrm{~m}$, only $5 \%$ from $\mathrm{Cu}-62$. For an 8-h run, the estimated field would be $382 \mathrm{mR} / \mathrm{h}$ at $1 \mathrm{~m}$; down to $53 \mathrm{mR} / \mathrm{h}$ after a $1.5-\mathrm{h}$ decay. The radiation field is then mainly from $\mathrm{Cu}-61$ (half life $=3.32 \mathrm{~h}$ ) and $\mathrm{Cu}-64$ (half life $=12.8$ h). For an 8-h run followed by a 16-h cooldown, the estimated radiation field would be about 14 $\mathrm{mR} / \mathrm{h}$ at $1 \mathrm{~m}$ from $\mathrm{Cu}-64$ activity alone. Daily operation at the safety envelope for $8 \mathrm{~h}$ will cause this residual radiation field to build up slightly. The residual radiation field is important for copper, since time for maintenance of the equipment very near the transition piece may need to be limited. If the injection process only takes a few minutes as expected, say two minutes, for the same power loss on the transition piece, the exposure rate immediately after shutdown would be $42.7 \mathrm{mR} / \mathrm{h}$ at $1 \mathrm{~m}$. Over 
$99 \%$ of the exposure rate would be from $\mathrm{Cu}-62$, so that at the end of a 1.5 -h decay, the exposure rate would be $0.4 \mathrm{mR} / \mathrm{h}$ at $1 \mathrm{~m}$.

\subsubsection{Iron}

Continuous operation for $1 \mathrm{~h}$ with an iron absorber results in about $90 \%$ of the saturation exposure rate. The main activities are $\mathrm{Mn}-52 \mathrm{~m}, \mathrm{Mn}-56, \mathrm{Fe}-52$, and Fe-53. The estimated combined exposure rate, based upon $61.6 \mathrm{~W}$ lost locally in the iron of the injection septum magnet at $1 \mathrm{~m}$ is about 32 $\mathrm{mR} / \mathrm{h}$, contributed mainly by $\mathrm{Mn}-52 \mathrm{~m}$ (half life $=21.1 \mathrm{~min}$ ) and Fe-53 (half life $=8.51 \mathrm{~min}$ ). After about $1.5 \mathrm{~h}$, the exposure rate should be about $0.5 \mathrm{mR} / \mathrm{h}$ at $1 \mathrm{~m}$. For $8 \mathrm{~h}$ of operation, Mn-56 (half life $=2.576 \mathrm{~h}$ ) and Fe-52 (half life $8.2 \mathrm{~h}$ ) will build up enough to make a slight contribution initially, $2.2 \mathrm{mR} / \mathrm{h}$ at $1 \mathrm{~m}$ after $1.5 \mathrm{~h}$, and about $0.33 \mathrm{mR} / \mathrm{h}$ after a 16 -h cooldown. The residual radiation field is only slightly important in the case of steel in the magnets.

\subsection{4 $\underline{\text { Lead }}$}

Using lead (provided it is free of antimony) as a stop material during injection will result in the activation of these products: Tl-206, Tl-207m, Tl-207, Pb-202m, Pb-203m, and Pb-204m. The estimated exposure rate at $1 \mathrm{~m}$ is $520 \mathrm{mR} / \mathrm{h}$ (not including self-shielding) immediately after $1 \mathrm{~h}$ of operation at the safety limit of the synchrotron. The radiation field after $1.5 \mathrm{~h}$ would still be about 80 $\mathrm{mR} / \mathrm{h}$ at $1 \mathrm{~m}$ but would be negligible by the next day. For $8 \mathrm{~h}$ of operation, the estimated initial radiation field would increase to $757 \mathrm{mR} / \mathrm{h}$ at $1 \mathrm{~m}$; down to $171 \mathrm{mR} / \mathrm{h}$ after a $1.5-\mathrm{h}$ decay, and negligible the next day. $\mathrm{Pb}-204 \mathrm{~m}$ (half life $=67 \mathrm{~min}$ ) accounts for most of the radiation field after a few minutes. The residual radioactivity is only slightly important for this material.

\section{Radioactivation of Cooling Water}

Activation of water for cooling the magnets in the system may be estimated in a manner similar to that for radioactivation in air. The primary reactions leading to activation products in water are bremsstrahlung reactions in O-16. The saturation activities of photoactivation products formed in O-16 are given in Table XXXIIb of (SWA 79a). The table is based upon 100\% energy absorption in the cooling water; whereas, a more acceptable estimate is that less than $10 \%$ of the energy will be absorbed in the cooling water. This is more reasonable since a fraction of the energy lost (assumed to be $\sim 0.5$ ) will be absorbed in the accelerator components, and a fraction of the remaining energy that escapes into the tunnel is absorbed in air, while some energy will be absorbed in the steel of the magnets or in shielding before reaching the cooling channels.

The most important of the radionuclides produced is $\mathrm{O}-15$. Other products that are formed include $\mathrm{C}-11$ (4.4\% of the $\mathrm{O}-15$ production), $\mathrm{H}-3$ (at saturation, $2.2 \%$ of the $\mathrm{O}-15$ production), $\mathrm{N}-13$ (about $1 \%$ of the $\mathrm{O}-15$ production), and Be-7 ( $0.44 \%$ of the $\mathrm{O}-15$ production). The production (yield) of O-15 may be estimated from Eq. (30), using an effective $Z$ of 3.34 for water, according to Schaeffer (Sch 73), and assuming that the abundance of O-16 is $100 \%$ :

$$
\mathrm{Y}^{\prime}=1.21 \times 10^{8}(1)(3.34)^{0.66}=2.68 \times 10^{8} \text { atoms } / \mathrm{Ws} .
$$


Because the half life of $\mathrm{O}-15$ is only $2.05 \mathrm{~min}$, it will reach equilibrium (saturation) rapidly. The saturation activity under static conditions will be given by a modified Eq. (33), in which $\mathrm{f}$, the fraction of energy absorbed, is the operational time weighted fraction as computed in Appendix B:

$$
A=\frac{\mathrm{WfY}^{\prime}\left(1-\mathrm{e}^{-\mathrm{x} / \lambda}\right)}{3.7 \times 10^{7}}(\mathrm{mCi}),
$$

where $\mathrm{x}$ is the average path length through the water channel in $\mathrm{m}$ (assumed $=0.02 \mathrm{~m}$ ), and $\lambda$ is the average attenuation length in $\mathrm{m}$ (taken as $0.5 \mathrm{~m}$ for $\mathrm{x}$-rays that penetrate to the water channels). Supplying values for the parameters in the equation, one arrives at

$$
\mathrm{A}=0.284 \mathrm{Wf}(\mathrm{mCi})
$$

For purposes of this estimate, the assumption is that $\mathrm{W}=111$ watts $(61.6 \mathrm{~W}$ on the septum, $49.3 \mathrm{~W}$ on the transition piece, and $0.258 \mathrm{~W}$ lost around the ring), so that the maximum saturation activity $\mathrm{A}$ is computed. This assumes that all energy lost in the vacuum chamber, the transition piece, and at the septum contribute to activation, and the irradiated water is near the region in which the energy loss occurs. Since the f parameter differs for each loss site, the total activity obtained by Eq. (35) must be summed over the three components:

$$
\mathrm{A}_{\text {Total }}=0.284 \sum_{\mathrm{i}=1}^{3} \mathrm{~W}_{\mathrm{i}} \mathrm{f}_{\mathrm{i}} .
$$

In a closed, circulating coolant system, the build-up of a radionuclide may be estimated from the following modified expression from Stapleton (STA 89):

$$
\mathrm{dN} / \mathrm{dt}=\mathrm{A}-\lambda_{\mathrm{R}} \mathrm{N}-\mathrm{FRN} / \mathrm{V}+\mathrm{f}^{\prime} \mathrm{FRN} / \mathrm{V}=\mathrm{A}-\left[\lambda_{\mathrm{R}}+\mathrm{FR}\left(1-\mathrm{f}^{\prime}\right) / \mathrm{V}\right] \mathrm{N}
$$

in which $\lambda_{\mathrm{R}}$ is the radioactive decay constant, $\mathrm{FR} / \mathrm{V}$ is the water turnover rate (the water flow rate, $\mathrm{FR}$, divided by the irradiated volume, $\mathrm{V}$ ), and $\mathrm{f}^{\prime}$ is the fraction of the radioactivity remaining after a complete circuit of the closed system $\mathrm{f}^{\prime}=\mathrm{e}^{-\lambda_{\mathrm{R}} \tau}$ (in which $\tau$ is the circuit transit time). The solution of the above, for $\mathrm{N}=0$ when $\mathrm{t}=0$, is

$$
\mathrm{N}=\frac{\mathrm{A}}{\lambda_{\mathrm{R}}+\mathrm{FR}\left(1-\mathrm{f}^{\prime}\right) / \mathrm{V}}\left(1-\mathrm{e}^{-\left[\lambda_{\mathrm{R}}+\mathrm{FR}\left(1-\mathrm{f}^{\prime}\right) / \mathrm{V}\right] \mathrm{t}}\right)
$$

and the activity, Act, is

$$
\text { Act }=\frac{0.284 \lambda_{R}\left(1-e^{-\left(\lambda_{R}+\frac{F R\left(1-f^{\prime}\right)}{V}\right) t}\right) \sum_{i=1}^{3} W_{i} f_{i}}{\lambda_{R}+\frac{F R\left(1-f^{\prime}\right)}{V}}
$$


For an assumed transit time of $10 \mathrm{~min}$ and a turnover rate of $3.464 \times 10^{-3} \mathrm{~min}^{-1}$, using the previous power loss $\mathrm{W}$ for each of the components to estimate the radioactivation, and assuming saturation conditions for the shorter-lived radionuclides, the estimated total saturation activities of the various radionuclides formed in water can be computed. Based upon $8 \mathrm{~h}$ of operation, equilibrium will be reached for all but Be-7 and $\mathrm{H}-3$. The resulting activities of the components would be: $0.14 \mathrm{mCi}$ of $\mathrm{O}-15,1.4 \times 10^{-3} \mathrm{mCi}$ of C- $11,5.9 \times 10^{-3} \mathrm{mCi}$ of N-13, $2.7 \times 10^{-6} \mathrm{mCi}$ of Be- 7 , and $1.5 \times 10^{-7} \mathrm{mCi}$ of $\mathrm{H}-3$. Any release into the air of the radioactive gases $\mathrm{O}-15, \mathrm{~N}-13, \mathrm{C}-11$ as carbon dioxide, and/or H-3 as water vapor will not contribute significantly to any on-site or off-site doses.

If some of the water is accidentally discharged from the assumed 250,000-gallon closed system, the estimated composite release concentration $\mathrm{C}_{\mathrm{H}_{2} \mathrm{O}}$ in the discharge would be:

$$
\mathrm{C}_{\mathrm{H}_{2} \mathrm{O}}=\frac{\operatorname{Act}(\mu \mathrm{Ci})}{2.5 \times 10^{5}(\mathrm{gal}) 3.785(1 / \mathrm{gal}) 10^{3}(\mathrm{cc} / \mathrm{l})}=1.6 \times 10^{-7} \mu \mathrm{Ci} / \mathrm{cc} .
$$

This concentration is below the discharge limits in DOE Order 5400.5 (DOE 90) for any one of the radionuclides in the composite.

Additional water systems in the storage ring tunnel (such as the sprinkler system) are located over a meter away from the beam orbit. The radiation fields at these locations should be at least four orders of magnitude less than those at the cooling water, so negligible activation of these systems is anticipated. 


\section{REFERENCES}

ACG 93 American Conference of Governmental Industrial Hygienists, Threshold Limit Values and Biological Exposure Indices for 1993-94, ACGIH, Cincinnati, OH (1993).

ANL 87 Argonne National Laboratory, $7 \mathrm{GeV}$ Advanced Photon Source - Conceptual Design Report, Draft, ANL 87-15, ANL Report, (April 1987).

BAT 67 G. Bathow et al., "Measurements on $6.3 \mathrm{GeV}$ Electromagnetic Cascades and Cascade Produced Neutrons," Nucl. Phys., B2, 669 (1967).

CER 81 K. Goebel, Editor, The Radiological Impact of the LEP Project on the Environment, CERN 81-08 (20 July 1981).

CER 84 A. Fasso et al., Radiation Problems in the Design of the Large Electron-Positron Collider (LEP), CERN 84-02 (5 March 1984).

DOE 88 Department of Energy, Radiation Protection for Occupational Workers, DOE Order 5480.11, Washington, DC (1988).

DOE 90 Department of Energy, Radiation Protection of the Public and the Environment, DOE Order 5400.5, Washington, DC (Feb. 2, 1990).

DOE 92 Department of Energy, Safety of Accelerator Facilities, DOE Order 5480.25, Washington, DC (Nov. 3, 1992).

DOE 93 Department of Energy, Guidance for an Accelerator Facility Safety Program, DOE 5480.25 Guidance, Washington, DC (Sep. 1, 1993).

DOE 94 Department of Energy, Radiological Control Manual, DOE/EH-0256T Revision 1, US Department of Energy, Washington, DC (April 1994).

EME 94 L. Emery, internal communication (March 8, 1994).

GOD 68 R.P. Godwin, "Synchrotron Radiation as a Light Source," Springer Tracts in Modern Physics, Vol. 51, Springer, Berlin/New York (1968).

GRE 76 G.K. Green, "Spectra and Optics of Synchrotron Radiation," BNL 50522, Brookhaven National Laboratory Report, Upton, Long Island, NY (1976).

ICP 87 International Commission on Radiation Protection, Data for Use in Protection Against External Radiation, ICRP Publication 51, ICRP (1987). 
REFERENCES (Continued)

ICR 78 International Commission on Radiation Units and Measurements, Basic Aspects of High Energy Particle Interactions and Radiation Dosimetry, ICRU Report 28, ICRU (1978).

IPE 93 N. Ipe et al., "Guide to Beamline Radiation Shielding Design at the Advanced Photon Source,” ANL Report ANL/APS/TB-7 (Nov. 1993).

JEN 79 T.M. Jenkins, "Neutron and Photon Measurements Through Concrete from a 15-GeV Electron Beam on a Target - Comparison with Models and Calculations," Nucl. Instrum. Methods, 159, 265 (1979).

LUM 94 A. H. Lumpkin and B. Yang, internal ASD report (Aug. 26, 1994).

MOE 91 H.J. Moe, “Advanced Photon Source: Radiological Design Considerations,” ANL Report, APS-LS-141 Revised (July 1991).

MOE 93a H.J. Moe, internal APS report to M. White (April 30, 1993).

MOE 93b H. J. Moe, internal APS report to M. D. Borland (Aug. 29,1993).

MOE 93c H. J. Moe, internal APS report to S. Milton (Sept. 10, 1993).

MOE 93d H. J. Moe, internal APS report to G. Decker (Sept. 18, 1993).

MOE 94 H. J. Moe, internal APS memo to B. Yang, dated April 28, 1994.

NEL 66 W.R. Nelson, "Electron Induced Cascade Showers in Copper and Lead at 1 GeV," Phys. Rev., 149, 201 (1966).

NEL 68 W. R. Nelson,'The Shielding of Muons Around High Energy Electron Accelerators: Theory and Measurements," Nucl. Instrum. Methods, $\underline{66}$ (1968).

RIN 75 A. Rindi and R. H. Thomas, "Skyshine - A Paper Tiger?," Part. Accel., 7, 23-29 (1975).

SCH 73 N.M. Schaeffer, Editor, Reactor Shielding for Nuclear Engineers, NTIS, Springfield, VA (1973).

SHU 92 D. Shu, T. Sanchez and T. Kuzay, "An Integrated Bremsstrahlung Safety Shutter and Collimator Designed for the APS Front End Operating in the Top-up Mode," ANL Report, ANL/APS/LS-192 (1992).

SHU 93 D. Shu and T. Kuzay, "General Design of the Layout for the Advanced Photon Source Beamline Front Ends,” ANL/APS/LS-228 (1993). 


\section{REFERENCES (Continued)}

STA 89 G. Stapleton, "Radiolysis and Radioactivation of Beam Dump Cooling Water," Review of the Radiological Aspects of the Conceptual Design Report for the CEBAF End Stations and Switchyard, TN-0174, CEBAF Report (1989).

SWA 79 W.P. Swanson, "Improved Calculation of Photoneutron Yields Released by Incident Electrons," Health Phys., 37, 347 (1979).

SWA 79a W.P. Swanson, Radiological Safety Aspects of the Operation of Electron Linear Accelerators, Technical Report Series 188, IAEA, Vienna, AUS. (1979), and references therein.

SWA 85 W.P. Swanson et al., Aladdin Upgrade Design Study: Shielding, University of Wisconsin Report (1985).

SWA 87 W.P. Swanson, "Proceedings of the CEBAF Workshop on Radiation Safety," TN0058, CEBAF Report (1987).

TES 88 K. Tesch, "Shielding Against High Energy Neutrons from Electron Accelerators - A Review," Rad. Prot. Dos., 22, 27 (1988).

TRO 90 G. Tromba and A. Rindi, "Gas Bremsstrahlung from Electron Storage Rings: A Monte Carlo Evaluation and Some Useful Formulae,” Nucl. Instrum. Methods, $\underline{\text { A292, }}$ 700 (1990).

TSA 74 Y. S. Tsai, "Pair Production and Bremsstrahlung of Charged Leptons," Rev. Mod. Phys., $\underline{46}, 815$ (1974).

WAT 48 G.N. Watson, Theory of Bessel Functions, The Macmillan Company, New York, NY (1948).

WIN 78 H. Winick and A. Bienenstock, "Synchrotron Radiation Research," Ann. Rev. of Nuc. and Part. Sci., 28, 33 (1978). 


\section{APPENDIX A \\ Discussion of MCI}

The maximum credible incident (MCI) is that incident which produces the highest dose rate when compared to the dose rates that result from other potential incidents that have been analyzed. It represents the largest risk associated with radiation incidents at the given facility. The incident usually involves postulating equipment failure and/or human error to attain the resultant radiation dose. However, the incident must be considered credible, so that many events which could occur are of such low probability that those events can be considered incredible. That is, one must assume that most, if not all, of the safety systems fail to operate simultaneously with an accompanying equipment failure and/or human error.

The maximum credible incident is defined as occurring when the synchrotron is set up to run at the safety envelope ( $7700 \mathrm{MeV}$ positrons at $308 \mathrm{~W}$ ) and the HET delivers that power of beam to the SR. For normal operating conditions, one would expect losses in the SR to occur primarily in the injection septum and at the transition section at the beginning of an ID. However, in the event that the beam becomes missteered, the loss pattern is not predictable and one could find losses almost anywhere along the ring. For the MCI, the conservative assumption has been made that the loss is localized throughout a high-dispersion region in one of the forty sectors of the ring (see region around AS4 in Figure 6). This region is $\sim 4 \mathrm{~m}$ long, which includes four quadrupoles and a sextupole at the center of the region. The beam would be expected to spray along a longer distance so the assumption of a 4-m-long dump should be conservative. The duration of the incident will depend upon the actuation of the shutdown system mechanisms. The dose rate is calculated to give an indication of the potential dose implications if failure of the shutdown mechanisms occur and the incident duration is extended for a significant period of time.

The parameters used in the dose rate assessment are:

- beam energy $7700 \mathrm{MeV}$,

- $308 \mathrm{~W}$ of beam power, $2.5 \times 10^{11} \mathrm{e}^{+} / \mathrm{s}$ in the beam,

- the total beam dumps along the length of the region $(4 \mathrm{~m})$, which results in the highest dose rate outside of the tunnel in an FOE,

- the shutdown system fails to shut down the beam within a few pulses,

- the dose point is $1.9 \mathrm{~m}$ perpendicular distance from the loss region and is shielded by $3 \mathrm{~cm}$ of $\mathrm{Al}$ and $56 \mathrm{~cm}$ of high-density concrete,

- an individual is standing in the FOE directly adjacent to the region for the duration of the incident.

In a spill, the radiation is emitted along a line source toward the dose point, as shown in the sketch in Section 5.3. The contribution at the point $\mathrm{P}$ from the differential line segment $\mathrm{dl}$ for the ith radiation component can be expressed by Eq. (9):

$$
\mathrm{d} \dot{\mathrm{H}}_{\mathrm{i}}=\left[3600 \mathrm{PF} \mathrm{F}_{\mathrm{i}} \prod_{\mathrm{i}, \mathrm{j}} \exp ^{-\mathrm{t}_{\mathrm{j}}(\sin \theta) \lambda_{\mathrm{i}, \mathrm{j}}}\right] \frac{\mathrm{dl}}{\mathrm{r}(\theta)^{2}},
$$

in which $\mathrm{P}$ is the power lost per $\mathrm{m}$ of length $(\mathrm{W} / \mathrm{m}), 3600 \mathrm{~s} / \mathrm{h}$ converts $\mathrm{W}$ to $\mathrm{J} / \mathrm{h}, \mathrm{F}_{\mathrm{i}}$ is the dose constant $(\mathrm{mrem} / \mathrm{J}$ at $1 \mathrm{~m})$ for the ith radiation component, $\mathrm{t}_{\mathrm{j}}$ is the thickness of the jth shield material 
in $\mathrm{g} / \mathrm{cm}^{2}, \lambda_{\mathrm{i}, \mathrm{j}}$ is the attenuation length of the ith radiation component for the $\mathrm{jth}$ shield material, $\mathrm{r}$ is the distance $(\mathrm{m})$ from the differential line segment to the dose point $\mathrm{P}$, and $\theta$ is the angle between the line segment and the dose point. The total contribution at the dose point $\mathrm{P}$ is given by Eq. (10):

$$
\dot{\mathrm{H}}_{\mathrm{i}}=3600 \mathrm{P} \sum_{\mathrm{i}} \int_{-\mathrm{x}}^{0} \frac{\mathrm{F}_{\mathrm{i}} \prod_{\mathrm{i}, \mathrm{j}} \exp ^{-\mathrm{t}_{\mathrm{j}} /(\sin \theta) \lambda_{\mathrm{i}, \mathrm{j}}}}{\mathrm{r}(\theta)^{2}} \mathrm{dl} .
$$

Since there are four radiation components, each with a different attenuation length in each of the two shields, and each component has its own dose constant that varies with the angle $\theta$ for all but the GRN component, Eq. (10) must be plotted and numerically integrated to obtain the total dose rate at the point $\mathrm{P}$ in the sketch of Section 5.3.

The average total dose in the region is $1.486 \mathrm{mrem} / \mathrm{pulse}$. During the MCI, the beam will continue to be lost in the same region at the rate of two pulses per second. The dose rate becomes $1.486 \times$ $2 \mathrm{pps} \times 3600 \mathrm{~s} / \mathrm{h}=10.7 \mathrm{rem} / \mathrm{h}$ for the duration of the incident (which, according to the DOE Guidance (DOE 93) for DOE Order 5480.25 (DOE 92), should be taken as $1 \mathrm{~h}$ ). 


\section{APPENDIX B}

The estimate of the parameter f, which appears in Eqs. (18)-(21), (23), (27)-(28), and (31)-(36), involves a contribution from three main loss regions: the injection septum, the transition piece for an ID, and the loss of stored beam. The value of the parameter for each of these contributors depends upon the material of the region and the local shielding around the material as discussed in the text. The parameter calculation for the septum is detailed here and the results for the remaining contributors are listed. Since most of the radiation energy is emitted in the forward direction, the backward contribution in the case of $f$ has been ignored. In addition to the parameter $f$, values of equivalent shield thicknesses for the component radiations are also presented.

\section{$\underline{\text { Parameter } \mathrm{f}}$}

The septum wall that may be struck by the positrons consists of a 1-mm-thick $\mathrm{Cu}$ wall next to a 1mm-thick Fe wall. The angle that the beam makes with the wall is $1.882^{\circ}$. At this angle, the total slant penetration distance through both the $\mathrm{Cu}$ and $\mathrm{Fe}$ is about $6.1 \mathrm{~cm}$, so for a beam striking this septum wall, the shower will not be totally contained within the wall but will continue toward the outside of the vacuum chamber and will strike the chamber wall a few meters downstream. To be conservative, the $20 \%$ of the beam lost will be considered lost at the septum. The radiation from the shower will pass radially through the walls of the septum magnet. For half of the radiation, the thickness of the wall is taken as $2.5 \mathrm{~cm}$ of steel and for the other half, the thickness is $1 \mathrm{~cm}$. The septum is surrounded by $\mathrm{Pb}$ on the sides and top, but has no shielding for the underside (see Figure $\mathrm{B}-1$ ). The Moliere radius for $\mathrm{Cu}$ is $11 \mathrm{~g} / \mathrm{cm}^{2}$ and that of $\mathrm{Fe}$ is $10.7 \mathrm{~g} / \mathrm{cm}^{2}$. An average value of 10.9 $\mathrm{g} / \mathrm{cm}^{2}$ was used for the Moliere radius and an average value of $8.42 \mathrm{~g} / \mathrm{cm}^{3}$ was used for the average density. For a radius of $1 \mathrm{~cm}\left(8.42 \mathrm{~g} / \mathrm{cm}^{2}\right)$, the number of Moliere radii is given by

$$
\mathrm{R} / \mathrm{X}_{\mathrm{m}}=\frac{8.42}{10.9}=0.7725
$$

Similarly, for a radius of $2.5 \mathrm{~cm}$, the number of Moliere radii is 1.93. Using Eq. (6), the fraction of energy escaping through the sides of the septum housing is estimated as

Fraction $\quad=0.8 \mathrm{e}^{-3.45(0.7725)}+0.2 \mathrm{e}^{-0.889(0.7725)}$

$=0.156$ for the case of the $1 \mathrm{~cm}$ wall and

Fraction $=0.8 \mathrm{e}^{-3.45(1.93)}+0.2 \mathrm{e}^{-0.889(1.93)}$

$=0.037$ for the case of the $2.5 \mathrm{~cm}$ wall, and since each side sees $1 / 2$ of the radiation, the average value is 0.0965 . Of this fraction, the $\mathrm{Pb}$ shield on the top and side of the septum will intercept more of the emitted radiation and absorb some of the energy so that the remaining fraction irradiating the air in the tunnel will be less than that computed above. Figure B-1 is an end view of the septum and its shielding. To model the shielding effect, the following idealized sketch was used: 


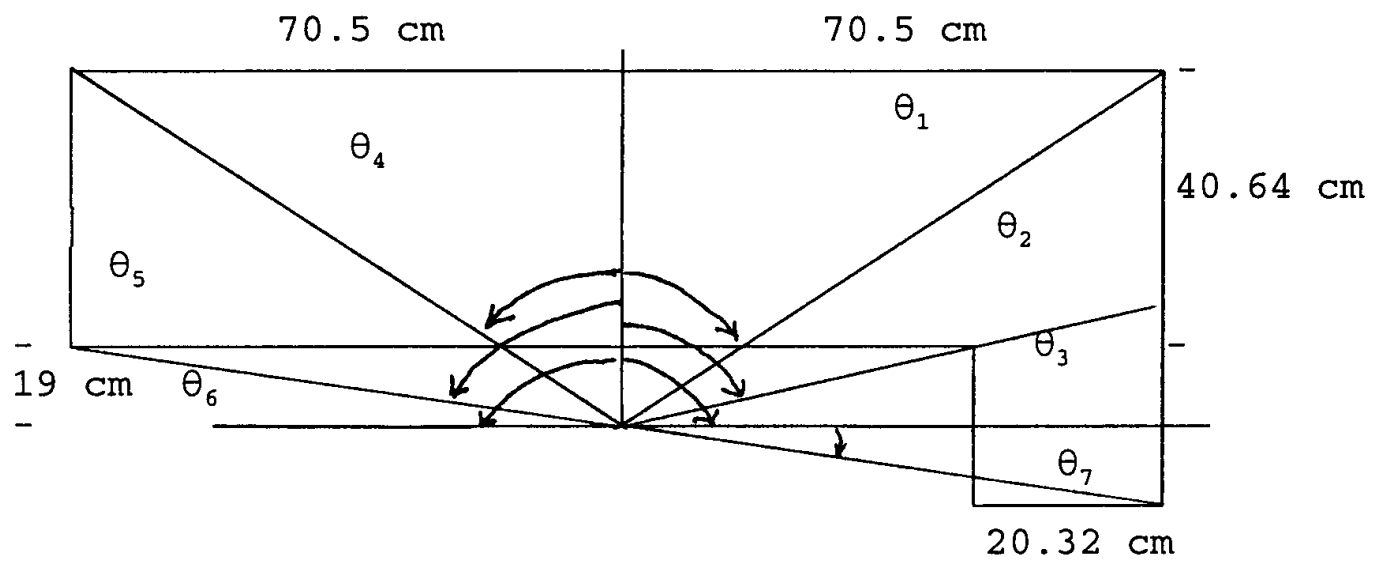

in which $\theta_{1}=49.8^{\circ}, \theta_{2}=69.26^{\circ}, \theta_{3}=90^{\circ}, \theta_{4}=\theta_{1}, \theta_{5}=74.9^{\circ}, \theta_{6}=\theta_{3}$ and $\theta_{7}=14^{\circ}$. The $\mathrm{Pb}$ shielding is $40.64 \mathrm{~cm}$ thick in the vertical direction and $20.32 \mathrm{~cm}$ thick in the horizontal direction on the side that is adjacent to the EAA. The average path length through the shield is computed for each of the regions marked off by the angles in the sketch, assuming azimuthal symmetry for a given region. For the first region, $\theta_{1}=\theta_{4}$ and the path through the shield is $\mathrm{x}=40.64 \mathrm{sec} \theta$, so that

$$
\begin{gathered}
\bar{x}=\frac{2 \pi(40.64) \int_{0}^{49.8^{\circ}} \sec \theta \sin \theta d \theta}{2 \pi \int_{0}^{49.8^{\circ}} \sin \theta d \theta} \\
\bar{x}=\frac{40.64\left(-\ln \cos 49.8^{\circ}\right)}{1-\cos 49.8^{\circ}}=50.2 \mathrm{~cm} .
\end{gathered}
$$

This is the average thickness of the Pb shielding in the upward solid angle fraction $\Omega / 2 \pi=1-\cos$ $49.8^{\circ}=0.355$. Proceeding similarly, in the range $\theta_{1}$ to $\theta_{2}, x=70.5 \csc \theta-19 \sec \theta$, and the average path is $43 \mathrm{~cm}$ for the upward solid angle fraction 0.146 . For the range $\theta_{2}$ to $\theta_{3}, \mathrm{x}=20.32 \mathrm{csc} \theta$, and the average path length is $20.8 \mathrm{~cm}$ for the upward solid angle fraction 0.177 . For the range $\theta_{4}$ to $\theta_{5}, \mathrm{x}$ $=70.5 \csc \theta-19 \sec \theta$, and the average path length is $35.4 \mathrm{~cm}$ of $\mathrm{Pb}$ for the upward solid angle fraction 0.192 . For the range $\theta_{5}$ to $\theta_{6}$, there is no $\mathrm{Pb}$ for the upward solid angle fraction 0.13 . For the downward solid angle, only a small fraction is covered by the $\mathrm{Pb}$. For the region $\theta_{3}$ to $\theta_{7}, \mathrm{x}=20.32$ $\sec \theta$, and the estimated average path length is $20.6 \mathrm{~cm}$ for the downward solid angle fraction of 0.0149 . 
Figure B-1 - End View of the SR Injection Septum Shield

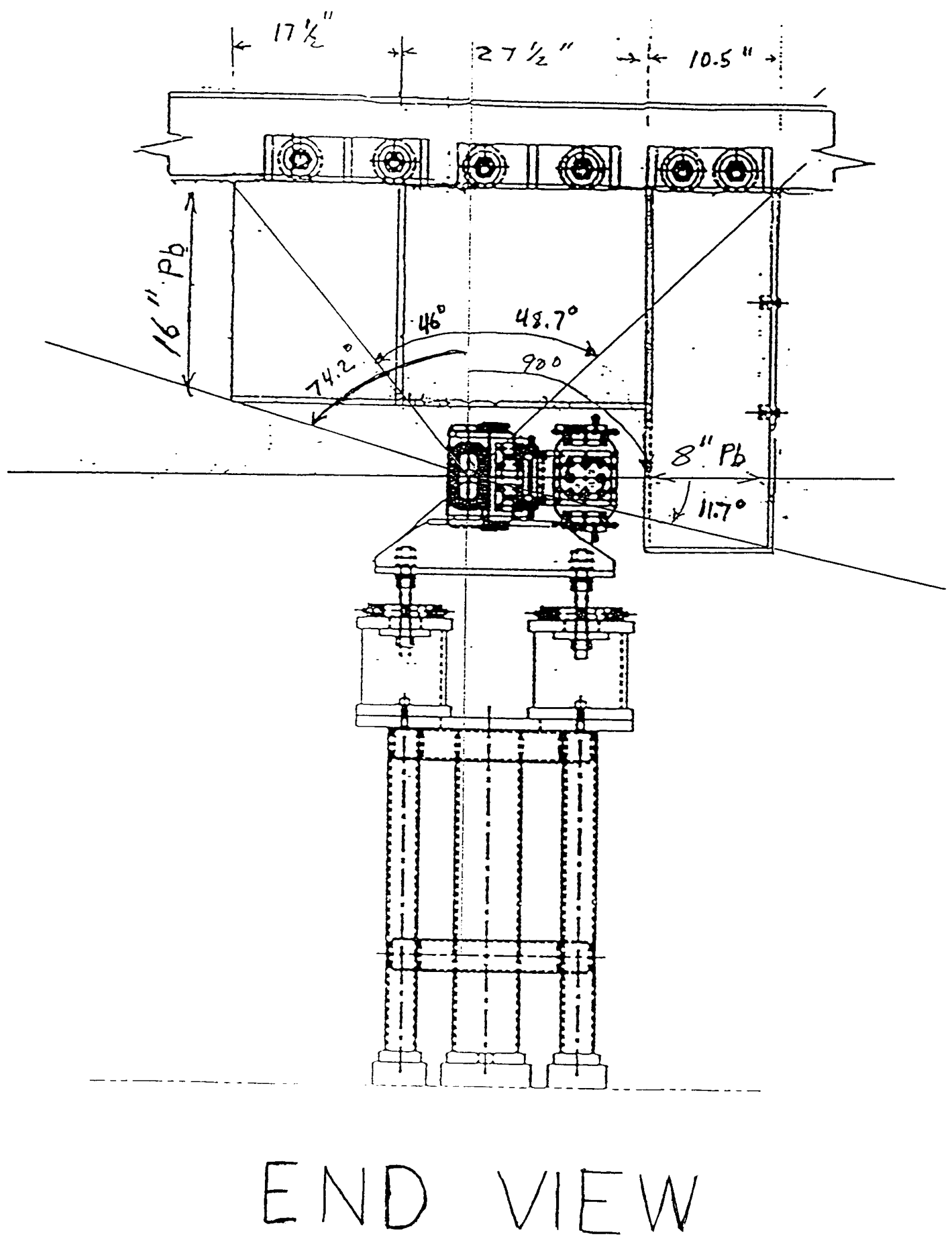


Considering all the radiation $(4 \pi), 0.558$ is the fraction that is unshielded, and 0.442 is the fraction shielded by $\mathrm{Pb}$. The fraction of the total radiation energy that escapes from the septum shield and into the tunnel is then

$$
\begin{aligned}
\mathrm{f}= & 0.558(0.0965)+0.435(0.0965)\left[0.355 \mathrm{e}^{-50.2(11.35) / 24}+\right. \\
& {\left[0.192 \mathrm{e}^{-35.4(11.35) / 24}+0.146 \mathrm{e}^{-43(11.35) / 24}+0.177 \mathrm{e}^{-20.8(11.35) / 24}\right] } \\
& +0.007(0965) \mathrm{e}^{-20.6(11.35) / 24}=0.0538
\end{aligned}
$$

When this fraction is prorated for the assumed operational time fraction of 0.1 , the final value of $f$ is

$$
\mathrm{f}=0.0054 \text {, for the septum. }
$$

The equivalent value of the shielding thickness in the septum for the shielded fraction of the bremsstrahlung radiation is $24.4 \mathrm{~cm}$ of $\mathrm{Pb}$. The equivalent shielding thickness of the septum shield for the upward-directed GRN component is $37 \mathrm{~cm}$ of $\mathrm{Pb}$, and that for the MEN and HEN components is $38 \mathrm{~cm}$ of $\mathrm{Pb}$. The equivalent shielding thickness of the septum itself for the GRN, MEN, and HEN components is $1.7 \mathrm{~cm}$ of Fe.

In the case of upward-directed neutrons, these will penetrate through the concrete tunnel wall and roof to become skyshine. The $\mathrm{Pb}$ shield over the septum is not as effective in stopping GRN neutrons as it is in stopping bremsstrahlung. The largest attenuation of this component occurs in the concrete. On the other hand, the $\mathrm{Pb}$ is more effective than the concrete in stopping both the MEN and HEN components. The concrete thickness of the SR tunnel in the vicinity of the injection septum is $0.8 \mathrm{~m}$ on the infield side of the tunnel, $1 \mathrm{~m}$ on the roof of the storage ring, and $1.1 \mathrm{~m}$ on the EAA side of the storage ring. The tunnel dimensions in this region are $2.74 \mathrm{~m}$ high by $3.18 \mathrm{~m}$ wide. The beam height is $1.4 \mathrm{~m}$ above the floor, and the distance from the beamline to the SR wall on the EAA side is 1.19 $\mathrm{m}$, while the distance from the beamline to the wall on the infield side of the tunnel is $1.99 \mathrm{~m}$. The layout is shown in the following sketch:

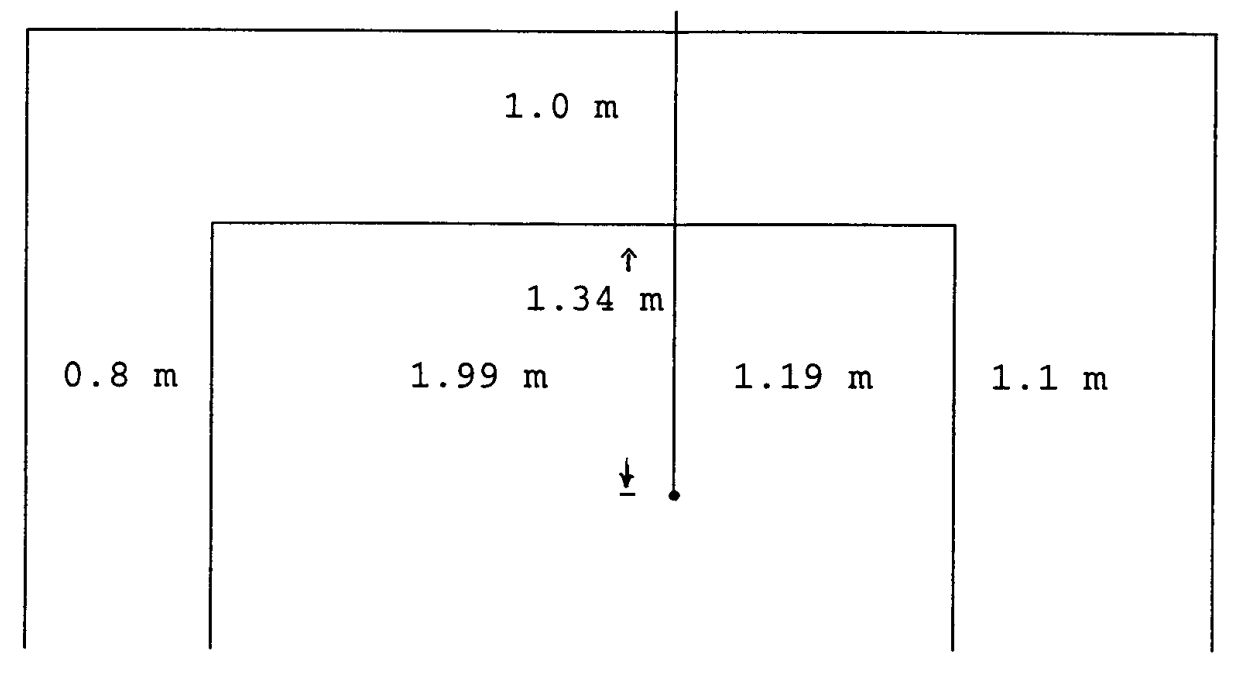


By repeating a similar analysis for the average path length through the concrete for the geometry shown in the sketch above, assuming azimuthal symmetry for the various solid angle fractions, one arrives at the following:

\begin{tabular}{cc} 
Solid Angle Fraction & Average Path Length, cm \\
\hline 0.126 & 115 \\
0.017 & 146 \\
0.357 & 123 \\
0.179 & 124 \\
0.042 & 126 \\
0.280 & 85
\end{tabular}

In this case, the entire upward solid angle is shielded by some thickness of concrete. The effective path length through the concrete in the vicinity of the septum shield is $102 \mathrm{~cm}$ for the GRN component, $106 \mathrm{~cm}$ for the MEN component, and $109 \mathrm{~cm}$ for the HEN component. These effective values will be used for the skyshine shielding determinations.

For the other two components that contribute to the radiation field in the tunnel and outside of the shield, the value of the parameter $\mathrm{f}$ is $2.9 \times 10^{-2}$ for losses at the transition piece, assuming the copper cone is an average of $2.4 \mathrm{~cm}$ thick and $1 \mathrm{~cm}$ of Fe shielding is provided by the steel box. The value of $\mathrm{f}$ is $6.92 \times 10^{-2}$ for the stored beam losses, assuming the Al of the chamber is $1.5 \mathrm{~cm}$ thick and 10.16 $\mathrm{cm}$ of $\mathrm{Fe}$ due to the magnets shields $90 \%$ of the radiation (which gives an effective shielding thickness of $7.5 \mathrm{~cm}$ of Fe for the bremsstrahlung, $8.7 \mathrm{~cm}$ for the GRN, and $8.8 \mathrm{~cm}$ for both the MEN and HEN components). When the f values are prorated for the fraction of the operational time, 0.1 for the transition piece and 0.9 for the stored beam, the final values of the parameters are

$$
\begin{aligned}
& f=2.9 \times 10^{-3} \text { for the transition piece, and } \\
& f=6.2 \times 10^{-2} \text { for the stored beam. }
\end{aligned}
$$


APPENDIX C

The ASD Diagnostic Beamlines

The ASD diagnostic beamlines are located in Sector 35 of the SR. Both the bending magnet (BM) and insertion device (ID) beamlines will be utilized for diagnostic purposes. The potential radiation hazards arising out of the use of these beamlines include gas bremsstrahlung, scattered bremsstrahlung, synchrotron radiation, and scattered synchrotron radiation under normal operating conditions. Interacting bremsstrahlung radiation may lead to the release of neutrons, which if present in sufficient number, represent an external exposure hazard and a potential for activation of accelerator components. Bremsstrahlung and synchrotron radiation can also produce noxious gases in air. The latter considerations have been addressed in Section 12 of this report. For normal operating conditions, the neutron production and subsequent activation potential are expected to be negligible.

The components that protect the photon beamline from radiations produced in the SR are located in the front end of the beamlines (LUM 94, SHU 93) within the SR tunnel (Figure C-1 shows a representative front end for a BM beamline). Figure C-2 shows the relative locations of the front ends for the BM and ID beamlines with respect to the SR tunnel and the radial ratchet sections, and the layout of the ASD diagnostic beamlines. The required shielding consists of two photon shutters and two safety shutters. Each photon shutter is capable of absorbing the synchrotron radiation and is water cooled to dissipate the large heat loading due to this component. One of these shutters must be closed, if the safety shutters are also closed, to protect the safety shutters (which are not cooled) from the heat generated by the synchrotron beam. The safety shutters are designed to act as both a beam stop for bremsstrahlung radiation and a collimator system (SHU 92). The tungsten safety shutters are each $30 \mathrm{~cm}$ thick (IPE 93), and each one is adequate for completely stopping the bremsstrahlung radiation, although two are provided for redundancy. The shutters are located at the end of the front end, just before the beam goes through the radial part of the ratchet wall (see Figure C-1) and into the first optic enclosure (FOE), shown as 35-BM-A and 35-ID-A in Figure C-2. During the injection phase, the safety shutters must be closed, and at least one of the photon shutters must be closed. During stored beam conditions, entry to the FOE is allowed if a photon shutter is closed and the safety shutters are closed. No entry is allowed if the safety shutters are opened.

For the $\mathrm{BM}$ and ID beamlines, the bremsstrahlung is collimated by Pb shielding so that no direct or scattered component intercepts the beam (LUM 94). The beam, which enters the FOE, is split into two components, one transported to 35-BM-C (about $46 \mathrm{~m}$ from the BM source) and the other to 35BM-D (about $70 \mathrm{~m}$ from the BM source), where they are terminated in beam stops. The beam stops and shielding of these enclosures exceed the shielding recommendations provided in ANL/APS/TB-7 (IPE 93) for BM beamlines and enclosures, as demonstrated by the results of the calculations in the conceptual design report (LUM 94), which utilized the methodology outlined in ANL/APS/TB-7. Similarly, the shielding of 35-ID-A (about $40 \mathrm{~m}$ from the ID source) and 35-ID-B (60 $\mathrm{m}$ from the ID source) exceeds the shielding recommendations of ANL/APS/TB-7 for insertion device beamlines and enclosures, also shown by the results of the calculations in the conceptual design report. The shielding of the transport beamline exceeds the recommendations in ANL/APS/TB-7, and additional calculations have been made in this appendix to estimate dose rates for poorer beam 
Figure C-1 - Schematic of an APS Bending Magnet Front End

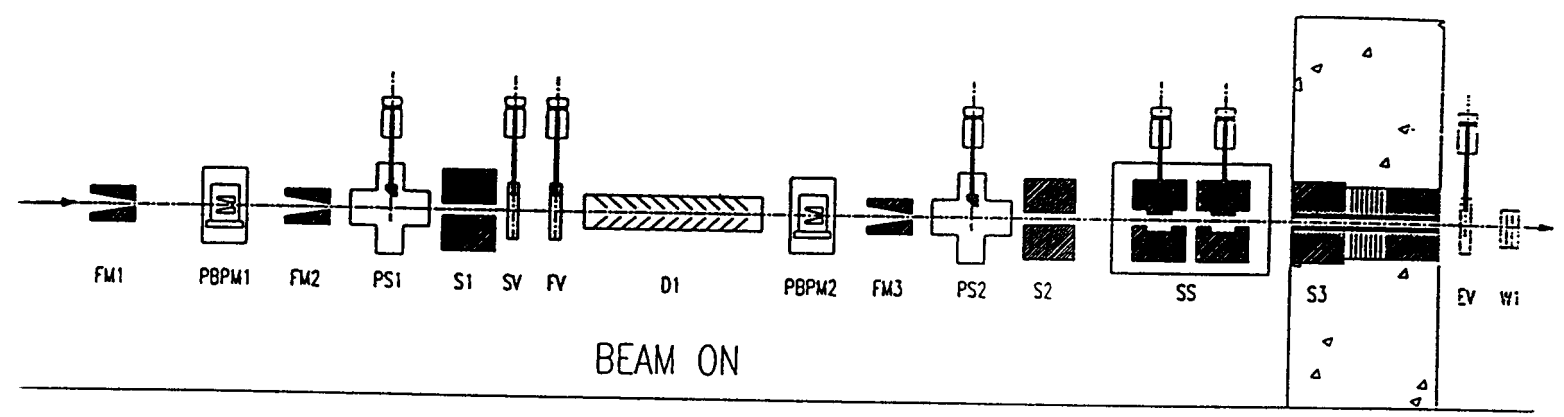

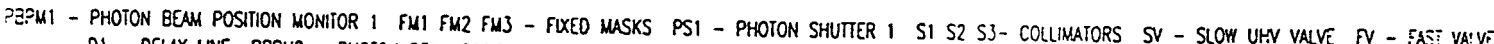
DI - DELAY LINE PBPM2 - PHOTON BEAM POSITION HONTOR 2 PS2 - PHOTON SHUTTER 2 SS - SAFETY SHUTTERS EV - EXIT VALVE W1 - VINDOWHS 
Figure C-2 - Layout of the Sector 35 ASD Diagnostic Beamlines

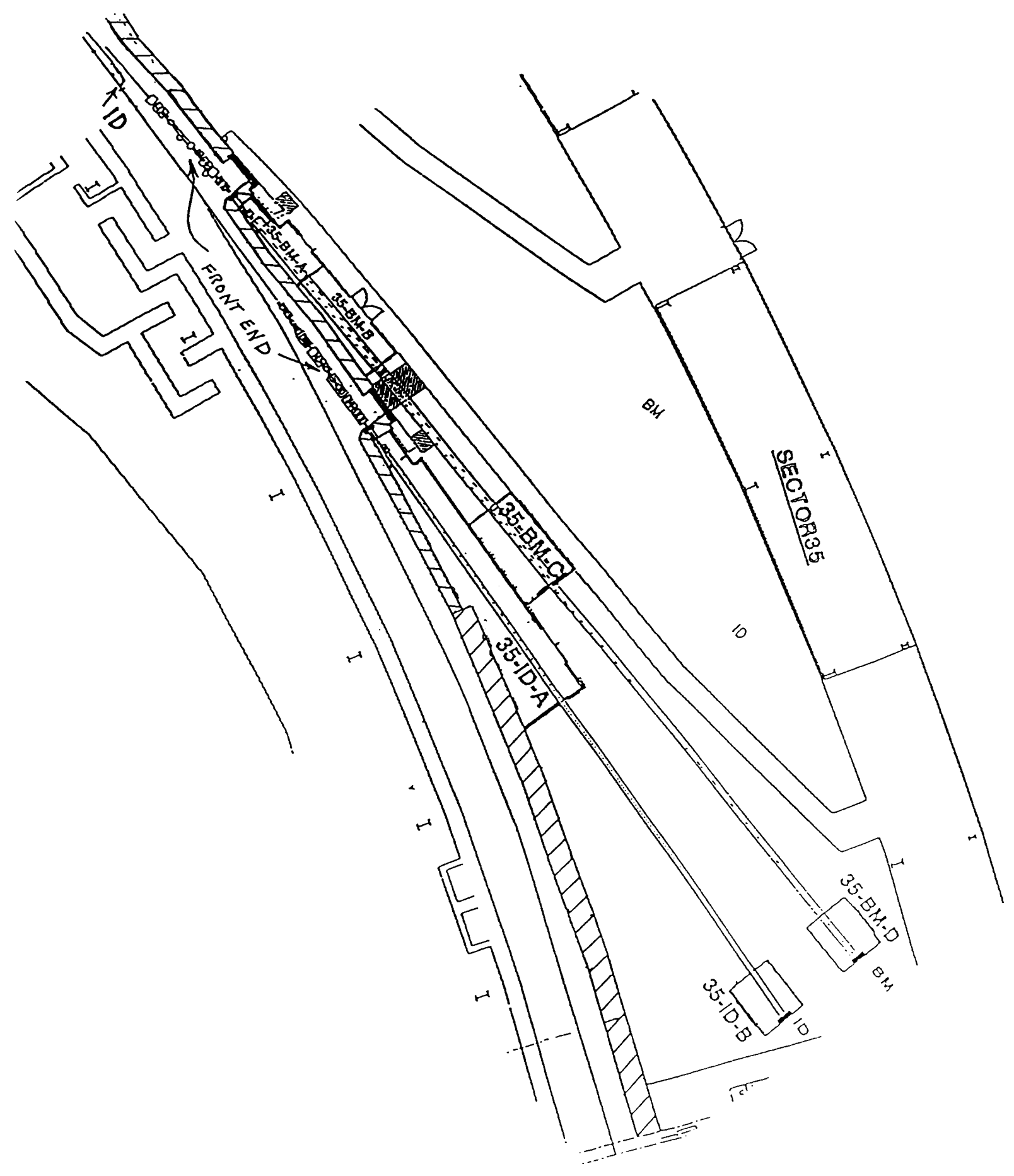


conditions. The calculations in the conceptual design report have been reviewed by H. J. Moe as part of the radiological considerations for the operation of the storage ring, and the results were found to be satisfactory. Some of the results presented in this appendix are based upon estimates made earlier in the body of this report, particularly for the cases of synchrotron radiation and gas bremsstrahlung. In all cases, the dose rates for normal operating conditions are within the DOE guideline of 0.25 $\mathrm{mrem} / \mathrm{h}$ for occupational exposure. Also included are estimates of dose rates and potential doses for some of the accident conditions that were discussed in Section 10 of this report.

\section{UV/Visible Light Transport}

For the use of UV/visible light, the beam is brought out of the tunnel by means of a series of mirrors and a penetration through the ratchet wall, as shown in the sketch below. The mirrors are used to deflect the UV/visible light away from the SR vacuum line and into the penetration in the roof of the SR tunnel. Another mirror located within the penetration deflects the light at right angles out onto the mezzanine floor. The shielding above this mirror consists of $15.24 \mathrm{~cm}$ of $\mathrm{Pb}$ and a $25-\mathrm{cm}$ concrete plug. An analysis of the expected dose rate on the SR roof from bremsstrahlung radiation, which comes from the positron orbit about $2 \mathrm{~m}$ away and could be scattered up into the penetration, showed that dose rates would be negligible (MOE 94) for the indicated shielding. Using the methodology of ANL/APS/TB-7 (IPE 93) and assuming that the photon shutter and safety shutters are located directly under the vertical penetration in the roof shield, the dose rates from the scattered gas bremsstrahlung and synchrotron radiation are negligible with the addition of a $0.635-\mathrm{cm}$-thick $\mathrm{Pb}$ plate to intercept the scattered radiation components from the shutters (see sketch below). This calculation assumed that operation was at the safety envelope (7700 MeV, $327 \mathrm{~mA}$ of circulating current).

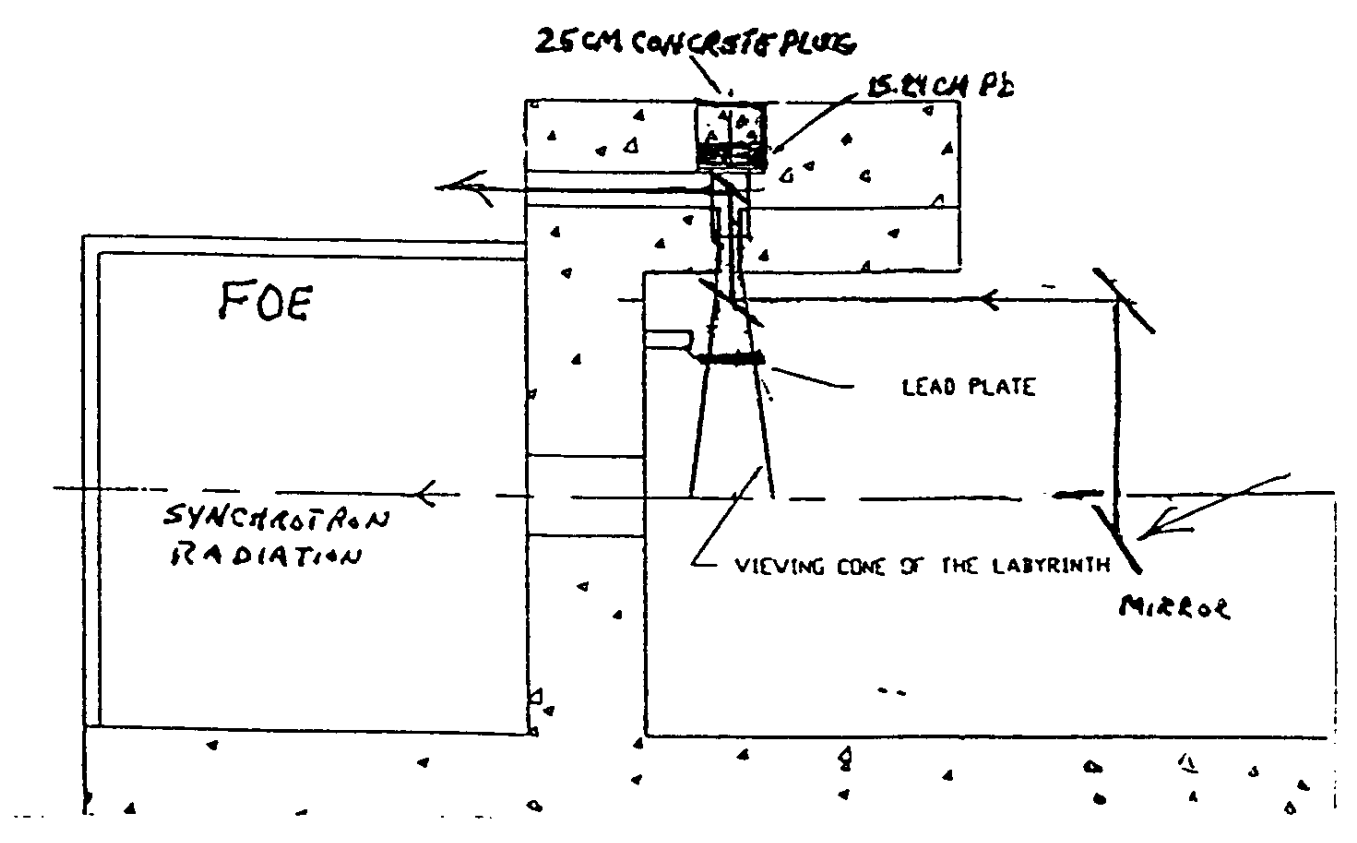


An additional estimation of the dose rate from scattered synchrotron and gas bremsstrahlung radiation was accomplished for safety envelope operation. Using Eq. (13) from Section 7 to generate the synchrotron radiation spectrum from the bending magnet, this spectrum was assumed to be scattered by a $2.5-\mathrm{cm}$-thick copper block located directly below the penetration opening in the tunnel roof, assuming no attenuation in the $\mathrm{Cu}$. The scattered radiation, at $90^{\circ}$, passes through the $0.635-\mathrm{cm}-$ thick $\mathrm{Pb}$ plate and through the $15.24 \mathrm{~cm}$ of $\mathrm{Pb}$ and $25 \mathrm{~cm}$ of concrete to the outside of the roof. The differential dose rate spectrum for the scattered synchrotron radiation at $1.34 \mathrm{~m}$ from a $1-\mathrm{cm} \mathrm{Cu}$ scatterer is shown in Figure C-3. The total dose rate from the bending magnet is found by integrating the curve in Figure C-3 over the energy spectrum of the scattered radiation and multiplying by 2.5 for the $\mathrm{Cu}$ thickness, by $6 \mathrm{mradh}$, and by $327 \mathrm{~mA}$, which gives about $4.4 \mathrm{mrem} / \mathrm{h}$ for a $2.5-\mathrm{cm} \mathrm{Cu}$ scatterer, neglecting attenuation in the scattering material. After passing through $15.24 \mathrm{~cm} \mathrm{of} \mathrm{Pb}$ and $25 \mathrm{~cm}$ of concrete, the dose rate on the roof is negligible. The dose rate at the mirror in the roof penetration is about $2.2 \mathrm{mrem} / \mathrm{h}$, so the radiation scattered at $90^{\circ}$ out to the mezzanine area will also be negligible.

For the scattered gas bremsstrahlung contribution, the spectrum of photons was generated using the methodology of Section 12.2 of APS-LS-141 Revised (MOE 91) for thin targets, but applied to the bending magnet path, which was taken as 6 mradians $(23.4 \mathrm{~cm})$. In the BM case, the path length is $23.4 / 1538$ of that in the long straight of an ID, so the number of photons produced will normally be less by the corresponding factor $(0.0152)$. For this estimate, it was assumed that the vacuum was only $1 \times 10^{-7}$ Torr since, during commissioning, the diagnostic lines may be used at a vacuum poorer than the design goal of $1 \times 10^{-9}$ Torr. The photons produced in the BM during safety envelope operation strike the tungsten safety shutter and are mostly absorbed. For this calculation, the extremely conservative assumption that no attenuation takes place in the stop was used. The $90^{\circ}$ scatter component was computed and attenuated by the $15.24 \mathrm{~cm}$ of $\mathrm{Pb}$ and the $25 \mathrm{~cm}$ of concrete, giving a negligible dose rate on the roof of the tunnel. Similarly, the scattered bremsstrahlung, which is again scattered at $90^{\circ}$ by the mirror in the roof penetration, results in a negligible dose rate on the mezzanine.

\section{$\underline{\text { ID Beamline }}$}

The ID beamline has only two diagnostic stations, which are used for the undulator beam and a beam from the downstream bending magnet. These beams are separated by 1.5 mradians and transported in a rectangular beam tube, $10.16 \mathrm{~cm} \times 20.32 \mathrm{~cm}$, shielded by $2.54 \mathrm{~cm}$ of $\mathrm{Pb}$. The $\mathrm{Pb}$ collimators in the front end and others along the transport provide a $1-\mathrm{cm}$ margin on each side of the beam (LUM 94). The collimators have been placed at specific locations along the photon beamline, based upon recommended ray-tracing techniques, to insure that no direct or scattered bremsstrahlung radiation interacts with the transport line. All shielding provided for the diagnostic stations and the transport line meet or exceed the recommendations in ANL/APS/TB-7 (IPE 93). 
Figure C-3 - Differential Dose Rate for the Scattered Synchrotron Radiation from a 1-cm Copper Scatterer

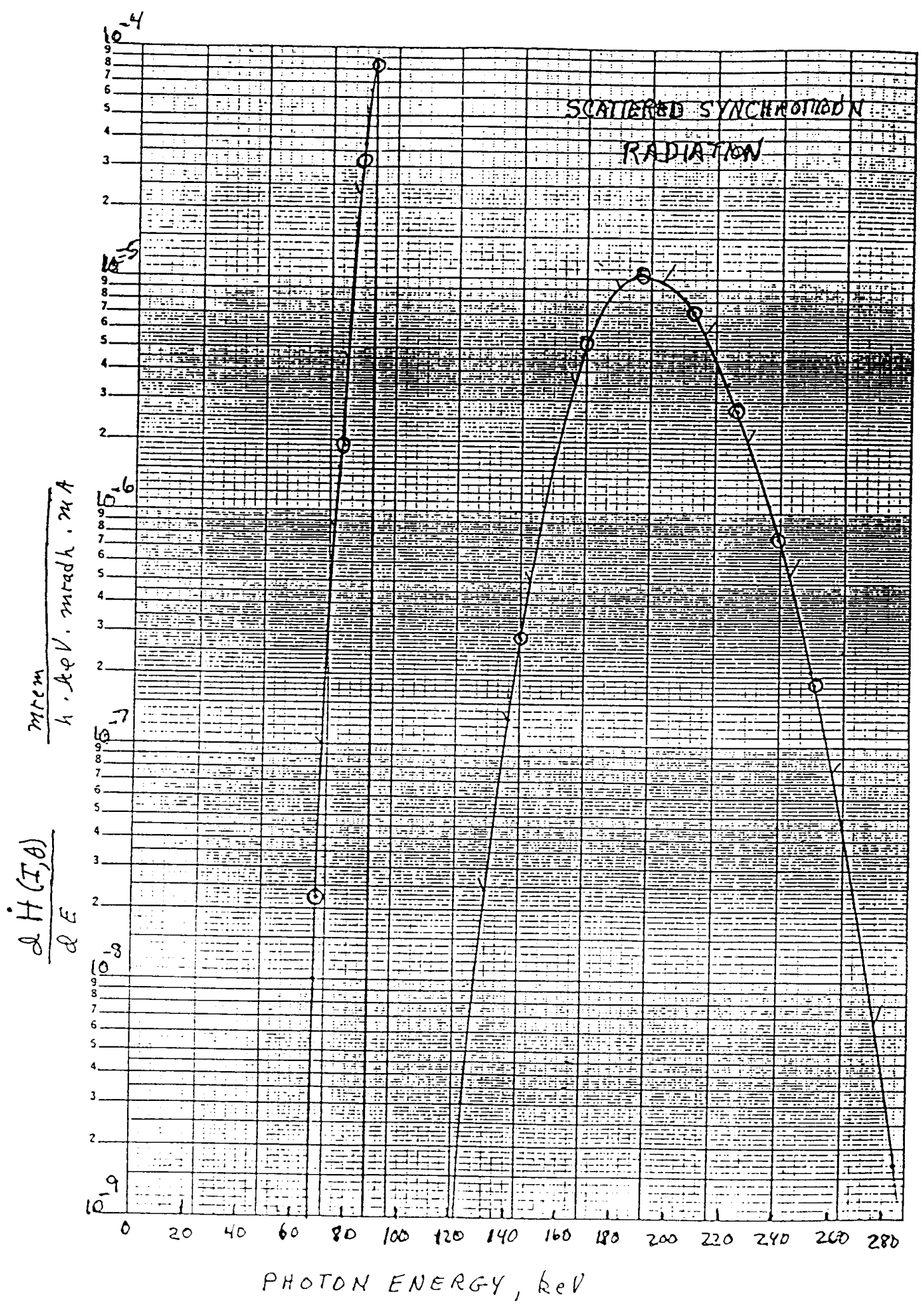


Since the transport may be used when the vacuum in the SR is higher than $1 \times 10^{-9}$ Torr, an estimate was made of the scattered radiation dose rate at $30 \mathrm{~cm}$ from the transport tube for the SR vacuum condition of $1 \times 10^{-7}$ Torr while operating at the safety envelope. Since the vacuum in the transport line could also be higher than the recommended $1 \times 10^{-6} \mathrm{Torr}$, it was assumed that the transport line was at atmosphere; a worst case. For the scattered gas bremsstrahlung contribution, the spectrum of photons was generated using the thin-target methodology of Section 12.2 of APS-LS-141 Revised (MOE 91) applied to the insertion device path, which is much longer than that of a bending magnet. The result for the ID transport was then divided by 65.8 to estimate the dose rate for the BM transport line. The geometry used for the computation is shown in the sketch:

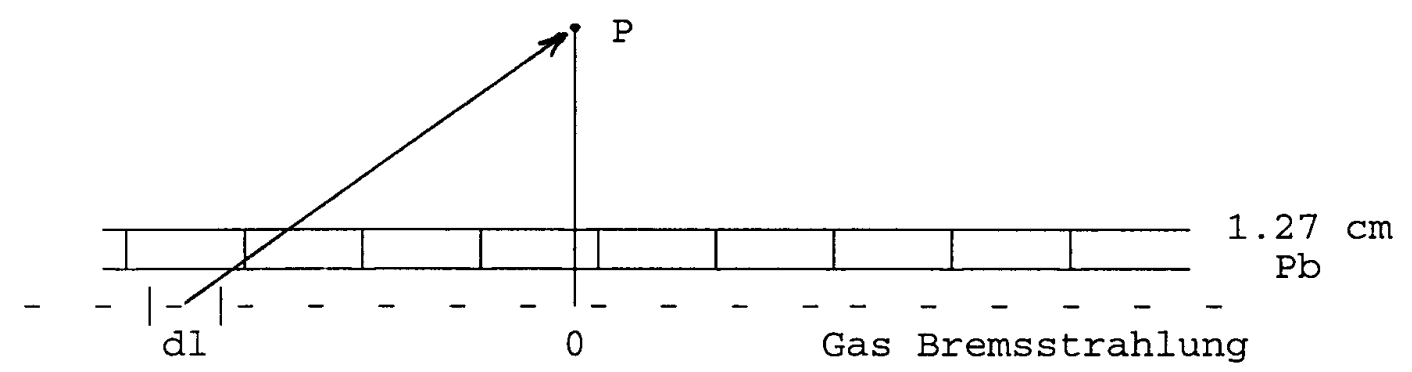

The differential contribution of Compton-scattered photons from the volume including the line segment $\mathrm{dl}$ to the dose point $\mathrm{P}$ represents the integrated contribution from all photons in the bremsstrahlung spectrum that are scattered from this elemental air volume about the line segment $\mathrm{dl}$. The dose point $\mathrm{P}$ is taken as $30 \mathrm{~cm}$ away from the top of the transport line, which is shielded by 1.27 $\mathrm{cm}$ of $\mathrm{Pb}$ (the ID transport is actually shielded by $2.54 \mathrm{~cm}$ of $\mathrm{Pb}$, but the BM transport only has 1.27 $\mathrm{cm}$ on top of the tube, and this value was used for conservatism). The gas bremsstrahlung beam is considered to be $1 \mathrm{~cm}$ from the transfer line top, which is the closest distance that the beam can approach the top. Figure C-4 shows the differential contribution from the elements along the line source plotted against the distance along the line from the point 0 , which represents the location along the line segment of the perpendicular from the point $\mathrm{P}$. The total dose rate at the point $\mathrm{P}$ is obtained by integrating over the entire length of the line source:

$$
\dot{\mathrm{H}}=\int_{-\infty}^{\infty} \frac{\mathrm{d} \dot{\mathrm{H}}}{\mathrm{dl}} \mathrm{dl} .
$$

The estimate for the ID transport is

$$
\dot{\mathrm{H}}=1.78 \mu \mathrm{rem} / \mathrm{h} \text {. }
$$

Since this result was based upon the transport line at atmospheric pressure, the dose rate should be negligible for a transport line with a vacuum of $1 \times 10^{-6}$ Torr. In addition, the use of only $1.27 \mathrm{~cm}$ of $\mathrm{Pb}$ as shielding also makes the result very conservative. It is interesting to note from Figure $\mathrm{C}-4$, that most of the dose rate contribution for this case is coming from about 0-4 m upstream of the dose point and very little from the downstream portion. In effect, regardless of the length of the line, effectively the total contribution is only from about a 4-m-long segment. Also, since the dose rate is a factor of about $10^{2}$ below the DOE guideline, the dose rate would not become important until the SR vacuum deteriorated to $10^{-5}$, in which case the beam lifetime in the SR would be shortened, making it difficult to sustain a beam for very long. 


\section{Figure C-4 - Differential Air Scattered Dose Rate from Line Source for Gas Bremsstrahlung}

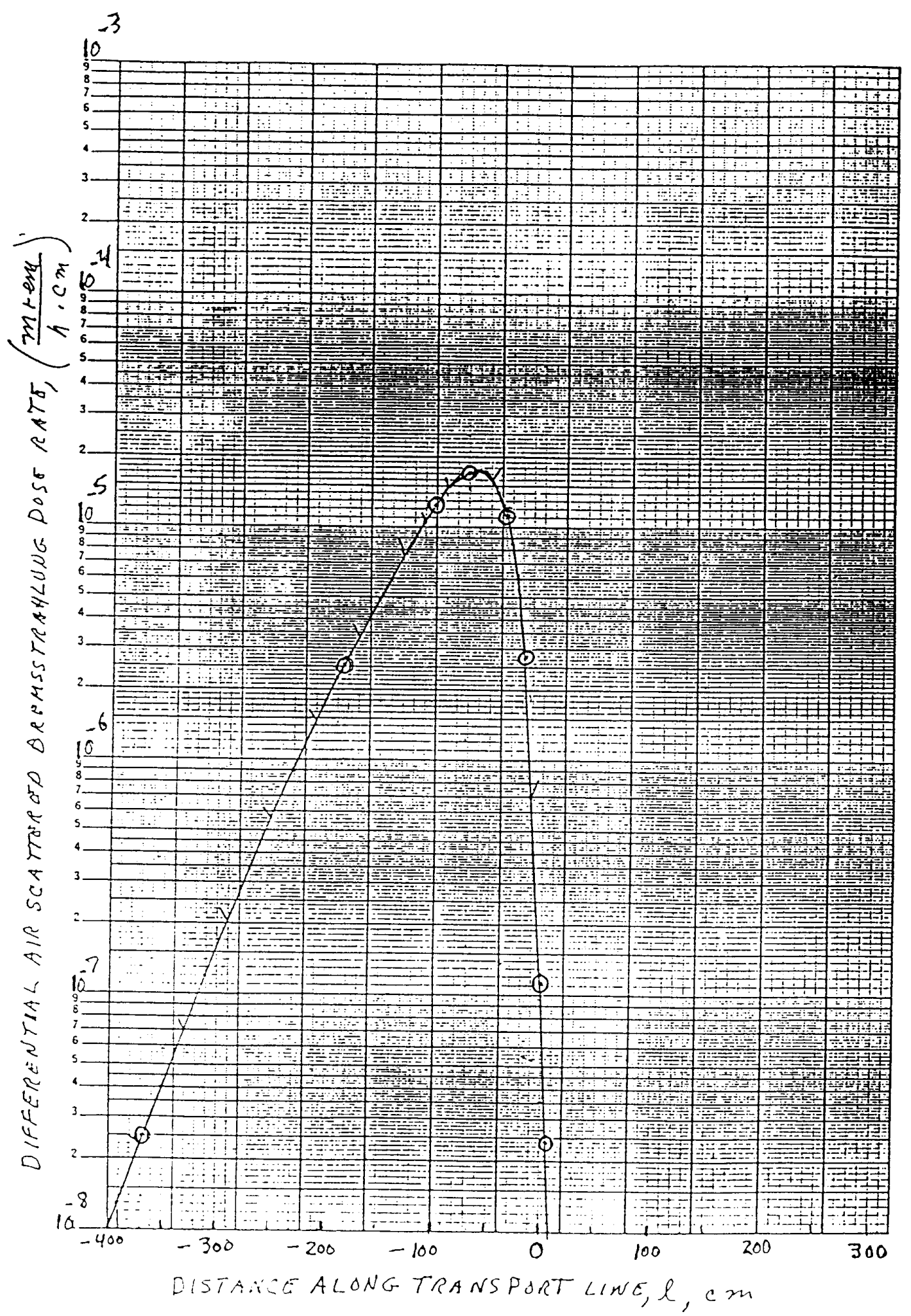




\section{Bending Magnet Beamline}

As mentioned before, the radiation from the bending magnet is split into two 1-mradian beams that are carried by transport line to stations 35-BM-C and 35-BM-D, where they are absorbed in beam dumps. The shielding for these diagnostic stations meets or exceeds the recommendations in ANL/APS/TB-7 for experimental stations. Lead collimators have been placed in the front end and at other locations along the beam transport to define the beam dimensions so that beam will not strike the wall of the transport beamline (LUM 94). The collimators have been placed at specific locations along the photon beamline, based upon recommended ray-tracing techniques, to insure that no direct or scattered bremsstrahlung radiation interacts in the transport line. The transport tube for the BM beamline is divided into two sections. One is $10.16 \mathrm{~cm} \times 10.16 \mathrm{~cm}$ and the other is $10.16 \mathrm{~cm} \times 30.48$ $\mathrm{cm}$. The top and bottom of the tube is shielded by $1.27 \mathrm{~cm}$ of $\mathrm{Pb}$ and the sides by $2.54 \mathrm{~cm}$ of $\mathrm{Pb}$. The $\mathrm{Pb}$ shielding on the transport line exceeds the recommended shielding in ANL/APS/TB-7 for the scattered synchrotron and gas bremsstrahlung radiation striking scattering materials.

For the case of the BM transport line, the result for the ID can be scaled by the ratio of the path lengths $(23.4 / 1538)$. The result is

$$
\dot{\mathrm{H}}=\frac{1.78}{65.8}=0.027 \mu \mathrm{rem} / \mathrm{h}
$$

Since this result was based upon the transport line at atmospheric pressure, the dose rate should be negligible for a transport line with a vacuum of $1 \times 10^{-6}$ Torr. The dose rate is a factor of about $10^{4}$ below the DOE guideline, so the dose rate would not become important until the SR vacuum deteriorated to $10^{-3}$, in which case the beam lifetime in the SR would be too short to sustain a beam for very long.

\section{Considerations During Accidents}

A number of accident situations around the ring and their dose consequences have been treated in Section 10 of this report. Most of these involve losses in the accelerator system and lead to doses outside of the SR tunnel. Losses on an unshielded transition piece of an ID during injection produce high dose rates in the FOE of the upstream ID (Section 10.1.7). If the radiation monitor fails to shut down the system, the dose rate of $8.2 \mathrm{rem} / \mathrm{h}$ could persist for a significant time. This could lead to the highest dose inside an FOE depending upon the duration. A shorted dipole could lead to some positrons being sent down a photon beamline but this would result in a low dose rate in the FOE because the shutters would be closed during injection (Section 10.1.8).

Two incidents that occur during stored beam conditions that produce doses of concern in the FOE or its vicinity were discussed in Sections 10.2.7 and 10.2.8. If a stored beam is lost on an ID chamber wall, a bremsstrahlung shower will be initiated and will propagate down the photon beamline and strike the $30-\mathrm{cm}$-thick tungsten beam stop, surrounded by $10 \mathrm{~cm}$ of polyethylene. For operation at the safety envelope, the highest total dose would be at $90^{\circ}$ to the beam stop and would be 78 mrem outside of the FOE. If an individual is in the FOE at $1 \mathrm{~m}$ from the beam stop, the dose would be 176 mrem. The other incident involves the loss of vacuum in a $20-\mathrm{cm}$ portion of the SR. The total time for the beam to interact is around $40 \mu \mathrm{s}$, and each positron makes a mean number of passes equal to 3.91. For operation at the safety envelope ( $9280 \mathrm{~J}$ of stored energy and $327 \mathrm{~mA}$ of $7700 \mathrm{Mev} \mathrm{e}^{+}$), the highest total dose computed in Section 10.2.8 was 3.05 rem in the transverse direction on the outside 
of the FOE. For an individual in the FOE at about $1 \mathrm{~m}$ from the tungsten beam stop, the dose would be 6.9 rem.

\section{$\underline{\text { Radioactive and Noxious Gases }}$}

Activation is not expected to be a problem since the amount of scattered bremsstrahlung is so small that not many neutrons will be released. The synchrotron radiation spectrum is mainly in the keV region, which is well below the threshold for $(\gamma, n)$ interactions.

Noxious products are formed mainly by unfiltered synchrotron radiation (white x-ray beam) in air. No air paths are planned for the white beam. Monochromatic x-rays of $10 \mathrm{keV}$ or higher (bandwidth of about $3 \mathrm{eV}$ ), produced by passing the white beam through a crystal monochromator, will be used. A filtered white beam (high-pass filter with half-pass energy at $20 \mathrm{keV}$ or higher) passing through a pinhole, which allows only $1 \mu$ radian or less of white beam to pass, is planned. In both cases, the length of the air paths will be limited to a meter or less. The production of ozone and other noxious gases has been calculated to be negligible. 